\title{
3. VERWEISE AUF DIE HERKUNFT DER WUNDERERZÄHLUNGEN
}

Im folgenden Kapitel stehen die Verweise auf die Herkunft der Wundererzählungen im Zentrum. Dabei stellt sich die Frage, welche Bedeutung diese Verweise in Guiberts Texten haben. Daran schließt die Frage an, ob aufgrund der Verweise auf ein Beziehungsnetz geschlossen werden kann, innerhalb dessen die Wundererzählungen kommuniziert wurden.

Da sich die Wundererzählungen im Werk Guiberts de Nogent im Grenzbereich zwischen Hagiographie und Historiographie befinden, muß, um die Frage nach der Bedeutung der Verweise zu klären, auf mehrere Forschungstraditionen zurückgegriffen werden. Die Historiographiegeschichte hat sich aus historischer Sicht mit Quellenverweisen in mittelalterlichen Texten beschäftigt. In diesem Kontext hat sie sich mit der Arbeitsweise von Verfassern mittelalterlicher historiographischer Werke auseinandergesetzt ${ }^{1}$. Auf ähnliche Weise widmeten sich hagiographische Studien der Arbeitsweise von Verfassern von Heiligenviten oder Mirakelbüchern ${ }^{2}$. Die Historiographieforschung ist aber auch von den Texten ausgegangen und hat sich mit den Realitätsbezügen und der rhetorischen Form von historiographischen Werken beschäftigt ${ }^{3}$.

Die Literaturwissenschaft beschäftigt sich seit längerer Zeit mit den Kennzeichen von fiktionalen und auch faktualen, wirklichkeitsbezogenen Texten, hat dabei aber den Schwerpunkt auf die Behandlung fiktionaler Texte gelegt ${ }^{4}$. Schon in der Poetik des Aristoteles wird die Referenzsituation verschiedener Gattungen der Dichtkunst thematisiert ${ }^{5}$. Die Frage nach den Quellenverweisen ist in den größeren Kontext der Inbezugsetzung des Inhalts einer Erzählung mit einer außertextlichen Realität zu stellen. Der Romanist Karlheinz Stierle hat gezeigt, daß Verweise auf andere Texte und auf die außertextliche Realität wichtig sind für die Einordnung und Beurteilung von Texten als fiktional oder als historisch, oder anders gesagt, als realitätsbezogen ${ }^{6}$.

Gerade für die Wundererzählungen in Guiberts Texten wird anhand der Verweise auf die Herkunft der Erzählungen zu bestimmen sein, wie sie durch diese mit einer außertextlichen Realität in Bezug gesetzt werden und dadurch

1 Guenée, Histoire et Culture Historique; GuenÉE, >Authentique et approuvé‘; GoETz, res gesta.

2 Sigal, Travail; Heinzelmann, Source de base; Dolbeau, Hagiographes au travail.

${ }^{3}$ Einen guten Überblick über die ältere Forschung bietet RAY, Medieval Historiography. Dazu auch PARTNER, Serious Entertainments; MORSE, Truth and Convention und vor allem WHITE, Klio. Eine Gegenposition zu den antipositivistischen Ansätzen bei GrNzbURG, Wahrheit der Geschichte.

4 GenetTE, Fiktion und Diktion, S. 65.

5 Aristoteles, Poetik, 1451b, S. 29-30. Zur Gegenüberstellung von Aussagen des Aristoteles in der Poetik und Rhetorik siehe GinzBurg, Wahrheit der Geschichte, S. 47-62.

6 STIERLE, Erfahrung, S. 97-107. 
Glaubwürdigkeit erlangen. Das erste Hinweisverfahren arbeitet mit Verweisen außerhalb der Erzählung, mit der Nennung von mündlichen oder schriftlichen Zeugen von Episoden. Das zweite Verfahren wird von der Literaturwissenschaftlerin Monika Otter in ihrer Dissertation über Berichte von Auffindungen (Inventiones) des 12. Jahrhunderts thematisiert. Diese lateinischen Texte aus dem anglonormannischen Bereich bewegen sich auf der Grenze zwischen Hagiographie und Historiographie. Otter konzentriert sich in ihrer Untersuchung auf Verweissituationen innerhalb der Erzählungen: Ort- Zeit- und Akteur-Raster bestimmen die Gattung eines literarischen Textes?. Während in nicht-fiktionalen Texten diese Verweise auf eine außertextliche Realität vorhanden sind, zeichnen sich fiktionale Texte nach Ricoeur durch deren Abwesenheit aus ${ }^{8}$. Otter zeigt für ihre Texte, die wie jene von Guibert Wundererzählungen beinhalten, daß sehr wohl Verweise auf die außertextliche Realität gemacht werden, daß die Verweissituation aber keineswegs durchgängig stabil ist und sich auch fiktive Elemente in diesen Texten finden?.

Die zweite Zielsetzung, die mit der Untersuchung der Verweissituation der Wundererzählungen verfolgt werden soll, betrifft die Frage, ob aus den Verweisen auf ein kommunikatives Umfeld außerhalb von Guiberts Texten geschlossen werden darf oder ob es sich bei diesen Verweisen um fiktive Konstrukte handelt, die keine über den Text hinausgehende Interpretationen zulassen.

Als These soll den Quellenangaben in den Werken Guiberts in vielen Fällen der topische Charakter abgesprochen werden. Dies aus verschiedenen Gründen: Wunder erfüllen eine Funktion als signa, als Zeichen, die Beweischarakter haben. Bezeugung ist ein wichtiger Charakterzug des Wunders ${ }^{10}$. Zeugenaussagen lassen sich in einem engen kommunikativen Umfeld nachprüfen. Deshalb muß untersucht werden, in welcher Beziehung Guibert zu den Zeugen stand, die in seinen Texten genannt werden. Weiter spielt das Publikum von Guiberts Schriften eine wichtige Rolle: Wie oben gezeigt, wurden Guiberts Schriften in einem relativ engen Umfeld zur Kenntnis genommen und rezipiert. Wenn die genannten Zeugen aus einem sozial, geographisch und zeitlich nahen Umfeld, oder gar aus diesem Rezipientenkreis stammen, ist es schwierig, sich vorzustellen, $\mathrm{da} \beta$ sie nur topisch in Verbindung mit wunderbaren Ereignissen gesetzt werden. Daß zeitgenössische Zeugen von Wundern diese in institutionellem Zusammenhang bestätigen oder beurteilen mußten, wurde oben im Kapitel 2.2. dargelegt. Zudem zeigen einzelne Fälle von Quellenangaben zu Wundererzählungen, daß in von Guibert unabhängigen Versionen die Erzählungen mit den gleichen Zeugen in Verbindung gebracht werden.

7 OTTER, Inventiones, S. 4, die das Konzept von Bachtin übernimmt.

8 Ibid. S. 17.

9 Ibid. S. 1-18; Rezension in: Speculum 74 (1999), S. 235-237. Vor allem William von Malmesbury, der in Otters Argumentation eine wichtige Rolle spielt, wurde in bezug auf seine Arbeitsweise schon mit Guibert de Nogent verglichen. Siehe Garand, Auteurs latins.

10 Rothmann, Zeichen und Wunder, S. $377 \mathrm{f}$. 


\subsection{Konventionen von Verweisen in historiographischen, hagiographischen und legendarischen Texten}

Guibert de Nogent ist der Forschung schon lange wegen seiner Arbeitsweise aufgefallen, für die auch die Quellenverweise in seinen Schriften charakteristisch sind. Ende des 19. Jahrhunderts betrachteten ihn positivistische Forscher fast als einen der Ihren ${ }^{11}$. In der älteren Forschung wurden so bei Guibert erste Ansätze zur selbständigen Quellenkritik im Sinne des 19. Jahrhunderts festgestellt ${ }^{12}$. Die Forschung hat dieses Bild seit den 1960er-Jahren revidiert. Jacques Chaurand hat 1965 erstmals die Betonung auf Guiberts exegetisch-tropologische Arbeitsweise gelegt ${ }^{13}$. Dieser Ansatz hatte gegenüber den vorher genannten den Vorteil, zeitgenössische Methoden der Textproduktion in die Überlegungen miteinzubeziehen. Unlängst hat Jay Rubenstein gezeigt, wie sehr Guibert durch die Exegese geprägt war ${ }^{14}$.

Die Wundererzählungen sind in Texten Guiberts enthalten, die unterschiedlichen Gattungen zugeordnet werden. Diese gattungsmäßige Zuordnung ist nur für die Kreuzzugschronik einigermaßen plausibel, die als historiographisches Werk eingeordnet werden kann' ${ }^{15}$. Die Monodiae können weder eindeutig als Autobiographie noch als Geschichtsschreibung klassifiziert werden. Gerade auch die umfangreichen Blöcke von Wundererzählungen verhindern, daß die Schrift einer Gattung zugeordnet werden kann ${ }^{16}$. Der Reliquientraktat ist sowohl polemisches Pamphlet als auch spirituelles Werk. Das Marienlob kann sowohl als spirituelles als auch als hagiographisches Werk bezeichnet werden. Bei der Auswertung von Verweisen auf eine außertextliche Realität kann daher nicht eindeutig von Gesetzmäßigkeiten einer Gattung ausgegangen werden. Zudem muß sowohl die Gattung des Gesamttextes als auch die der Wundererzählungen beachtet werden.

11 Lefranc, Traité, S. 294-296: "Il est moins naturel de voir notre auteur raconter un peu plus loin (ch. XVIII) un miracle assez grossier, sans l'apprécier comme il le mérite. [...] Que Guibert ait accepté ce miracle ridicule [...] voilà ce qu'il est bien difficile d'admettre, quand on songe au bon sens habituel de l'abbé de Nogent dans d'autres questions analogues. [...] cette crédulité, réelle où non, n'est qu'une exception dans son œuvre tandis qu'elle était la règle pour tous ceux qui l'entouraient.«

12 Bspw. Simon, Topik, Teil II, S. 92.

13 Chaurand, Conception; Letrnick, Comment les historiens, S. 53, der Guibert mit Hugo von Fleury, William von Malmesbury und Orderic Vitalis als Autor konservativer monastischer Tendenz charakterisiert.

14 Rubenstein, Guibert of Nogent.

15 Zur Kreuzzugschronik siehe die Untersuchung von Böнм, Geschichtsschreibung.

16 GenetTE, Fiktion und Diktion, zählt in der Einleitung auf S. 9 sowohl die Geschichtsschreibung wie auch die Autobiographie mit dem Tagebuch und der Reportage zu den nichtfiktionalen Erzählungen. 


\subsubsection{Verweise in historiographischen Texten}

Verfasser historiographischer Texte bezogen sich für die Form ihrer Werke auf antike Modelle. Für lateinische historiographische Werke in Prosa war die Form der römischen Geschichtsschreibung als Vorbild bestimmend ${ }^{17}$. Die chronologische Ordnung, die Datierung und die Bezeugung von Ereignissen waren wichtige Elemente, welche den Bezug zu einer außertextlichen Realität, letztlich zur Wahrheit des Berichteten, garantierten. Diese Elemente sind schon in der Rhetorik Quintilians beschrieben ${ }^{18}$. Auch in den Etymologien Isidors von Sevilla, die im Mittelalter große Verbreitung erfuhren, wird die Bezeugung als Merkmal von historiographischen Texten genannt ${ }^{19}$.

Für die mittelalterliche Historiographie ist zudem der Bezug zur biblischen Geschichte prägend. Geschichte wird interpretiert als Gottes Wirken in der Welt und befindet sich somit in Kontinuität zur biblischen Geschichte. Dies erlaubt die Inbezugsetzung der Geschichtsdarstellung zu einer mehrfachen Wahrheit: im historischen Sinne, der die Ereignisse feststellt (res gesta), im moralischen Sinne, der daraus Handlungsanleitungen zieht (exempla), im allegorischen Sinne, der die übertragene Deutung beinhaltet und teilweise im anagogischen Sinne, der die Ereignisse in einen göttlichen Heilsplan einordnet ${ }^{20}$. Das Bemühen um den historischen Sinn biblischer und gegenwärtiger Ereignisse ging aber auch in einem christlich-exegetischen Kontext nie verloren, der historische Sinn bildete im Gegenteil das Fundament jeglicher Bibelauslegung 21 .

In spätantiker wie in biblischer Tradition steht die Augenzeugenschaft zuoberst in der Hierarchie der Garanten narrativer Tradition ${ }^{22}$. Neben dem ei-

17 Guibert nennt als Referenzwerke seiner Kreuzzugschronik zwei Werke der römischen Geschichtsschreibung: den gallischen Krieg des Caesar und den spanischen Krieg des Hirtius Pansa, siehe dazu unten, S. 99.

18 Dazu Buda, Medieval history, S. 31.

19 Isidorus Hispalensis, Etymologiae, I, 41.

20 Die Einteilung in drei oder vier Schriftsinne war im Mittelalter nicht konstant. Guibert beschreibt in seiner Predigtanleitung, Guibert de Nogent, Quo ordine, S, Z. 198-204, die vier Schriftsinne: Quattuor sunt regulae scripturarum, quibus quasi quibusdam rotis volvitur omnis sacra pagina, hoc est historia, quae res gestas loquitur, allegoria, in qua ex alio aliud intellegitur, tropologia, id est moralis locutio, in qua de moribus componendis ordinandisque tractatur, anagoge, spiritualis scilicet intellectus, per quem de summis et caelestibus tractaturi ad superiora ducimur. Siehe GoETZ, »Geschichte«, S. 194. Zur Bibelexegese nach dem dreifachen und vierfachen Schriftsinn siehe LuBAC, Exégèse. Zum Zusammenhang zur Geschichtsschreibung siehe GoETZ, res gesta, S. 712; BuDA, Medieval history, S. 5-9.

21 Schmale, Geschichtsschreibung, S. 77.

22 IsIDORus Hispalenis, Etymologiae, I, 41: Apud veteres nemo conscribebat historiam, nisi is qui interfuisset, et ea quae conscribenda essent vidisset. Melius enim oculis quae fiunt deprehendimus, quam quae auditione colligimus. Mittelalterliche Beispiele nennt auch GoETZ, res gesta, S. 699. In diesem Zusammenhang wird oft auf Ioh. 19,35 als biblische Autorität verwiesen. 
genen Augenzeugnis sind dies andere, dem Autor persönlich bekannte, möglichst ehrenhafte Augenzeugen ${ }^{23}$.

Die Bedeutung der Nennung von Augenzeugen für Werke, die sich als historisch verstehen, wird in Guiberts Vorwort zur Kreuzzugschronik deutlich. Da Guiberts Erzählung eine Überarbeitung eines schon bestehenden Textes ist, begründet er sein Vorgehen im Vorwort. Augenzeugen spielen eine wichtige Rolle: die im Text erzählten Ereignisse sollen mit mündlich referierten Erlebnissen von Beteiligten des Kreuzzuges verglichen, Widersprüche ausgeräumt werden ${ }^{24}$. Indem er erst später im Text einen Vergleich mit antiken Geschichtswerken anstellt, dem Gallischen Krieg des Caesar und dem Spanischen Krieg des Hirtius Pansa, die beide von an den Kriegszüge Beteiligten verfaßt wurden, zeigt er das Bewußtsein der geforderten Hierarchie: eigene Augenzeugenschaft wird über die Augenzeugenschaft von Gewährsleuten gestellt ${ }^{25}$.

Die Ohrenzeugen werden ambivalenter beurteilt. So konstatieren mittelalterliche Historiographen, auch wenn sie oft von Ohrenzeugnissen Gebrauch machen, daß die vulgaris opinio auch Gefahren birgt, da sie unzuverlässig sei. Spielleute und Waschweiber würden unglaubwürdige Erzählungen kolportieren und sie nach Belieben formen. Diese Argumentation findet sich beispielsweise in der Historia Ecclesiastica des Ordericus Vitalis (†1142) ${ }^{26}$. Diese fabulae, erfundene Geschichten, stehen im Gegensatz zu den res gestae ${ }^{27}$. In diesem Zusammenhang wird deshalb oft die Vertrauenswürdigkeit und Integrität solcher Zeugen ins Feld geführt.

Neben diesen Bezugnahmen auf die mündliche Tradition griffen die Geschichtsschreiber auf schriftliche Zeugnisse, Monumente und Inschriften zurück$^{28}$. Unter den schriftlichen Zeugnissen stellten sie Bezüge zur Bibel oder zu Kirchenvätern als Autoritäten, aber auch zu historiographischen, hagiographischen oder anderen Schriften her. Oft kommentiert wurde Guiberts Deutung der Anordnung von Gräbern in Nogent als vor- oder frühchristlich ${ }^{29}$. Diese Beschreibung verwendet Guibert als Argument, daß das Kloster von Nogent, durch die Herren von Coucy um 1056 gegründet, an einem sehr alten Kultort

23 Partner, Serious Entertainments, S. 190: "Historians often obtained their information form sources that disarmed suspicion: friends, ecclesiastical superiors, men of high rank, bystanders with, seemingly, nothing to gain by lying."

24 Prolog zu Dei Gesta, Guibert DE Nogent, Dei Gesta, S. 82.

25 Guibert de Nogent, Dei Gesta, VII, 32, Z. 2184 f.

26 Ordericus Vitalis, Ecclesiastical History, VI, 3, Bd. 3, S. 218: Vulgo canitur a ioculatoribus de illo cantilena, sed iure preferenda est relatio authentica, quae a religiosis doctoribus sollerter est edita.

27 Dazu GoETz, »Geschichte «, S. 171-174, dazu auch unten, S. 160.

28 Siehe dazu Geary, Phantoms, S. 124-128.

29 Guenée, Histoire et Culture Historique, S. 76; Zu Beschreibungen von Gebäuden, Gräbern etc. siehe Gransden, Realistic Observation (siehe dazu OtTER, Inventiones, S.3); Chaurand, Conception; LetTnick, Comment les historiens; zur Deutung der Stelle auch BARTHÉLEMY, Les Sires Fondateurs. 
stehe. Für diese Behauptung kann er nicht auf eine schriftliche Tradition zurückgreifen, sondern muß sich auf Monumente berufen ${ }^{30}$. Die christliche Gründungsgeschichte seines Klosters setzt Guibert durch eine Inschrift in Bezug zur außertextlichen Realitä $t^{31}$. Er nennt neben der Inschrift, welche die Geschichte belegt, auch ein Reliquienkästchen. Dieses spielt in der Geschichte eine wichtige Rolle, als Beweis und dauerhaftes Zeugnis der Wahrhaftigkeit derselben ([...] et antiquis hucusque praebet testimonia nova relatibus) ${ }^{32}$. Das Kästchen fungiert sozusagen als Bindeglied zwischen der Vergangenheit und der Gegenwart ${ }^{33}$.

Auf die genannten Quellengruppen, Augenzeugen, Ohrenzeugen, schriftliche Zeugnisse, Monumente und Inschriften, die in mittelalterlichen Texten Zeugnischarakter hatten, konnte in historiographischen Texten mehr oder weniger ausführlich verwiesen werden. Auf welche Art und Weise auf Quellen verwiesen wurde, hing von den Intentionen des Werkes, aber auch vom Publikum $\mathrm{ab}^{34}$. Das Bewußtsein für die Regeln der Gattung war in den gebildeten Kreisen Guiberts sicher vorhanden.

$\mathrm{Da} \beta$ mit diesen Modellen auch gespielt werden konnte, zeigt ein Beispiel aus Guiberts Monodiae. In der Beschreibung der Schrecken der Adelsfehde zwischen Godefridus und Ingelrannus in der Grafschaft Porcien wird zu Anfang auf einen ungenannten Augenzeugen hingewiesen, um das Berichtete, die Gefangennahme und Tötung von ungefähr zwölf Männern, glaubhaft zu machen: Audivi certe a quodam, qui quondam tali carnificinae interfuit $[. . .]^{35}$. Die Beschreibung schließt mit der Bemerkung, daß die Schrecken so groß waren, daß diejenigen, die darüber berichten wollten, verstummten: Quis praedas, quis incendia hinc et inde facta enunciet et caetera quae parere hujusmodi tempestas solet, quae tanta fuere, ut mutos faciant referre volentes ${ }^{36}$. Im Spiel mit den Hinweisen auf das Berichten und Verschweigen der Ereignisse liegt gleichzeitig Wertung des Berichteten wie geschickter Umgang mit den Konventionen der Bezeugung.

\subsubsection{Verweise in hagiographischen Texten}

Der Bezug zu einer außertextlichen Realität ist nicht nur Texten eigen, die als historiographisch bezeichnet, sondern auch solchen, die als hagiographische

30 Guibert DE Nogent, Autobiographie, II, 1, S. 210: Quam opinionem si nulla literalis juvaret traditio, suppeteret profecto affatim peregrina et non, putamus, christiani nominis sepulchrorum inventa contextio.

31 Ibid. II, 1, S. 210-212. Zitat siehe unten, S. 127.

32 Ibid. II, 1, S. 224. Das Reliquienkästchen soll vom legendären König Quilius von Jerusalem nach Nogent überbracht worden sein. Zur Quilius-Legende ausführlicher siehe unten, S. 127.

33 Sowohl Kästchen als auch Inschrift sind nicht mehr vorhanden. Siehe dazu STock, Implications, S. 512.

34 GuenÉE, Histoire et Culture Historique, S. 117.

35 Guibert dE Nogent, Autobiographie, III, 3, S. 278.

36 Ibid. III, 3, S. 278. 
Texte beurteilt werden. Pierre André Sigal hat in einem 1980 erschienenen Aufsatz die engen Beziehungen von Hagiographie und Historiographie am Beispiel der Mirakelsammlungen aufgezeigt ${ }^{37}$. Diese engen Beziehungen zeigen sich deutlich in der Art des Umgangs mit den Quellen des Dargestellten. Hagiographen stellen in ihren Werken Wahrheitsbezüge mit den gleichen Mitteln wie Historiographen her. Heinzelmann macht innerhalb der hagiographischen Gattung Vita und Miracula den Unterschied aus, daß in diesem Punkt die Wundererzählungen enger mit Geschichtsschreibung verwandt seien als mit Heiligenviten. Die Vita des Heiligen diene als Modell, das zur Nachahmung aufruft. Die Wundersammlung beruhe hingegen auf der Darstellung aktueller Geschehnisse, welche die Heiligkeit beweisen ${ }^{38}$. Dieser unterschiedliche Charakter von Vita und Miracula scheint sich auch in der Darstellung der Vita des Theodericus von Saint-Rémi in Reims in einer Handschrift aus Corbie zu zeigen: anschließend an die Vita des Heiligen folgt eine Wundererzählung, die unter eine rubrizierte Datierung gesetzt wird: Anno ab incarnatione dominica octingentesimo octogesimo octavo hoc factum est miraculum ${ }^{39}$. Die hervorgehobene Datierung dient dazu, das Wunder als ein in der Realität verankertes Ereignis zu betonen.

Die Ähnlichkeiten von Mirakelsammlungen und historiographischen Werken lassen sich auf mehreren Ebenen beobachten:

Einerseits wird der Wahrheitsanspruch von historiographischen Werken und Mirakelsammlungen in den Vorworten auf ähnliche Weise begründet ${ }^{40}$. Die gleiche Hierarchie der Quellenverweise, persönliche Beobachtung, Augenzeugenschaft bekannter Personen, Ohrenzeugnisse wird dort genannt ${ }^{41}$. In bezug auf hagiographische Texte warnt Guibert, auf ähnliche Weise wie Ordericus Vitalis, vor Ohrenzeugnissen, die in die Nähe von Waschweibergeschichten rücken ${ }^{42}$. Gregor der Große führt die Wunderberichte in den Dialogi un-

37 Sigal, Histoire et hagiographie. Auch Heinzelmann, Source de base, und Dolbeau, Hagiographes au travail, sind im Laufe ihrer Untersuchungen über die Arbeitsweise von mittelalterlichen Verfassem hagiographischer Werke auf diese engen Beziehungen gestoßen.

38 Heinzelmann, Source de base, S. 245, 247.

39 Vita beatissimi Thoederici, abbatis sancti Remigii, Remensis achiepiscopi, quae celebratur kalendas julii. BN lat. 12604, fol. 109r, Handschrift aus dem 12. Jh. aus Corbie; Ed. in AASS 1. Juli, t. 1, S.6470.

40 Sigal, Histoire et hagiographie, S. 242-246, der in Anm. 42 auch Guiberts Vorwort zu den Dei Gesta zitiert. Siehe dazu EAdmer, Vita Sancti Anselmi, S. 149: Falsa vero scienter aliquem in sacris historiis scribere, nefas esse pronuncio. Nam quotiens ea vel leguntur vel audiuntur, anima scriptoris occiditur, eo quod omnibus per ea quae falso scripsit infando ore mentitur. Siehe dazu auch OTTER, Inventiones, S. 40f., die als Beispiele für Wahrheitsbezeugung von Hagiographen den sogenannten Odo von Ostia und Thomas von Monmouth zitiert. Zum Zusammenhang auch DolbEAU, Hagiographes au travail, S. 50-52.

41 Sigal, Travail, S. 151, Anm. 12 und 13. Dazu auch, aus der Perspektive der Historiographie PARTNer, Serious Entertainments, S. 187: „Natural and supernatural events differed in immediate cause, intention, and frequency, but not in their inherent probability, and did not, at the time, require different kinds of evidence."

42 Guibert de Nogent, Quo ordine, P, I, Z. 443-445. 
ter Bezug auf glaubwürdige Zeugen ein, um Zweifel am Berichteten zu zerstreuen ${ }^{43}$. Auch Gregor von Tours, mit den Martinswundern eine Art Gründervater der >Gattung< Wundersammlung, nennt seine Zeugen genau: sich selbst, der wunderbare Ereignisse sieht, Augenzeugen des wunderbaren Geschehens, den Küster des Kultorts, dem Wunder berichtet wurden ${ }^{44}$. In hagiographischen Texten werden überdies ähnliche Vorbehalte gegen die mündliche Tradition geäußert wie in historiographischen ${ }^{45}$, schriftliche Quellen werden in ähnlicher Weise zitiert ${ }^{46}$.

In Guiberts Kreuzzugschronik zeigt sich, daß dieser zwischen hagiographischen und historiographischen Texten unterscheidet. Gleichzeitig spricht er Parallelen der Wahrheitsgarantien der beiden Gattungen an. Er betont im Prolog zum vierten Buch der Chronik, daß Historiographen und Verfasser von Heiligenviten die gleiche Vorgehensweise bei ihrer Informationsbeschaffung hätten. Sie würden nämlich nicht nur niederschreiben, was sie gesehen hätten, sondern auch das, was ihnen von anderen erzählt worden sei. Damit stünden sie in bester biblischer Tradition ${ }^{47}$.

Annegret Wenz-Haubfleisch hat anhand der sprachlichen Untersuchung von Mirakelsammlungen aus dem ostfränkischen Raum vor allem in bezug auf die Zeugennennung und auf die chronologische Einordnung von Ereignissen Parallelen zu historiographischen Texten festgestellt ${ }^{48}$.

Eine weitere Parallele, welche die Unterschiede zwischen historiographischem und hagiographischem Genre verschwimmen läßt, ergibt sich aus dem Eingebettetsein aller weltlichen Ereignisse in den göttlichen Heilsplan. Die Bibelexegese als Interpretationsrahmen ist hierfür prägend. Weder der historische Schriftsinn, noch der moralische, noch der mystische Schriftsinn ist auf die Unterscheidung zwischen im modernen Sinne historischen und wunderbaren Ereignissen angewiesen. Ja gerade die wunderbaren Ereignisse als direkte Eingriffe Gottes verlangen nach Fixierung in Zeit und Raum.

43 GrÉGolre le Grand, Dialogues, S. 16-18. Zu den Quellenverweisen und dem Wahrheitsanspruch der Dialogi siehe MCCREADY, Signs of Sanctity, S. 111-154, der auch die Forschungspositionen zur Problematik Faktualität vs. Fiktion abwägt.

44 Wenz-Haubfleisch, Miracula post mortem, S. 61, welche die Rolle des persönlichen Berichtes in Zusammenhang mit der im Vergleich zur Spätantike geringeren Schriftlichkeit bezieht. Augustin beruft sich auf schriftliche Berichte (libelli) als Quellen für Wundererzählungen.

45 Siehe dazu oben, S. 99. Dazu Beispiele bei Sigal, Travail, S. 155.

46 BarRÉ, Plaidoyer, S. 382. Als Beispiel eines expliziten Verweises auf schriftliche Quellen in der Hagiographie sei die Erzählung des Bildwunders von Konstantinopel in einer Marienmirakelsammlung aus St. Sépulchre in Cambrai (Cambrai BM 834) genannt, das Hieronymus zugeschrieben wird. Die Wundererzählung wurde dem Pilgerbericht des Adamnan, De locis sanctis III, 5, S. 233f., entnommen. Der Prolog der Wundererzählung bezieht sich explizit darauf.

47 Guibert de Nogent, Dei Gesta, IV, Prolog, Z. 11f., unter Bezug auf Ioh. 3, 32: [...] tamen quis historiographos, quis eos qui sanctorum Vitas edidere ambigat non solum quae obtutibus, sed ea scripsisse quae aliorum hauserant intellecta relatibus?

48 WenZ-HaubfleISCH, Miracula post mortem, S. 167-169. 


\subsubsection{Verweise in legendarischen Texten}

Die dritte narrative Form, für welche nachvollzogen werden muß, wie die Garantien des Wahrheitsbezugs gehandhabt wurden, ist die viel weniger klar abgegrenzte Form der Legenden und Exempla. Guibert de Nogent setzt Wundererzählungen in seinen Werken als argumentative oder paränetische Exempla ein. Die Verwendung als paränetische Exempla rückt die Wundererzählungen in den Zusammenhang der Legende. Diese sind nach Alain Boureau Erzählungen, die als religiöse Erzählung gelesen und interpretiert werden können ${ }^{49}$. Diese offene Definition ist in unserem Zusammenhang angebracht, da ja nicht von vorneherein klar ist, in welchem Gebrauchskontext Guiberts Werke stehen. Boureau entwickelt ein System der Wahrheitsgarantie religiöser Texte ${ }^{50}$. Auf die höchste Stufe stellt er die biblischen Texte, die offenbart sind (»le révélé «) ${ }^{51}$. Als zweite Gruppe nennt er die Texte der Kirchenväter ("l'autorisé «), die noch weniger genau abgegrenzt ist. Die Wundererzählungen gehören in den großen Bereich des Authentifizierten (»'authentifié«), dessen Wahrhaftigkeitsgarantien immer wieder ausgehandelt werden müssen, daher flexibel sind. Aber auch hier spielt die schon für historiographische und hagiographische Texte genannte Hierarchie der Zeugnisse eine Rolle: eigene Augenzeugenschaft, Augenzeugen, Ohrenzeugen. Für Boureau, der sich in seiner Argumentation oft auf die Legenda aurea des Jacobus de Voragine stützt, erreicht die Legende die Glaubwürdigkeit eher durch ihre erbauliche Funktion als durch ihre Referentialität auf eine außertextliche Wirklichkeit ${ }^{52}$.

Ruth Morse geht ebenfalls davon aus, daß neben den Kategorien »wahr/ falsch « andere wie "autorisiert «, »beispielhaft « oder "überzeugend « bestehen. Morse hat aber gezeigt, daß selbst für Exempla die Rückbindung an eine auBertextliche Realität höher eingeschätzt wird als an plausible Erfindung. Dies einerseits, weil wahre Beispiele als wirkungsvoller eingeschätzt wurden als erfundene und andererseits, weil erfundene Beispiele im Verdacht standen, der reinen Belustigung wegen erfunden worden zu sein ${ }^{53}$.

49 Boureau, Événement, S. 18.

50 Ibid. S. 35.

51 Die apokryphen Texte zeigen, daß diese Gruppe nicht so klar abgegrenzt ist, wie dies auf den ersten Blick scheint. Guibert ist sich des Problems der Apokryphen bewußt, die Zweifel selbst für die Gruppe autoritärer Texte wecken. In der Reliquienkritik zitiert er das Beispiel der Thomas-Akten, die das gesicherte Wissen über die Apostel stören. GUIBERT DE NoGENT, Quo ordine, P, I, Z. 85-95.

52 Boureau, Événement, S. 34.

53 Morse, Truth and Convention, S. 92. Dazu auch Trappen, Fiktionsvorstellungen, S. 140145. Nach LAUSBERG, Rhetorik, S. 228 entsprechen in der klassischen Rhetorik die Quellen von Exempla den Arten der Vorgangserzählung: historia, fabula, exemplum verisimile. 


\subsubsection{Problematik der Auswertung von Quellenverweisen}

Der Vergleich der Konventionen in historiographischen, hagiographischen und legendarischen Texten hat gezeigt, daß die Bedeutung von Bezügen auf eine außertextliche Realität darin besteht, die Glaubwürdigkeit des Textes zu erhöhen. Wundererzählungen als Bestandteile hagiographischer Texte sind Beweise der Kraft von Heiligen oder der Gnade Gottes. Deshalb ist eine Scheidung von wahren und unwahren Erzählungen notwendig. Auch Exempla haben weniger Wirkung, wenn sie als fabulae entlarvt werden.

Bezüglich der Form des Bezuges zur außertextlichen Realität hat in allen drei Gattungen die Augenzeugenschaft die größte Bedeutung. Das Verhältnis von Textzeugnissen zu Ohrenzeugnissen ist weniger genau bestimmt. In allen drei Gattungen ist der Bezug zur Wahrheit über die Hinweise auf eine außertextliche Realität wichtig. Die Legenden und Exempla sind am wenigsten auf diese Hinweise angewiesen.

Um zu untersuchen, wie Guibert seinen Texten Glaubwürdigkeit zu verleihen sucht, wird im Folgenden aufgezeigt, welche Verweise Guibert auf mündliche und schriftliche Quellen macht, die außerhalb der Wundererzählungen stehen. Anschließend wird dargelegt, wie er innerhalb der Erzählungen auf eine außertextliche Realität verweist.

Die Analyse dieser Verweise soll schließlich zeigen, in welches gesellschaftliche Umfeld Kommunikationshandlungen über Wunder und Wundererzählungen zu situieren sind. Dabei stellt sich die Frage nach der Topik der Verweise, die in bezug auf Mirakelsammlungen immer wieder formuliert wird. Dies unter der Annahme, daß Zeugen genannt werden, um Authentizität zu simulieren oder um den Anforderungen der Gattung zu genügen. Diese Verweise würden daher nicht auf reale Kommunikationssituationen schließen lassen. Dieselbe Problematik wird anhand der Dialogi Gregors des Großen diskutiert, worin für den größten Teil der Wunder Zeugen genannt werden ${ }^{54}$. Den Zeugenangaben für die Martinswunder des Gregor von Tours gesteht Felix Thürlemann nur topischen Charakter zu. Diese würden eher als Verweise auf einen Metadiskurs, das heißt auf Gattungskonventionen, dienen denn als Hinweise auf Kommunikationssituationen ${ }^{55}$. Dieser Ansicht widerspricht Martin Heinzelmann, der konstatiert, daß in oraler Gesellschaft Zeugenschaft zur Rückfrage gedacht war ${ }^{56}$. Dieser Meinung stimmt auch Hedwig Röckelein für karolingische Mirakelsammlungen $\mathrm{zu}^{57}$. Diese Autoren gehen also davon aus, daß die Bezeugung von Wundern in ein kommunikatives Umfeld zu situ-

54 Dazu McCready, Signs of Sanctity, S. 111-125, 152f., der die Zeugenangaben nicht nur und nicht in jedem Fall als Legitimation frommer Erfindung ansieht.

55 Thürlemann, Historischer Diskurs, S. 28-30. Zu diesem Metadiskurs gehören auch die Gattungskonventionen. Siehe dazu Wenz-HAubfleisCH, Miracula post mortem, S. 61.

56 Heinzelmann, Diskurs, S. 242, Anm. 29.

57 Röckelein, Miracle Collections, S. 271. 
ieren sind, in dem auch die Texte, die diese bezeugten Wundererzählungen wiedergeben, eine Rolle spielten und damit gerechnet werden mußte, daß darauf aus diesem Umfeld reagiert werden konnte ${ }^{58}$.

Sogar topikverdächtige Zeugennennungen wie quidam können in die Irre leiten, wie dies Annegret Wenz-Haubfleisch an den Mirakelbüchern des Virgil von Salzburg vom Ende des 12. Jahrhunderts gezeigt hat. Im Gegensatz zu Wattenbach in der Scriptores-Ausgabe der MGH von 1854 konnte sie in nachträglich aufgefundenen Handschriften eine frühere Redaktionsstufe des Mirakelbuchs ausmachen. In einem Bericht über einen frevlerischen Diakon, der Virgil nicht als Heiligen anerkannte, wurde dieser in der späteren Redaktionsstufe vage als iuvenis quidam diaconus et ecclesiae eiusdem canonicus bezeichnet. In der früheren Redaktionsstufe hingegen wurde derselbe Diakon noch namentlich erwähnt: quidam diaconus et noster canonicus Otto nomine 59 . Ob der Name in der späteren Redaktion aus Diskretion gestrichen wurde oder weil der Diakon Otto zu einem späteren Zeitpunkt in der Gemeinschaft nicht mehr bekannt war, ist nicht klar. Deutlich wird aber, daß der Akteur in einer den Ereignissen näherstehenden Redaktionsstufe genauer beschrieben wurde.

58 Eine ähnliche Diskussion um den "Sitz im Leben« von historiographischen Werken wird in Bezug auf Widmungsbriefe und Prologe geführt. Schon SimoN, Topik, Teil I, S. 93, Anm. 40 ging von kommunikativen Gemeinschaften aus, innerhalb deren auf solche Werke reagiert wurde. Die Frage nach den Rezipienten von Guiberts Schriften ist für die Frage nach dem Umgang mit Quellenverweisen nicht ohne Belang. Siehe dazu auch oben, Kap. 1.3.3.

59 Wenz-Haubfleisch, Miracula post mortem, S. $90 \mathrm{f}$. 


\subsection{Verweise auf Quellen der Erzählungen}

Guibert de Nogent weist für fast die Hälfte der Wundererzählungen nach, aus welcher Quelle er schöpft. Der Anteil Erzählungen mit Quellennennung ist in den vier betrachteten Werken unterschiedlich. In den Monodiae wird fast die Hälfte der Erzählungen, 29 von 67, durch die Nennung von Zeugen oder Hinweisen auf Quellen außerhalb der Handlung zu einem kommunikativen oder textuellen Umfeld in Bezug gesetzt. Im Reliquientraktat wird für einen großen Anteil von Erzählungen, für 12 von 15 Episoden, auf Zeugen oder Quellen verwiesen. Bei zwei der drei Erzählungen ohne Nachweis handelt es sich einerseits um eine Begebenheit aus der biblischen Geschichte, andererseits um ein Alexander-Wunder aus der literarischen Tradition. Von den drei Wunderepisoden im Marienlob nennt Guibert in zwei Fällen Zeugen (»Petrus von Grenoble«, »Ehefrau und Nebenbuhlerin«), in einem Fall unterläßt er es (»femme de Laon«). In der Kreuzzugschronik wird nur im Falle einer Wundererzählung ein Zeugnis angegeben, ohne es zu problematisieren. In zwei weiteren Fällen wird das Zeugnis erwähnt, aber auch in Frage gestellt. Für sechs weitere wunderbare Gegebenheiten werden keine Zeugnisse genannt.

Einerseits situiert Guibert in den Verweisen seine Quellen im mündlichen Bereich. Dies muß jedoch nicht heißen, daß diese nicht schon in schriftlicher Form bestanden ${ }^{60}$. So sagt Guibert von einer Erzählung, diese sei zwar berühmt, er wisse aber nicht, ob sie schon jemals verschriftet worden sei61. Auch daß Guibert eine schriftliche Zwischenstufe ausläßt, ist denkbar. Andererseits verweist Guibert mehrmals explizit auf schriftliche Quellen. In diesem Falle wählt er Elemente aus schriftlichen Vorlagen aus, um sie in seine Texte einzufügen. Der Anteil an explizit genannten schriftlichen Quellen ist jedoch sehr viel kleiner als der an Nennungen, die sich auf mündliche Kommunikation beziehen oder ungenau bleiben. Sie weisen aber darauf hin, daß Guibert ein groBes Bewußtsein für die schriftliche und die mündliche Ebene von Erzählungen zeigt. Die Annahme, daß Guibert de Nogent als Vertreter der gebildeten klerikalen Elite schriftlichen Quellen den Vorzug geben würde, läßt sich in bezug auf die Wundergeschichten nicht nachweisen. Oft existieren Geschichten zugleich in schriftlicher wie auch mündlicher Form ${ }^{62}$. Daß Guibert für seine Exempla mit Vorliebe mündliche Quellen nennt, hängt auch mit der Einschätzung ihrer Wirksamkeit zusammen. Mündliche Quellen signalisieren Aktuali-

60 Siehe z. B. die Santiagopilgerlegende, unten, S. 113-116. Boureau, Événement, S. 18 liegt nicht richtig, wenn er behauptet, daß Guibert diese Erzählung zum ersten Mal verschriftete.

61 Guibert De Nogent, Autobiographie, III, 19, S. 448: Celebris quoque relatio est, sed nescio utrum syllabis uspiam commendata [...].

62 SMrth, Oral and Written, S. 310f., hat gezeigt, daß die Annahme eines klaren Antagonismus zwischen mündlichen und schriftlichen Quellen nicht haltbar ist, sondern vielfache Bezüge hergestellt werden können. Dazu auch GeARY, Phantoms, S. 124-128. 
tät (modernitas), schriftliche Quellen Vergangenheit63. Für moralische Unterweisung wurden aktuelle Beispiele als wirksamer eingeschätzt als solche, die weit von der Lebenswelt der Rezipienten entfernt waren. Aufgrund der Zeugennennungen soll daher auf kommunikative Gemeinschaften geschlossen werden, innerhalb derjenigen Guibert über Wunder und Wundererzählungen kommunizierte.

\subsubsection{Wundererzählungen in weltlichen, monastischen und klerikalen Kommunikationsnetzen}

Aus der Verortung der genannten Zeugen lassen sich drei soziale Kreise erkennen, in denen sich Guibert bewegte und mit deren Angehörigen er über Wunder kommunizierte. Diese Kreise waren keineswegs abgeschlossen, vielmehr bestanden vielfache Beziehungen zwischen deren Angehörigen.

Das adelige Umfeld: Guibert stammt aus dem regionalen Adel und hatte auch während seiner Zeit in Saint-Germer-de-Fly immer wieder Kontakt zu seiner Familie64. Als Abt in Nogent kam er wiederum in Kontakt mit dem Adel: mit kleinen Rittern, die ihm die Güter der Abtei streitig machten, mit den Herren des nahegelegenen Coucy und auch mit der städtischen Gesellschaft in Laon.

Das monastische Umfeld: Seit dem Alter von 12 Jahren lebte Guibert im Kloster und verfügte als Mönch und danach als Abt über ein regionales Netz von Beziehungen, nicht nur zu seinen Mitmönchen in Saint-Germer-de-Fly oder in Nogent, sondern auch zu Äbten aus der Kirchenprovinz Reims oder zu einem weiter gespannten monastischen Umfeld.

Das Umfeld des Weltklerus: Guibert unterhielt vor allem zu den Weltklerikern des Bistums Laon vielfältige Beziehungen, so zu seinem Bischof und zu dessen Domkanonikern. Darüber hinaus stand Guibert aber auch mit den Bischöfen der Kirchenprovinz Reims in regelmäßigem Kontakt.

Innerhalb dieser drei sozialen Gruppen müssen die Beziehungen der erwähnten Zeugen zu Guibert genauer bestimmt werden. So können Kommunikationshandlungen im Zusammenhang mit Übernatürlichem und Wunderbarem besser sozial verortet werden.

Für die Wunderserien, die sich im Umkreis von Saint-Germer-de-Fly ereignen, aber auch für diejenigen während der Reliquienreisen können die Informanten ohne Probleme geographisch und personell genauer eingegrenzt werden. Deutlich wird dabei, daß es sich um einen lokalen oder regionalen Kreis

63 Als Parallelbeispiel kann Walter MAP, De nugis curialium genannt werden. Dieser fügt eine Sammlung von Anekdoten und Fazetien als Chronik der modernitas zusammen. Zu Walter Map siehe OTrER, Inventiones, S. 111. Zum Umgang des Walter Map mit Zeit siehe Schmirt, Temps, folklore et politique.

64 So versuchte diese wiederholt, Guibert zu einer höheren kirchlichen Funktion zu verhelfen. Siehe dazu Rubenstern, Guibert of Nogent, S. 87-92. 
von Personen handelt. Für eine andere Gruppe von Wundererzählungen sind die Zeugen namentlich so genannt, daß sie als Referenzpunkte dienen können, das heißt, daß es Personen sind, die durch ihre kirchlichen und weltlichen Aufgaben in Bezug zu Guibert gesetzt werden können ${ }^{65}$. Dieser Kreis von Personen muß in einen überregionalen Kontext gestellt werden. Eine weitere Gruppe von Zeugen wird ohne nähere Präzisierung genannt, beispielsweise »ein Priester« oder »eine Kammerfrau«. Deren Bezug zu Guibert kann nicht genauer bestimmt werden, ihre Nennung ist typenhaft.

\section{Wunder aus dem weltlichen Umfeld}

Die Fieberheilung, die Guibert in den Monodiae beschreibt, hatte er in seiner Jugend in einer Eigenkirche seiner Mutter erlebt ${ }^{66}$. Das Wunder geschah über Nacht. Seine Mutter ordnete an, daß der kranke Junge mit einer Gruppe von Klerikern die Nacht vor dem Altar des heiligen Leodegar verbringe. Guibert kehrte nach der so verbrachten Nacht gesund zu seiner Mutter zurück. Die Deutung der plötzlichen Genesung als Wunder war im Mittelalter üblich und würde heute wohl mit dem normalen Krankheitsverlauf erklärt. Guibert erlebte an sich selbst eine Fieberheilung, die er mit den zeitgenössischen Erklärungsschemata deutete. Dieses Wunder verortet er in seiner Kindheit im familiären, adeligen Umfeld.

Auch die Heilung von Skrofulösen durch König Ludwig VI. spielt im weltlichen Milieu. Die wunderbare Heilung soll infolge der Berührung des Königs erfolgt sein. Guibert gibt an, einer solchen Berührung des Königs beigewohnt zu haben ${ }^{67}$. Inwieweit neben Guibert andere Geistliche diesem Ereignis beiwohnten, präzisiert er nicht.

Guibert erfährt ebenfalls aus seinem familiären Umfeld von zwei weiteren wunderbaren Ereignissen. Das erste mirakulöse Ereignis, das er als eventus bezeichnet, geschah als Zeichen während der Taufe eines Judenknäbleins ${ }^{68}$. Kerzenwachs tropfte ins Wasser und formte von selbst ein Kreuz ${ }^{69}$. Diese Geschichte wird von Guibert im Nachhinein als Vorzeichen der guten Lebensführung des Knäbleins gedeutet ${ }^{70}$. Er erfährt sie von Hélissende von Chester, der Witwe des Grafen William I. von Eu ${ }^{71}$. Sie ist mit Guibert familiär verbunden $([\ldots]$ mihi familiaris esset [...]) und scheint ein freundschaftliches Verhältnis zu ihm gepflegt zu haben $([\ldots]$ ut non nisi filium me vocaret $[. .]$.$) . Die$

65 Zum Publikum von Guiberts Schriften siehe oben, Kap. 1.3.3.

66 Zur ausführlichen Besprechung der Geschichte siehe oben, S. $41 \mathrm{f}$.

67 Guibert de Nogent, Quo ordine, P, I, Z. 158-163.

68 Ein Adliger, ein Sohn der Hélissende von Chester, hatte diesen Knaben während des Pogroms an den Juden von Rouen zu sich genommen. Guibert ist eine der wenigen Quellen dieses Pogroms. Siehe Guibert De Nogent, Autobiographie, II, 5, S. 246-248.

69 Ibid. II, 5, S. 248-250.

70 Siehe oben, Kap. 2.1.2.

71 Guibert de Nogent, Autobiographie, II, 5, S. 250, Anm. 1. Dazu Newman, Seigneurs de Nesle. 
Erwähnung der Gräfin von Eu als familiaris ist in bezug auf das anglonormannische Beziehungsnetz Guiberts und seiner Familie wichtig. Hugo, Graf von Chester, stattete die Abtei Bec mit Gütern in England aus, etablierte eine Mönchsgemeinschaft aus Bec in Chester und scheint ein Freund und Bewunderer des Anselm von Bec/Canterbury gewesen zu sein ${ }^{72}$. Auch die Grafen von Eu unterstützten die Abtei von Bec mit Gütern73. Der Judenknabe wurde später von Hélissende dem Kloster Saint-Germer-de-Fly übergeben, wo er auch bezeugt ist ${ }^{74}$.

Die zweite Episode ist eine verwickelte Geschichte um die Entwendung von klösterlichem Vermögen. Sie spielt in Saint-Germer-de-Fly. Der Mönch, der die Tat beging, starb bald eines schlechten Todes. Er hatte das Geld einem Diener gegeben, der es in der Wiege seiner Tochter versteckt hatte. Das Kind wurde darauf von Dämonen geplagt. Erst als die Frau des Dieners, die Kammerfrau von Guiberts Mutter, dieser den Frevel gestand, wurde das Kind erlöst ${ }^{75}$. Diese Episode spielt sich auf Zeugen- und inhaltlicher Ebene in nächster Nähe von Guibert ab: erzählt wird sie ihm von seinem ehemaligen Lehrer, der Prior des Klosters von Saint-Germer-de-Fly war. Guiberts Mutter ist ebenfalls in die Geschichte involviert. Beide Episoden weisen auf ein Beziehungsnetz um die Abteien Bec und Saint-Germer-de-Fly und um Guiberts Familie hin $^{76}$. Auffällig ist, daß beide Episoden nicht eindeutig als Wunder bezeichnet werden. Sie müssen eher als merkwürdige Gegebenheiten interpretiert werden, die mündlich weitererzählt und mit anderen Ereignissen in Bezug gesetzt wurden und so Zeichencharakter bekamen. Beide Episoden werden als Intervention einer höheren Macht gedeutet.

Guibert hatte, wie schon erwähnt, auch als Abt des kleinen Klosters Nogent Kontakt zur weltlich-ritterlichen Umgebung. Davon zeugt ein Strafwunder, das einen Adeligen traf, welcher der Abtei Nogent die Fischrechte im nahen Flüßchen Ailette streitig gemacht hatte. Nachdem dieser durch die allmächtige Maria an verschiedenen Körperteilen von Lähmungserscheinungen getroffen war, diese aber dem Zufall und nicht dem Zorn Mariens zuschrieb, erschien sie ihm im Traum und gab ihm mehrere Ohrfeigen. Darauf rannte der Adelige, vor Hast barfuß, zu Guibert, erzählte ihm seinen Traum und restituierte alle Güter, um die er vorher so vehement gekämpft hatte ${ }^{77}$. Diese

72 Chibnall, English Possessions of Bec, S. 276, die vermutet, daß die Schenkung von Atherstone als Wegstation der Mönche von Bec nach Chester gedient haben könnte.

73 Gazeau, Effect of the Conquest, S. 139; Chibnall, English Possessions of Bec, S. 277; Henry von Eu gründete 1106 das Priorat von St. Martin-du-Bosc und machte Landschenkungen in Sussex.

74 Guibert de Nogent, Autobiographie, S. 250, Anm. 2.

75 Ibid. 21, S. 170-174.

76 Siehe zu diesem Beziehungsnetz auch unten, S. 113, Anm. 89 und 90.

77 GUIBERT DE NOGENT, Autobiographie, III, 18, S. 438-440: cumque fratrum piscator ab illa parte fluminis per ipsum militem omnino absterretur et pro hoc ecclesia multis placitis urgeretur, a Domina praepotenti in membris aliquibus paralyseos valetudine conquassatur. Sed 
Episode, im 18. Kapitel des dritten Buches der Monodiae in einer Serie von Strafwundern an Adligen stehend, wird von Guibert in keiner Weise als Wunder bezeichnet. Sie ist in verschiedene Richtungen interpretierbar: Einerseits dient sie der ökonomischen Verteidigung des eigenen Klosters, die durch die Patronin übernommen wird und eher in Klosterchroniken erwartet würde. Andererseits hat die Episode eine Funktion als Exemplum, das sich an Laien wendet und das auch in einer Serie solcher Exempla steht. Guibert ist in zweifacher Hinsicht von diesem Strafwunder direkt betroffen: Als Abt der betroffenen Institution wird er vom Wunder begünstigt. Zudem verarbeitet er literarisch ein Zeugnis eines »miraculé«, eines Betroffenen eines Wunders. Obwohl er ihn nicht namentlich nennt, muß er den Betroffenen, auch gerade wegen dieses Streits, gekannt haben. Die namentliche Nennung des Zeugen und gleichzeitig Betroffenen ist jedoch in dieser Serie von Übergriffen von Adeligen auf kirchliches Gut nicht nötig, es genügt ein Verweis auf seinen sozialen Stand. Dieses Wunder ist das zweite einer Serie von vier Strafwundern an Laien. Das Ohrfeigen-Wunder weist als einziges aus dieser Serie eine Zeugennennung auf, Guibert führt sich gar selbst als Ohrenzeugen der Ereignisse $a^{78}$.

Die Zeugen, die Guibert aus dem adeligen Umfeld nennt, stehen in relativ enger Beziehung zu ihm. Bei den Erzählungen handelt es sich eher um wunderbare, merkwürdige Ereignisse. Im Falle des königlichen Berührungswunders an Skrofulösen durch Ludwig VI. erzählt Guibert als Augenzeuge lediglich von der königlichen Berührung. Ob er auch Augenzeuge solch wunderbarer Heilungen war, läßt er im unklaren. Im Falle seines eigenen Erlebnisses handelt es sich um ein Heilungswunder, eine schnelle Fieberheilung in der Kindheit, das sich in gewohnten, kirchlich autorisierten Bahnen abspielte.

\section{Wunder aus dem monastischen Umfeld}

Saint-Germer-de-Fly als Kloster, in dem Guibert mehr als 30 Jahre verbrachte, ist ein weiterer Ort, woher Guibert seine Episoden schöpft ${ }^{79}$. Diese Wundererzählungen fügt er in einem Block an den Schluß des ersten Buches. Guibert behandelt exemplarisch Vorfälle aus dem eigenen Kloster, stellenweise fügt er Parallelbeispiele aus anderen Klöstern ein. Auch hier erzählt Guibert keine klassischen Heilungswunder, sondern zumeist Strafen durch schlechten Tod oder Dämonenerscheinungen. Die Kommunikationssituation scheint eine mündliche zu sein. Wenn auch Guibert seine Zeugen nicht immer explizit nennt, wird aufgrund der Beziehungen der Akteure dieser Episoden zu ihm

hoc cum fortunae, non ultioni divinae ascriberet, dormienti illi piissima Virgo astitit et aliquot ei alapas, non sine severitate, in facie dedit; qui exinde experrectus, et ex verbere sensatior factus, ilico nudipes ad me venit, veniam petit, quid beata Maria animositatis sibi intendisset aperuit, usurpata remisit.

78 Ibid. III, 18, S. 438-440.

79 Garand, Secrétaires, S. 14. 
klar, daß es sich zumeist um mündliche Erzählungen von Vorfällen in der Umgebung des Verfassers handeln muß.

Vorfälle wie schlechte Todesarten oder Hexereiversuche erzeugten in der Klostergemeinschaft Handlungsbedarf. Vorfälle, welche die Regeln der Klostergemeinschaft verletzten, mußten sanktioniert werden. Wenn ein Mönch starb, war die ganze Gemeinschaft in die Begleitung des Sterbenden involviert. Dies zeigt Guibert am Fall eines Mönchs, der wegen der Veruntreuung von Geld eines schlechten Todes starb: Der Abt, der sich nach dem Tod des Unglücklichen auf eine Reise begab, mußte nach der Entdeckung des versteckten Geldbeutels die Entscheidung treffen, ob der mutmaßliche Dieb inner- oder außerhalb des Friedhofs beerdigt werden sollte. Zu diesem Zweck hatte er sich mit viri prudentes beraten, bevor er beschloß, den Mönch außerhalb des Friedhofs zu begraben ${ }^{80}$. Eine ähnliche Kommunikationssituation nennt Guibert auch im Fall einer komplizierten Geschichte eines Mönchs, der erst mit Hexerei in Berührung kam und dann Umgang mit einer Frau hatte. Als er seine Sünden beichtete, wurde die Angelegenheit ad judicium sapientium, worunter sich auch Anselm von Bec/Canterbury befand, zur Beurteilung übertragen ${ }^{81}$. An diese Erzählung reiht Guibert eine weitere an, die thematisch (eine versuchte Hexerei) und in Bezug auf die Kommunikationssituation (eine Beichte) an die vorhergehende anschließt. Diese spielt jedoch im weltgeistlichen Milieu ${ }^{82}$. Solche zweifelhaften Vorfälle erzeugten Unsicherheit und verlangten nach Beurteilung durch weise Männer in mehr oder weniger fixierten Prozeduren. Die Vorfälle wurden somit einer gewißen Öffentlichkeit zugänglich gemacht.

Vorfälle, die Guibert von Einzelnen erfährt und als Beispiele für geeignet befindet, fügt er zumeist als Exemplum in den Kontext seiner Schriften ein. So berichtet er von Visionen oder von Teufelserscheinungen, wie beispielsweise von der Vision eines todkranken Priors von Saint-Germer-de-Fly, dem der Teufel erschien und den Verfall der klösterlichen Disziplin ankündigte ${ }^{83}$. In der Klostergemeinschaft wurden solche Geschichten als Lehrstücke in Versammlungen ausgetauscht. Dieser Austausch könnte analog zum hagiographischen InformationsbeschaffungsprozeB, wie er in Vorworten von Mirakelsammlungen beschrieben wird, geschehen sein. So erwähnt Pierre André Sigal einen Hagiographen, welcher die Informationen über seinen Heiligen, Bertrand de Comminges, teilweise aus dem Kloster hatte, in dem er seine Jugend-

80 Guibert de Nogent, Autobiographie, III, 22, S. 178.

81 Ibid. I, 26, S. 200-206. Anselm war bekannt als Vermittler und auch Erzieher von Mönchen, siehe Southern, St. Anselm at Canterbury, S. 22.

82 Es handelt sich um die versuchte Hexerei eines Klerikers aus Beauvais, die dieser anschließend Guiberts Onkel Lisiard beichtete. GuIBERT DE Nogent, Autobiographie, I, 26, S. 206-208, siehe dazu unten, S. 153.

83 Guibert formuliert in Bezug auf die Zeugennennung eine Reserve: Er war sich nicht mehr ganz sicher, ob dies der Bruder derjenigen Frau war, mit der sich seine Mutter von der Welt zurückgezogen hatte. GuIBERT DE NOGENT, Autobiographie, I, 20, S. 170. 
zeit verbrachte. Aus dem Vorwort eines anderen Mirakelbuchs wird klarer, wie eine solche Kommunikationssituation ausgesehen haben kann: Während einer Versammlung erzählte jeder Mönch, welche Zeichen des Heiligen er erlebt hatte; der Verfasser des Wunderbuchs hielt diese Erzählungen dann fest ${ }^{84}$.

Eine ähnliche Kommunikationssituation läßt sich auch im Falle eines weiteren unerklärlichen Ereignisses erkennen. Der Verantwortliche für den Friedhof (ille cui id officii attinebat) entdeckte, daß ein großer Teil des Körpers eines begrabenen Mönchs fehlte. Die Klostergemeinschaft konnte sich gemäß Guibert keinen Reim auf diese rätselhaften Ereignisse machen. Dies ist ein Hinweis darauf, daß innerhalb der Gemeinschaft ein Austausch über das leere Grab stattgefunden haben könnte, daß die Klostergemeinschaft Erklärungsinstanz außergewöhnlicher Vorfälle war ${ }^{85}$.

Ereignisse, die schwierig einzuordnen waren und die Klostergemeinschaft als Ganze tangierten, beispielsweise Vergehen von Einzelnen gegen die Klosterregeln, ein schlechter Tod oder auch das Gerücht eines Wunders, wurden in der monastischen Gemeinschaft diskutiert und bei Bedarf auch ausgewählten Mönchen zur Beurteilung unterbreitet. Wann und wie breit sich Berichte über ungewöhnliche Vorfälle als Erzählung fixierten, ist nicht mehr nachzuvollziehen. Auch nicht, wann sie zum Exemplum wurden, ob ihnen erst Guibert diese Funktion gab oder, was wahrscheinlicher ist, ob sie schon in der Klostergemeinschaft als Exempla erzählt wurden. Der Zusammenhang zu schiedsgerichtähnlichen Situationen als Ausgangspunkt der Erzählung wird aber in vielen Fällen deutlich.

Die Nennungen von Zeugen und Akteuren der Wundererzählungen in Guiberts Schriften gehen auch über seine eigenen Klostergemeinschaften SaintGermer-de-Fly und Nogent hinaus und weisen zum Teil auf große benediktinische Klöster hin. Guibert nennt als Zeugen Mönche aus Cluny, Montecassino, Fleury und aus dem anglonormannischen Raum.

Wohl am besten bekannt ist Anselm von Bec/Canterbury. Vielfach behandelt wurde dessen Wirken als Lehrer Guiberts, das letzterer in den Monodiae beschreibt ${ }^{86}$. Das Verhältnis Guiberts $z u$ ihm wurde bis jetzt vor allem aus theologisch-philosophischer Perspektive beschrieben. $\mathrm{Da \beta}$ die Lehrtätigkeit Anselms nur ein Aspekt seines Bezugs zu Saint-Germer-de-Fly und Guibert war, wurde bis anhin zu wenig beachtet. Aus den Monodiae geht hervor, daß dieser zu Guiberts Mutter in Kontakt gestanden hatte. Er hatte ihr noch als Abt von Bec vom Ergreifen des Schleiers abgeraten, da sie Witwe sei, war ihr

84 SIGAL, Travail, S. 153, 159 (Miracula S. Folliani, IV, $\$$ 322-334, ed. in: AASS Oct. XIII, 29-31). Einen ähnlichen Prozeß der Informationsbeschaffung zeigt GearY, Phantoms, S. 11-12 am Beispiel der Miracula S. Maximini des Letald von Micy, der sein Wunderbuch unter den älteren Mönchen zirkulieren läßt und Ergänzungen einfügt.

85 Guibert DE Nogent, Autobiographie, I, 24, S. 192-194, siehe dazu oben, S. 54.

86 Guibert de Nogent, Autobiographie, I, 17, S. 138-140. Siehe dazu v.a. Rubenstein, St Anselm's Influence; RUBENSTEIN, Guibert of Nogent; GUTH, Exegese und Philosophie; LAbande, Disciple; Pelikan, A First-Generation Anselmian. 
also mit einem Rat zur Seite gestanden ${ }^{87}$. Wie das oben genannte Beispiel zeigt, wurde Anselm auch von der Gemeinschaft in Saint-Germer-de-Fly beigezogen, um in einem Fall von Hexerei ein Urteil über das Verhalten gegenüber dem Sündigen zu sprechen ${ }^{88}$. Im Kreis um Lanfranc und Anselm in Bec und Canterbury bestanden Beziehungen zum Bischofshof in Beauvais, welche die Nähe Anselms zu Saint-Germer-de-Fly und auch zu Guiberts Familie plausibel machen ${ }^{89}$. Sowohl das Kloster wie auch Guiberts Familie standen in enger Beziehung zum Bischof von Beauvais ${ }^{90}$.

Des weiteren weist auch die Santiagopilgerlegende in den Umkreis des Anselm. Die Geschichte des Santiagopilgers wird von Guibert in den Monodiae im letzten Teil des dritten Buches erzählt ${ }^{91}$. Die Geschichte sei hier kurz zusammengefaßt: Ein junger Mann, der mit einer Frau unehelichen Verkehr hatte, unternahm als Sühneleistung eine Pilgerfahrt nach Santiago de Compostella. Als Andenken nahm er einen Gürtel der Frau mit, womit er sich wiederum versündigte. Unterwegs erschien ihm der Teufel in Gestalt des heiligen Jakobus und riet ihm, sich als Strafe das Glied abzuschneiden, mit dem er sich versündigt hatte und sich danach sein Leben zu nehmen. Dies unternahm der Pilger in einer Herberge und starb. Während die herbeigeeilten Pilger für ihn beteten, kehrte er, durch die Interzession Mariens, wieder ins Leben zurück.

Als Zeugen der Erzählung nennt Guibert den Mönch Joffredus, der vor seinem Eintritt ins Kloster Herr über die Burg Semur und andere Burgen in Burgund gewesen sei. Dieser habe die Geschichte von jemandem erfahren, der den auferstandenen Pilger gesehen habe ${ }^{92}$.

87 Guibert de Nogent, Autobiographie, II, 4, S. 244. Zur Schleiernahme und dem Status von Witwen siehe WETLI, Weibliche Religiosität.

88 Siehe oben, S. 111.

89 Diese Beziehungen werden in der Literatur immer wieder herangezogen, um zu erwägen, ob Ivo von Chartres in Bec bei Lanfranc studiert hatte. Ivo war erst Kanoniker in Nesle und von 1072 oder 1078 bis 1090 Probst in St. Quentin de Beauvais. Siehe dazu RIchÉ, Vie scolaire, S. 218, der sich auf GiBSon, Lanfranc, S. 36f., bezieht. Für unseren Kontext nennt Gibson folgende Beziehungen: Ernulf, Mönch aus St. Symphorien de Beauvais, wurde in Christchurch Schulmeister, als Lanfranc in Canterbury war. Ein Schatzmeister der Kathedrale von Beauvais wurde unter Anselm Mönch in Bec, und letzterer verhandelte mit dem Papst in Angelegenheiten der Bischofswahl in Beauvais. Zu Beziehungen von Saint-Germer-de-Fly mit dem anglonormannischen Reich siehe LohrmanN, St. Germer, S. 194-196.

$90 \mathrm{Zu}$ den Beziehungen des Klosters mit dem Bischof von Beauvais siehe unten, S. 154, Anm. 302. Zu den Beziehungen von Guiberts Familie zu Guido von Beauvais siehe GuIBERT DE Nogent, Autobiographie, I, 14, S. 100. Daß Guiberts Familie in Beziehungen stand mit dem Kloster Saint-Germer-de-Fly, macht Guibert in einer Nebenbemerkung im ersten Buch der Monodiae deutlich. Er bezeichnet den Abt Garnier als alumnus seines Großvaters und wegen eines Lehens von dessen Haushalt (curia) abhängig. Ibid. I, 15, S. 108. Zu den Grafen von Clermont, in deren Umfeld sich Guiberts Familie bewegte und im 11. Jahrhundert als Schenker von Saint-Germer-de-Fly belegt sind, siehe LohrmanN, St. Germer, S. 203.

91 Guibert de Nogent, Autobiographie, III, 19, S. 442-449.

92 Ibid. III, 19, S. 444: Quae dicturus sum nostris inaudita temporibus relatione cujusdam religiosi ac vere humilis monachi accepi, qui quidem Joffredus vocatur. Samurensis quon. 
Diese Zeugenangabe bildet das Bindeglied zwischen Guiberts Text und der Verortung des Erzählens der Geschichte des Santiagopilgers in Cluny. In vielen Marienmirakelsammlungen des 12. und 13. Jahrhunderts ist die Erzählung ebenfalls eingefügt. Als Zeuge wird Hugo von Semur, Abt von Cluny von 1049-1109, genannt, als Akteur Giraldus, der nach der Auferstehung als Mönch in Cluny eingetreten war ${ }^{93}$.

Die Erzählung ist parallel zu Guibert mehrfach überliefert. Das wohl wichtigste Zeugnis sind die Dicta Anselmi des Anselm von Bec/Canterbury ${ }^{94}$. Gemäß den Dicta Anselmi wurde diese Erzählung während Anselms zweimonatigem Aufenthalt in Cluny auf seiner Romreise 1104 anläßlich eines der vielen Gespräche des Abtes Hugo von Cluny mit Anselm erzählt ${ }^{95}$. Die Dicta Anselmi bestehen aus zwei Teilen, den dicta und den miracula. Die dicta geben Reden Anselms wieder, welche dieser in commune gehalten hatte, seien dies Predigten oder Reden im Kapitel. Diesen Reden werden einige Wundererzählungen angehängt, die zum kleineren Teil die Wunderkraft Anselms beweisen. Der Verfasser hat sie aber zum größeren Teil im Beisein Anselms gehört ${ }^{96}$. So auch im Fall der Santiagopilgerlegende. Anselm von Bec/Canterbury war während seines zweiten Exils von 1103-1106 auf seinem Weg nach Lyon während zwei Monaten in Cluny bei Abt Hugo zu Gast ${ }^{97}$. Gemäß der Einleitung zu den miracula wurde im Beisein des Autors oft über Moral, Tugenden und das Leben heiliger Männer diskutiert, so auch über den heiligen Jacobus ${ }^{98}$.

Von den Dicta Anselmi bestehen zwei Handschriftengruppen, die zwei Stufen der Überarbeitung des Textes repräsentieren. Vor allem die miracula wurden vom Autor relativ stark überarbeitet. Die erste Version wurde vermutlich

dam castri et aliorum castrorum in Burgundia dominus fuit; cujus vita quia vero cognata dignoscitur, verba suae (sua in Paris BN Baluze 42 und Berlin, Deutsche Staatsbibliothek, Phillipps 1690, siehe dazu DolbeaU, Manuscrits, S. 169.) personae conferenda putamus. GUIBERT DE Nogent, Autobiographie, III, 19, S. 448: Senior ergo, qui haec mihi retulit, ab eo qui redivivum viderat se audisse narravit. Nam ferebatur etiam, quod cicatrix evidens et insignis illi remansit in gutture, quae miraculum circumferret, et abrasa tentigo pertusulum, ut sich dicam, ad urinas residuum habuisset.

93 So z. B. in der Handschrift Toulouse BM 482, fol. 24v: Neque hoc debemus silere quod beate memorie dominus Hugo abbas Cluniacensis solet narrare de quodam sui monasterii fratre.

94 Alexander of Canterbury, Dicta Anselmi, S. 200-207.

95 Ibid. S. 196: Ubi cum duobus mensibus moraremur, frequenter in die antistes videlicet et abbas colloquebantur de caelestis vitae patria, de virtutis morum institutione, de bonorum virorum sancta et admirabili operatione. Quibus cum saepe interfuissem, de beato Iacobo apostolo, fratre Iohannis evangelistae, et alia nonnulla, quae eodem abbate narrante cogno$v i$, memoriae ne posteris laterent commendare curavi.

96 Ibid. S. 19.

97 Siehe ibid. S. 20 (Einleitung) und S. 196. Von dieser Reise stammen die meisten Wundergeschichten in den Dicta. Diese Variante der Santiagopilgerlegende wurde auch fälschlicherweise Anselm selbst zugeschrieben und in PL 159, Sp. 337 abgedruckt. KJELLMAN, Miracles, S. XLVII.

98 Alexander of Canterbury, Dicta Anselmi, S. 196, siehe oben, Anm. 95. 
nach 1109 fertiggestellt, die zweite nach $1115^{99}$. Diese Überarbeitungen betreffen für die Santiagopilgerlegende auch die Zeugenangaben.

In der ersten Version werden als Zeugen der Erzählung sowohl Hugo, Abt von Cluny von 1049-1109, als auch sein Neffe Goffridus angeführt ${ }^{100}$.

Goffridus, der Neffe des Hugo von Cluny ist derselbe, den Guibert als Zeuge seiner Version der Geschichte als Joffredus nennt. Hugo von Cluny ist der älteste Sohn des Dalmatius von Semur, dessen zweiter Sohn der Vater des genannten Goffridus ist ${ }^{101}$. Guibert führt als Zeugen seiner Version der Erzählung nur Goffridus an. Möglich ist, daß er von der ersten Version der Dicta Anselmi nach 1109 auf schriftlichem oder mündlichem Wege erfahren hat. Die Beziehungen Guiberts zu Cluny könnten über Guy, Bischof von Beauvais und Freund von Guiberts Familie, oder aber über Yves de Saint-Quentin, beide in den Monodiae erwähnt, gelaufen sein. Beide sind als Mönche in Cluny belegt ${ }^{102}$.

In der zweiten Version der Dicta Anselmi ist die Zeugenangabe einiges kürzer: Hunc hominem senior reverentissimus, cuius superius, domnus videlicet Hugo abbas Cluniaciensis, et omnia signa mortis eius vidit, et pro admiratione hoc, ut relatum est, enarrare consuevit ${ }^{103}$.

Im Laufe der Überarbeitungen der Dicta werden die Zeugenangaben geglättet: Der Neffe des Abtes fällt in der zweiten Version weg, es wird nur noch der Abt als einflußreicherer Zeuge genannt. Dieser wird sich auch in späteren Zeugnissen der Santiagopilgerlegende zumeist als Zeuge durchsetzen ${ }^{104}$.

Die Santiagopilgerlegende wird in der zweiten Hälfte des 11. Jahrhunderts, um 1060 in versifizierter Form, von Gaiferius von Montecassino überliefert.

99 Die erste Version wird in der Handschrift Corpus Christ College, Cambridge 318, aus dem Dominikanerpriorat in London vom frühen 13. Jahrhundert repräsentiert, die zweite in der Handschrift Corpus Christ College, Cambridge 457 aus Christ Church, Canterbury. Alexander of Canterbury, Dicta Anselmi, S. 26.

100 Ibid. S. 207: Hunc hominem senior reverentissimus, domnus videlicet Hugo abbas Cluniaciensis vidit, et pro admiratione saepe hoc, ut relatum est, narrare consuevit. Domnus quoque Goffridus, nepos et monachus eiusdem abbatis, vir boni testimonii et religionis, praefatum virum et omnia signa mortis eius saepe videre consuevit, qui hoc et aliud, quod subiunctum est, domino archiepiscopo Anselmo, me praesente, narravit.

101 Siehe Signori, Rechtskonstruktionen, S. 43f.; zu Semur siehe Richard, Art. "Semuren-Brionnais«.

102 Guibert DE Nogent, Autobiographie, I, 14, S. 100: Als sich Guiberts Mutter von der Welt zurückzog, begab sie sich auf ein bischöfliches Gut des Bischofs von Beauvais. Nachdem dieser 1078 auf dem Konzil von Poitiers der Simonie angeklagt wurde, Pontal, Conciles capétiens, S. 181 (dort Verweis auf einen Brief des Hugo von Die an Gregor VII., PL 157, Sp. 509), verzichtete er 1085 auf sein Bischofsamt und zog sich nach Cluny zurück. Siehe auch GC 9, Sp. 710. GuiberT DE Nogent, Autobiographie, I, 15, S. 118: Yves de St. Quentin war im Umfeld des Bischofs von Beauvais, inter familiares suos, und folgte als Prior von Cluny auf Odo (den zukünftigen Papst Urban II.).

103 Alexander of Canterbury, Dicta Anselmi, S. 207.

104 Hugo von Saint-Victor erzählt die Geschichte in seinem Traktat De sacramentis christiane fidei, II, 16, 2, Sp. 583, im Abschnitt De exitu animarum unter Bezugnahme auf einen ungenannten Mönch, der sie von seinem ebenfalls ungenannten Abt erfahren hat. Siehe dazu SignORI, Rechtskonstruktionen, S. 44. 
Seine Carmina sind in einer einzigen Handschrift, Montecassino, Archivio 280 $\mathrm{Q}$, aus dem 11. Jahrhundert, überliefert ${ }^{105}$. Die versifizierte Version kann darauf hinweisen, daß die Legende mündlich schon vor den Dicta verbreitet war. Als Zeuge wird in dieser Version ebenfalls Hugo von Cluny genannt. Obwohl der Bezug von Guibert zu Montecassino gegeben ist - in seinen Monodiae folgt einige Erzählungen nach der Santiagopilgerlegende eine Simoniegeschichte des Desiderius von Montecassino, wofür Guibert als Zeugen einen Mönch aus Montecassino anführt ${ }^{106}$-, ist aufgrund der Zeugenangabe Guiberts Version näher an der Version aus den Dicta als an der Version des Guaiferius.

Die Legende des Santiagopilgers wird in den meisten Sammlungen von Marienwundern aufgeführt, aber auch in den Zusammenstellungen des William von Malmesbury, bei Hugo von St. Viktor, in der Legenda aurea und in spätmittelalterlichen Legendensammlungen und Marialen, lebt zudem in volkssprachlichen versifizierten Sammlungen wie derjenigen des Gauthier de Coincy weiter ${ }^{107}$. Die Erzählung ist auch in einer Gruppe von Wundern im Liber Sancti Jacobi eingefügt, dort aber Anselm von Bec/Canterbury als Zeugen zugeordnet ${ }^{108}$. Auch die Version der Erzählung im Liber Sancti Jacobi scheint von den Dicta Sancti Anselmi abhängig.

In der von Eadmer verfaßten Vita des heiligen Anselm wird auf ähnliche Gesprächssituationen hingewiesen, wie wir sie uns im Falle des Santiagopilgers vorstellen können: Anselm sorgt sich um junge Mönche, schreibt Briefe an Ratsuchende und berät auch in Gesprächen Mönche und Laien ${ }^{109}$. Eadmer erwähnt zudem einen Aufenthalt Anselms in der Gemeinschaft von Christchurch, Canterbury, während dessen dieser lehrreiche und staunenswerte Erzählungen aus dem Mönchsalltag vorträgt ${ }^{110}$. In solchen Gesprächssituationen wurde über Wunder sowohl im beurteilenden wie auch im exemplarischen Kontext gesprochen ${ }^{111}$.

105 Ediert in PL 147, Sp. 1285-1288 und in: Limone, Opera agiographica. Zu Gaiferius von Montecassino siehe WiLliam of Malmesburx, Liber de laudibus, S. 25; DHGE VIII, 1935, S. 210; Mirra, Guaiferio di Montecassino; Ders., Versi.

106 Guibert DE Nogent, Autobiographie, III, 19, S. 456-459.

107 Siehe dazu Signori, Rechtskonstruktionen, S. 41-48.

108 Siehe Herbers, Liber Sancti Jacobi, S. 18f., 111 und Ders., Mentalidad y milagro, S. 329-331.

109 EADMER, Vita Sancti Anselmi, S. 20 (Sorge für junge Mönche), dazu auch RubENSTEIN, Osbert of Clare, S. 28-30, 32 (Briefe an Ratsuchende), 42.

110 EADMer, Vita Sancti Anselmi, S. 50: [...] degens per dies aliquot inter eos, et cotidie aut in capitulo, aut in claustro mira quaedam et illis adhuc temporibus insolita de vita et moribus monachorum coram eis rationabili facundia disserens.

111 McGuire, der in seiner Untersuchung über das Konzept monastischer Freundschaft das Netzwerk Anselms untersucht hat, konstatiert, daß von den meisten seiner Zeitgenossen Anselms Gespräche, Ratschläge und moralische Exempla wohl mehr beachtet wurden als seine theologischen Werke. McGuire, Friendship and Community, S. 221. Obwohl diese Aussage für Guibert wohl nur bedingt zutrifft, spielen Erzählungen und Exempla in 
Zum Kreis um Anselm gehörte auch sein Neffe, Anselm von St. Saba. Dieser war in Chiusa erzogen worden, begleitete den älteren Anselm dann auf seinem Weg nach Lyon und Canterbury, wo er bis 1109 blieb. Von 1110 bis 1121 war er Abt von St. Saba in Rom, weilte dann als päpstlicher Legat in England und der Normandie, bis er 1121 Abt in Bury St. Edmunds wurde. Dieser Anselm wird von Guibert nicht als Zeuge erwähnt, wird aber sowohl in Zusammenhang der Edmund-Geschichte als auch der Marienwunder eine Rolle spielen ${ }^{112}$.

Guiberts Zeuge für die Santiagopilgerlegende, Joffredus von Semur, der Neffe des Abtes Hugo von Cluny, weist nach Cluny. Auch der Zeuge, den Guibert für Wunder am Grab von Urban II. in Rom nennt, Odo II., Bischof von Ostia, war vorher Mönch in Cluny gewesen ${ }^{113}$.

Des weiteren nennt Guibert als Zeugen einen Mönch von Montecassino, der ihm eine Simonie-Geschichte im Zusammenhang mit dem Investiturstreit erzählt habe, ein Strafwunder des heiligen Benedikt an Desiderius von Montecassino, den nachmaligen Papst Victor III. Dieser habe sich durch Entwendung von Mitteln der Abtei von Montecassino die Papstwahl erkauft. Während der ersten Messe sei er zusammengebrochen, habe auf den Rat des heiligen Benedikt hin auf sein Amt verzichtet und sei in sein Kloster zurückgekehrt. Die Wortwahl deutet auf Mündlichkeit: Audivi nuperrime a quodam montis Cassini monacho quod inferam ${ }^{114}$. Diese Erzählung, von Guibert ohne sichtbare kritische Distanzierung wiedergegeben, veranlaßt den Editor Labande zu einer verzweifelten Bemerkung, daß hier Guiberts kritischer Geist wohl gänzlich ausgesetzt habe. Bezeichnend für die umstrittene Wahl und das kurze Pontifikat des gemäßigten Victor III. als Nachfolger Gregors VII. ist aber, da $B$ in verschiedenen narrativen Quellen der Zeit Elemente dieser Legende auftauchten ${ }^{115}$. In der Chronik von Montecassino wird vermerkt, da $\beta$ Victor III. krank war, während er vor dem von Anhängern des Gegenpapstes Clemens III. besetzten Petersdom lag. Diese Version aus Montecassino wird die wohlwollendste gewesen sein. Sie wurde dann sowohl von Seiten der strengen Reformer wie auch von der kaiserlichen Partei ausgebaut. Die Chronik des Hugo von Flavigny berichtet, nach dem eingeschobenen Brief des Hugo von Lyon an Mathilde von Tuszien, von einem judicium Dei, durch welches Victor III. während der Messe geschlagen wurde. Danach sei er nicht als

monastischen Netzwerken sicher eine große Rolle. Darauf weist später auch die große Verbreitung der Marienmirakelsammlungen hin.

112 Siehe unten, S. 138 und S. $232 \mathrm{f}$.

113 Guibert de Nogent, Dei Gesta, II, 1, S. 107. Urban II. war vor seiner Papstwahl als Bischof Odo I. von Ostia bekannt.

114 GuiberT DE NoGENT, Autobiographie, III, 19, S. 456.

115 Ibid. S. 458, Anm. 1. Aufzählung der Zeugnisse der Legende bei Fliche, Réforme grégorienne, Bd. 3, S. 213, Anm. 1. Siehe zu Victor III. auch PICASso, Vittore III., welcher dessen Abbatiat in höchsten Tönen lobt. Zu Desiderius von Montecassino siehe CowdreY, Age of Abbot Desiderius, zu seiner Wahl zum Papst siehe S. 185-206. 
Papst, sondern als Abt von Montecassino beerdigt worden ${ }^{116}$. In den Augsburger Annalen wird zum Jahr 1087 ebenfalls von der simonistischen Papstwahl und einem schmählichen Ausfluß der Eingeweide während einer Messe berichtet, infolgedessen Victor III. bald gestorben sei117. Auch Orderic Vitalis und William von Maimesbury berichten später vom Tod des Papstes ${ }^{118}$. Guiberts Erwähnung eines Zeugen aus Montecassino und der Umstand, daß seine Version von den genannten abweicht, läßt vermuten, daß parallel zu diesen Erwähnungen in der Chronistik auch auf mündlichem Wege unterschiedlich ausgestaltete Legenden über Victor III. kursierten.

Eine weitere Gruppe von Erzählungen zum Thema Absetzung oder Erschleichung der Abtwürde weist in die Abtei Fleury/Saint-Benoît-sur-Loire ${ }^{119}$. Familiäre Beziehungen können die Verbindung zu diesem Kloster erklären. Im Zusammenhang mit diesen Geschichten wird Veranus, ein cognatus Guiberts, genannt. Dessen Geschichte - er wurde als Abt von Fleury abgesetzt enthält keinerlei wunderbare Züge. Sie fügt sich aber in eine Serie von Wunder, die Mißbräuche der Abtwürde bestrafen.

Sowohl die Santiagopilgerlegende als auch die Legenden über Desiderius von Montecassino scheinen über das Netz der großen benediktinischen Häuser wie Cluny oder Fleury weitergegeben worden zu sein. Auf der Romreise machte Anselm von Bec/Canterbury Station in Cluny. Wo und ob Guibert sich mit dem Mönch aus Montecassino über Desiderius von Montecassino unterhalten haben soll, wird im Text nicht präzisiert.

116 Hugo von Flavigny, Chronicon, liber II, S. 466-468.

117 Annales Augustani, S. 132, ad annum 1087: Sed miser ille atque maledictus, dum missarum sollemnia celebraret, inter ipsa sacramenta nondum perfecta, fetore turpissimo effusis intestinis, labitur, atque extra ecclesiam semivivus deportatur; Das Motiv der herausquellenden Gedärme ist vor allem mit dem schmählichen Tod des Judas Ischariot verbunden. Siehe Act. 1, 18: Hic quidem possedit agrum de mercede iniquitatis; et pronus factus crepuit medius, et diffusa sunt omnia viscera eius. Auf zahlreichen Darstellungen wurde die in Matth. 27, 3-5 erwähnte Erhängung des Judas und das in der Apostelgeschichte genannte Bersten seines Leibes in einem Motiv harmonisiert. Siehe dazu LCI II, Sp. 444-448; DACL 8, Sp. 259-264; STOTz, Erdichtetes, S.317f.; GoETz, »Hie hencktt Judas«, S. 106-117. In der Bearbeitung der Kirchengeschichte des Eusebius durch Rufinus wird beschrieben, wie der Häretiker Arius im eigenen Kot verendet sei (Hist. eccl. X, 14). Siehe dazu RATPERT, Klostergeschichten, S. 159, Anm. 98.

118 Ordericus Vitalis, Ecclesiastical History, VIII, 7, Bd. 4, S. 164-166: Victor papa, postquam apicem pontificatus ascendit, primam missam in die sancto pentecoste solemniter cantare cepit, sed occulto Dei nutu gravem morbum subito incurrit. Nam, diaria cogente, ter latrinam de missa ductus est et sic in papatu vix una tantum missa perfunctus ... repente infirmatus est; in aegritudine tamen a pentecostes usque ad augustum languens defunctus est. William von Malmesbury erwähnt als Todesursache einen vergifteten Kelch, bringt aber auch seinen Zweifel an dieser Erklärung zum Ausdruck: WiLliam of MalmESBURY, Gesta Regum, III, 266, Bd. 1, S. 492: Victor [...] ad primam missam incertum quo discrimine, cecidit exanimatus, calice, si dignum est credere, veneno interfectus. Siehe dazu Fuche, Réforme grégorienne, Bd. 3, S. 213.

119 GuiberT DE Nogent, Autobiographie, III, 19, S. 458. 


\section{Wunder aus dem Umfeld des Weltklerus}

Die Zeugenangaben der Wundererzählungen weisen nicht nur auf ein monastisches Umfeld, sondern auch auf ein Netz des weltlichen Klerus, dessen Angehörige mit den Mönchen in regelmäßigem Kontakt standen. Dies rührt wohl daher, daß Bischöfe oft aus monastischem Milieu stammten und deshalb auch ihre Beziehungen zu diesen Kreisen aufrechterhielten.

Die Bischöfe der Kirchenprovinz Reims sind als Zeugen von Wundererzählungen wichtig120. Wunder und Heiligkeit waren in diesem Umfeld immer wieder ein Thema. So wurde beispielsweise auf Kirchenversammlungen über Heiligsprechungen und wunderbare Ereignisse entschieden ${ }^{121}$. Wie die Beispiele des Gottfried von Amiens oder des Arnulf von Soissons zeigen, wurden für Mitglieder dieser Gruppe kirchlicher Würdenträger bald nach ihrem Tod Heiligenviten verfaßt und ihre Anerkennung als Heilige vorangetrieben ${ }^{122}$.

Explizit als Zeuge genannt wird in zwei Fällen Barthélémy de Jur, der Nachfolger Gaudrys im Amt des Bischofs von Laon. Im ersten Fall nennt ihn Guibert als Zeugen der Erzählung eines Marienwunders. Als solcher soll er mit Guibert zusammen von diesem Wunder, dem Fall des Petrus von Grenoble, gehört haben. Das Wunder soll ihnen der Bischof von Châlons, Wilhelm von Champeaux, erzählt haben. Dieser habe es wiederum vom Bischof Leodegar von Viviers gehört, in dessen Diözese sich die Geschichte abgespielt habe. Leodegar habe das Wunder zuvor schon König Ludwig und Wilhelm von Châlons berichtet ${ }^{123}$.

Im zweiten Fall handelt es sich um die Geschichte des Büßers Erlebaldus, der nach seinem Tod verschiedenen Personen in Visionen erschien. Über diese Ereignisse gibt Guibert als Zeugen seinen Bischof Barthélémy an. Zudem führt er eine Umfrage an, die unter Zeugen aus der Kirchenprovinz des BüBers Erlebaldus durchgeführt wurde ${ }^{124}$. Diese Episode wird in der Reliquien-

$120 \mathrm{Zu}$ dieser Gruppe schon GuIBERT/Ed. Bourgin, S. XIV.

$121 \mathrm{Zu}$ den Kirchenversammlungen als Kommunikationsort der Wundererzählungen siehe oben, Kap. 2.2.

122 Arnulf von Soissons: 27 Jahre nach seinem Tod wurde seine Vita verfaßt, weitere sieben Jahre später fand die Synode statt, an der seine Heiligkeit anerkannt wurde. Siehe oben, S. 87-91. Die Vita des Gottfried von Amiens wurde 1137/38 von Nicolaus von St. Crépin/Soissons 22 bzw. 23 Jahre nach dem Tod des Bischofs verfaßt. Siehe dazu OTT, Bishops of Amiens, S. 63, Anm. 93.

123 Guibert de Nogent, De laude, Sp. 572: Quod minus ideo ratum constat, quia Vivariensis episcopus, qui hęc ipsa quę magna ex parte viderat, domino nostro regi excellentissimo Ludovico praesente, venerabili Guillelmo Catalaunensi episcopo retulisse dignoscitur, nil tale dixerit. Et hoc quam nuperrime a Vivariensi auditum Laudunensi episcopo domino Bartholomeo, et mihi cum ante paucos dies Catalaunensis ipse narraverit, cum Petri monachatum ei, sicut ab aliis audieram, objecissem, Vivariensem nil super hoc dixisse perhibuit. Zur Überlieferung dieser Wundererzählung siehe unten, Kap. 5.2.3.

124 Guibert DE NoGent, Quo ordine, P, I, Z. 363: Haec ab episcopo Laudunensi domino meo Bartholomeo cum audissem, tot propemodum postea de provincialibus huius beati hominis testes secuti sunt qui super hac re indissimilia sonuerunt, quot iam in mea memoria recenseri non potuerunt. 
kritik im Gegensatz zu Wundern aufgrund von Reue (Geschichte des Mädchens im Brunnen) oder zu Wundern an Unbewußten, durch die Gott ein Zeichen für ihr Umfeld wirkt (wie die Wunder an Kindern in Soissons und Saint-Quentin), als spirituelles Wunder bezeichnet ${ }^{225}$. Wichtig ist in diesem Zusammenhang der Hinweis, daß Guibert mit Erlebaldus freundschaftlich verbunden war ${ }^{126}$.

Barthélémy de Jur stammte mütterlicherseits aus einer der wichtigen Familien in der Region von Laon, der Roucy. Er war verwandt mit Manasses, Erzbischof von Reims, der seine Erziehung überwachte und ihm auch ein Kanonikat in Reims verschaffte ${ }^{127}$. Guibert stand mit dem Bischof seiner Diözese regelmäßig in Kontakt. So widmete er ihm die überarbeitete Version der Moralia Geneseos. Zudem zeigen die Bischofsurkunden, daß Guibert als Abt von Nogent auf den Diözesansynoden anwesend und in den Urkunden als Zeuge aufgeführt war ${ }^{128}$.

Weitere Zeugen von Wundern aus der Kirchenprovinz Reims sind der Erzbischof Manasses II. (1086-1106) von Reims und sein Nachfolger Radulfus $(\dagger 1124)^{129}$. Manasses II. wird von Guibert als Zeuge der Öffnung eines Grabes angeführt, in dem die Gebeine eines früheren Reimser Erzbischofs auf wunderbare Weise abhanden gekommen waren ${ }^{130}$. Auch in der Angelegenheit der heiligen Lanze, die in der Kreuzzugschronik abgehandelt wird, nennt Guibert Manasses II. als Gewährsmann. Dieser soll von König Balduin einen Brief bekommen haben, den Guibert in seiner Kreuzzugschronik erwähnt ${ }^{131}$. In diesem Brief wird die Echtheit der heiligen Lanze bestätigt. Für das Eucharistiewunder aus Soissons nennt Guibert Erzbischof Radulf von Reims, den Nachfolger des Manasses II., als Gewährsmann. Radulf von Reims spielte eine nicht unbedeutende Rolle in der Stadtgeschichte Laons. Er rekonziliierte die Kathedrale nach dem städtischen Aufstand und sorgte für das Begräbnis von Toten. Guibert gibt in seinem dritten Buch auch die Predigt wieder, die der

125 Siehe dazu oben, Kap. 2. Guibert DE Nogent, Quo ordine, P, I, Z. 309 f.: Sunt denique et alii, qui non pro sola fide ad subitum, sed modernas et supercelestes glorias multa sancti laboris longevitate merentur.

126 Ibid. P, I, Z. 358-360: Fuit autem homo iste cum sacerdotio, quo fulgebat, et in Scripturae scientia copiosus et michi valde amicicia affinis [...].

127 Siehe dazu Saint-Denis, Apogée d'une cité, S. 112 mit Anm. 3; Canivez, Art. »Barthélemy de Vir «.

$128 \mathrm{Zu}$ den Bischofsurkunden siehe Actes Laon. Siehe auch oben, Kap. 2.2.1., S. 81. Zu den Urkunden siehe Guibert/Ed. Bourgin, S. XI. Zur Urkunde von 1120 zudem BarthÉLEMY, Les deux ages, S. 58f.

129 Siehe dazu GC, Bd. 9, Sp. 80.

130 GuiberT DE Nogent, Autobiographie, I, 24, S. 194. Zur Geschichte siehe oben, S. 54.

131 Guibert de Nogent, Dei Gesta, VII, 34, S. 332. Dieser Brief ist nicht überliefert. Siehe Inventaire critique; Guibert DE NoGeNT, Geste, S. 20, Anm. 24. Guibert erwähnt zwei weitere Briefe, die Manasses von Anselm von Ribemont bekommen haben soll, von denen der zweite ebenfalls von der heiligen Lanze berichtet. Diese zwei Briefe sind in Handschriften des 12. Jahrhunderts überliefert und in Epistolae et chartae, Nr. 8, S. 144-146 und Nr. 15, S. 156-160 ediert. 
Prälat zu dieser Gelegenheit gehalten hatte ${ }^{132}$. Guibert kam infolge des Aufstandes mehrmals in Kontakt mit Radulf.

Leodegar von Viviers und der nicht namentlich genannte Bischof von Arras werden nur je einmal als Erzähler eines Wunders genannt. Guibert spricht auch in anderen Zusammenhängen nicht von ihnen. Leodegar nimmt hingegen eine wichtige Funktion bei dem oben besprochenen Marienwunder (Petrus von Grenoble) aus dem Marientraktat ein. Er ist einer der wenigen genannten Bischöfe, die nicht aus der Kirchenprovinz Reims stammen. Die der Erzählung des Petrus von Grenoble nachfolgende Wundererzählung hat Guibert ex relatione Atrebatensis episcopo erfahren. Diese Quellennennung ist sehr vage und bringt keine genaueren Angaben zur Kommunikationssituation ${ }^{133}$. Der Zeuge dieser Wundererzählung wird von Guibert nicht weiter präzisiert. Ein Bischof von Arras ist im Reliquientraktat ebenfalls ohne Namensangabe erwähnt. Dies, als Guibert den Streit um den Leichnam des heiligen Firminus zwischen dem Bischof von Amiens, Gottfried, Guiberts Vorgänger als $\mathrm{Abt}$, und den Mönchen von Saint-Denis, nennt. Die Quellenangabe läßt eine mündliche Kommunikationssituation vermuten, es kann daher ein Zeitgenosse Guiberts gemeint sein. Der Bischof von Arras wird gleichzeitig mit dem betroffenen Bischof von Amiens, Gottfried, erwähnt ${ }^{134}$.

Bei den genannten Zeugen aus Kreisen der kirchlichen Würdenträger, die in den Texten zumeist auch explizit benannt werden, handelt es sich durchwegs um Zeitgenossen Guiberts. Über Wundererzählungen wurde also in einem regionalen weltgeistlichen Milieu auf hoher Ebene diskutiert. Sowohl Barthélémy von Laon als auch Gottfried von Amiens und Lambert und Robert von Arras ${ }^{135}$ gehörten einer Gruppe von Vertretern der Kirchenreform in Nordfrankreich an. Dasselbe kann auch von Wilhelm von Châlons ge-

132 Guibert de Nogent, Autobiographie, III, 10, S. 358 f.

133 Diese Erzählung kann im Gegensatz zu anderen nicht genauer situiert werden, da die Quellenangabe einerseits ungenau ist, andererseits die Geschichte auch keine Orts-, Zeitoder Akteurangaben liefert.

134 Gulbert DE Nogent, Quo ordine, P, I, Z. $555 \mathrm{f} .:$ ab Atrebatensi et ipso Ambianensi episcopis audivi quod refero. Ob es sich in diesem Fall um Lambert von Arras (†1115) oder seinen Nachfolger Robert (1115-1131) handelt, geht aus dem Text nicht hervor.

135 Siehe zu den Beziehungen des Gottfried von Amiens zu Lambert von Arras und Johannes von Thérouanne, die ihn bei seinem Einzug in die Bischofskathedrale begleiteten MoRelle, Grégorien, S. 185. Dazu auch BeCKer, Investiturproblem, S. 115 und Anm. 44. Zum Reformbistum Arras siehe oben, Kap. 2.2.1., S.81. Daß diese Gruppierungen innerhalb des Episkopats nicht als zu abgeschlossen gesehen werden dürfen, zeigt ein Brief der Subdiakons Lisiard, des Onkels von Guibert, und des Diakons Hugo von Beauvais an Lambert von Arras. Sie baten Lambert um Unterstützung für ihren Kandidaten Etienne de Garlande in der Sache Bischofswahl in Beauvais. Dieser Streit war in Beauvais zur Zeit aktuell, als Guibert in Saint-Germer-de-Fly nach einer Aufstiegsmöglichkeit strebte. Etienne de Garlande kann sicher nicht der Reformpartei zugeordnet werden, und auch Guiberts Familie hätte auf simonistische Praktiken zur Plazierung ihres Sohnes nicht verzichtet. Siehe RubensteIN, Guibert of Nogent, S. 90-92. Zu Guiberts Verhältnis zur Kirchenreform siehe auch RuBENSTEIN, Principled passion. 
sagt werden ${ }^{136}$. Diese Bischöfe kamen an Konzilien zusammen, aber auch zur Beurteilung von Streitfällen, die sie als kirchliche Autoritäten schlichteten. Sie unterhielten zudem gegenseitigen Briefkontak $\mathrm{t}^{137}$. Durch Briefe ist beispielsweise belegt, daß Lambert von Arras in freundschaftlichem Kontakt zu Anselm von Bec/Canterbury stand ${ }^{138}$.

Die Zeugenangaben in Guiberts Werken zeigen, daß auch in der Gruppe der Bischöfe vielfach über Wunder gesprochen wurde. Dies hängt vor allem mit der Überwachung und Lenkung des Kultes als Bestandteil des kirchlichen Lebens in den Diözesen zusammen. Daß in dieser Guibert nahestehenden Zeugengruppe vor allem über eine bestimmte Art von Wundern verhandelt wurde, kann nicht beobachtet werden. Vielmehr wurde über ein Eucharistiewunder, eine Wiedergängerlegende, ein kombiniertes Straf- und Heilungswunder oder auch über eine Reliquie aus dem Heiligen Land diskutiert. Sichtbar ist jedoch, daß die von Guibert genannten Zeugen zu einer regionalen Gruppe von Bischöfen gehören, die auch sonst durch mannigfache Beziehungen als Kreis von reformfreundlichen Bischöfen zu umschreiben ist. Guibert pflegt zu diesem Kreis vielfältige Beziehungen und verdeutlicht durch die Nennung von Angehörigen dieser Gruppe seine eigene Zugehörigkeit zum Kreis der reformfreudigen Prälaten im Erzbistum Reims.

Guibert kommunizierte nicht nur mit den Angehörigen des hohen Weltklerus, sondern auch mit den Domklerikern von Laon oder von anderen Kathedralen oder Kirchen der Region. In den Monodiae finden sich im dritten Buch gruppiert einige ausgewählte Wunderepisoden, die sich auf den Reliquienreisen der Domkleriker von Laon ereigneten. Diese wurden veranstaltet, um nach dem Stadtbrand Geld für den Wiederaufbau der Kathedrale zu sammeln ${ }^{139}$. Guibert lehnt den Brauch der Reliquienreisen ab, erzählt jedoch gleichwohl einige ausgewählte Wunderepisoden, wie er betont, zu Predigtzwecken ${ }^{140}$. Sie sind eingefügt zwischen der Darstellung der tragischen Geschichte der Bischöfe von Laon und der Schilderung der Verhältnisse in und um die Stadt zur Zeit der Niederschrift der Monodiae ${ }^{141}$. Durch wen und auf welche Weise Guibert von den Wundern erfahren hat, führt er nirgends aus. Er gibt jedoch verschiedene Hinweise auf seine Quellen. Er steht dem Milieu der Kleriker von Laon geographisch sehr nahe und die Wunder können mit den Reliquienreisen auf die Jahre 1112 und 1113 datiert

136 Dieser ist auch auf der Synode von 1120 zur Heiligsprechung des Arnulf von Soissons anwesend (siehe oben, Kap.2.2.). Siehe dazu Bauthier, Paris; Miethke, Abaelards Stellung, S. 159 und Anm. 6.

137 Morelle, Grégorien, S. 187; Morelle, Pratique épistolaire.

138 Chartes Arras, S. XXXIV.

$139 \mathrm{Zu}$ solchen Reliquienreisen, wie sie ab dem 11. Jahrhundert vielfach veranstaltet wurden, siehe KAISER, Quètes itinérantes.

140 GuiberT DE NoGENT, Autobiographie, III, 13, S. 388: Non enim odeporicum eorum scribimus, ipsi conscribant, nec facta viritim, sed quaeque predicatoria decerpimus.

141 Ibid. III, 12-13, S. 376-395. 
werden $^{142}$. In Form eines Mirakelbuchs werden sie erst dreißig Jahre später, 1145, durch Hermann von Tournai festgehalten. Aus Guiberts Seitenbemerkung: Non enim odeporicum eorum scribimus, ipsi conscribant, [... $]^{143}$ geht hervor, daß das Wunderbuch oder Itinerar der Reise noch nicht geschrieben war, er dies aber auch nicht tun wollte. Ob er sich auf schriftliche Notizen der Kleriker stützen konnte, ist nicht klar. Im Falle einer ähnlichen, etwas späteren Reliquienreise, der circumvectio S. Taurini von 1158, ist bekannt, daß die Notizen der Reise nach der Rückkehr bearbeitet wurden ${ }^{144}$.

Durch das Mirakelbuch des Hermann von Tournai sind wir über die Namen der Kleriker, Priester und Laien unterrichtet, die an den Reliquienreisen teilnahmen ${ }^{145}$. Guibert stand mit den Domklerikern von Laon in engem Kontakt. Zum einen scheint er auf einer nicht bestimmbaren Reisestation anwesend gewesen zu sein. Im Reliquientraktat verurteilt er den Reliquienmißbrauch eines Sprechers der Kanoniker auf dieser Reise. AnläBlich einer Station der Reise hatte dieser behauptet, ein Stück Brot, das von Jesus gekaut worden sei, in seinem Reliquienkasten (phylacterium) zu haben und rief Guibert als Zeugen für diese Aussage auf. Aus Rücksicht auf die Auftraggeber des Sprechers vermied Guibert, offenzulegen, was er über diese falsche Reliquie dachte und stimmte $\mathbf{z u}^{146}$.

$\mathrm{Ob}$ Anselm von Laon als Leiter der Kathedralschule in die Organisation der Reliquientournee involviert war, erwähnen weder Guibert noch Hermann. Dies ist jedoch aufgrund der Nähe der Kathedralschule zum Domkapitel zu vermuten $^{147}$. Zuden machten die Kleriker auf ihrer Reise oft bei Anselms Schülern Station ${ }^{148}$. So in Canterbury, in Essex und in Salisbury. Sowohl der Erzbischof von Canterbury, der Archidiakon Robert aus Essex als auch die Verwandten des Bischofs von Salisbury hatten Unterricht bei Anselm in Laon genossen $^{149}$. Der sonst von Guibert so verehrte Magister scheint als Mit-

142 SIGNORI, Maria, S. 100, dort Hinweise auf weitere Literatur.

143 Guibert de Nogent, Autobiographie, III, 13, S. 388. Dazu Signori, Maria, S. $106 f$.

144 Sigal, Travail, S. 175.

145 Hermann von Tournai, De miraculis sanctae Mariae Laudunensis, Sp. 968: Eorum itaque consilio elegimus septem canonicos ex fratribus nostris, Bosonem scilicet, Robertum, Anselmum, Herbertum, Robertum, Bonefacium, Amisardum presbyterum, Odoonem, qui postea fuit abbas monasterii quod dicitur Bona Spei, in episcopatu Cameracensi. Sex quoque laicos ex civibus eis addidimus, Ricardum videlicet, Joannem Piot, Odonem, Lambertum, Bosonem, et Theodericum de Brueriis. Sp. 973 die Zusammensetzung für die zweite Reise: Electi sunt itaque ex canonicis Boso presbyter, neposque ejus Robertus, Radulphus presbyter, Mattaeus, cognatusque eus Bonifacius, Robertus genere Anglicus, et Helinandus, Joannes presbyter parochiae Sancti Martini, et Amisardus clericus. Zur Zusammensetzung der Gesandtschaften siehe auch SIGNORI, Maria, S. 101f.

146 Guibert De Nogent, Quo ordine, P, I, Z. 406-415. Dazu siehe oben, S. 66f., und RubenSTEIN, Guibert of Nogent, S. 125, der auch die Distanzierung Guiberts von den Reliquientourneen beschreibt.

147 Rubenstein, Guibert of Nogent, S. 125.

148 Signori, Maria, S. $103 \mathrm{f}$.

149 Hermann von TournaI, De miraculis sanctae Mariae Laudunensis, Sp. 977B, 982A, 983A. 
organisator der Reliquientournee in den Monodiae sowie im Reliquientraktat Ziel harscher und im Text kaum verdeckter Kritik zu sein. Anselm wird sonst in den Monodiae in wissenschaftlicher ebenso wie in moralischer Hinsicht sehr gelobt und spielt in den Tragödien von Laon ${ }^{150}$ eine ausgleichende Rolle ${ }^{151}$.

Die Nähe Guiberts zu den Reliquienreisen zeigt auch eine Erzählung über die Heilung eines Taubstummen, den die Kanoniker anschließend als Laienbruder in ihre Gemeinschaft aufnahmen. Guibert berichtet, er habe diesen in der Kirche zu Nogent selbst gesehen und festgestellt, daß er von einfachem Geist war und nicht viel sagte oder begriff. Hingegen erzählte er überall vom Wunder, das an ihm geschehen war ${ }^{152}$. Die Erzählung zeigt, wie auch die Überprüfung des geheilten Beines durch den Bischof Leodegar von Viviers im oben erwähnten Fall des Petrus von Grenoble, die wichtige Funktion, welche die "miraculés « für die Verbreitung der Wunder einnahmen.

$\mathrm{Da}$ Guibert den Domklerikern nahestand, kann auch außerhalb seiner Texte anhand der Bischofsurkunden gezeigt werden. Guibert agierte bei der bischöflichen Urkundenproduktion mehrfach als Zeuge oder Unterschreiber ${ }^{153}$. Die Urkunden sind bis 1117 von Anselm als Kanzler geschrieben oder bestätigt und von Angehörigen des Domkapitels, beispielsweise von Anselms Bruder Radulf mitunterzeichnet. Die Urkunden sind oft, wenn sie genau datiert sind, auf die Diözesansynode zu Anfang November datiert. An diesem Datum versammelte sich der weltliche und monastische Klerus der Diözese jährlich. Die Wunder aus dem Kreis der Domkanoniker hatten sich nahe bei Guibert ereignet und wurden ihm von Zeugen berichtet, ehe die hagiographische Produktion in Form des Wunderbuches des Hermann von Tournai angelaufen war.

An die Erzählung der Wunder auf der Reliquientournee fügt Guibert eine weitere Erzählung über eine wunderbare Begebenheit anläßlich der Reparatur des Kirchendachs an. Als Zeugen dieses Ereignisses nennt er den Kleriker, der die Reparatur organisieren mußte und von seiner Aufgabe her dem Wundergeschehen am nächsten war ${ }^{154}$. Ein Ochse kam von irgendwo her und bot sich an, beim Transport der Materialien mitzuwirken. Wie er gekommen war, verschwand er auch wieder auf unerklärliche Weise. Guibert ordnet das Wunder keiner wunderwirkenden Kraft zu.

In zwei Fällen von Wundern, die sich in Kirchen ereigneten, nennt Guibert den Klerus dieser Kirche als Zeugen. Im ersten Fall ist der Ort des Geschehens die Kathedrale von Noyon, die der Jungfrau Maria geweiht ist. Ein Mädchen, das an einem Feiertag des heiligen Nicasius gearbeitet hatte, war be-

150 Siehe dazu KAISER, Guibert de Nogent.

151 GuiberT DE NogENT, Autobiographie, III, 4, S. 284-290 anläßlich der Wahl Gaudrys zum Bischof; III, 7, S. 334; III, 10, S. 356.

152 GuIBERT DE NogENT, Autobiographie, III, 12, S. 382.

153 Actes Laon, Nr. 58 (1111), 61 (1112), 72 (1115), $76(1116), 78$ (1116), 90 (1121), 97 (1122), 98 (1122).

154 Guibert DE Nogent, Autobiographie, III, 13, S. 392: [...] dictum mihi a quodam bonae indolis clerico est, cui materiei advehendae officium fuerat delegatum [...]. 
straft worden, indem ihr der Faden einer Näharbeit in der Zunge stecken blieb. Das Mädchen und ihre Mutter zogen dann mit einer großen Volksmenge zur Kathedrale und erreichten durch inniges Gebet die Erlösung vom Strafwunder durch Maria: die Loslösung des Fadens. Der Zeuge, der Priester und Sakristan Ansellus, wird im Lauf der Erzählung zweimal genannt. Zum ersten Mal zur Untermauerung der Schilderung von wunderprovozierenden Bittgebeten, welche die Opfer der Strafwunder aussprachen ([...] et, sicut Ansellus presbyter, ecclesiae sacrista, mihi rettulit [...]), zum zweiten Mal am Schluß der Erzählung, wo der Priester nicht nur die Ereignisse erzählt, sondern auch den blutigen Faden als Beweis zeigen kann ([...] Hoc in eadem, qua factum est, ecclesia mihi est relatum, et filum mirae grossitiei cum nodo adhuc cruento / a praefato presbytero ostensum. [...] $)^{155}$.

Auch das Eucharistiewunder in der Basilika von Saint-Quentin wurde Guibert vom Klerus der Kirche berichtet, in der das Wunder stattgefunden hatte. Nach dem gleichen Schema wurde ihm vom Klerus das Grab des wundersam Verstorbenen gezeigt ${ }^{156}$. Diese Art der Wunderbezeugung ist in Mirakelsammlungen durchaus üblich: Funktionsträger wie der Sakristan oder der Priester am Ort des wundersamen Geschehens berichten dieses als Augenzeugen und führen bestärkend Objekte an, welche das Wunderwirken dingfest machen $^{157}$.

Neben den hohen kirchlichen Würdenträgern werden Angehörige des Weltklerus von Guibert in zwei unterschiedlichen Zusammenhängen als Zeugen genannt. Einerseits sind dies die Domkanoniker von Laon, mit denen er im Rahmen der Diözese regelmäßig in Kontakt stand. Deren Reliquienreise scheint er aus der Nähe verfolgt zu haben, auf gewißen Stationen selbst anwesend gewesen zu sein. Auch die Schilderung des städtischen Aufstandes in den Monodiae legt nahe, daß Guibert mit dem Bischofshof in Laon in regelmäßigem Kontakt stand. Eine andere Qualität hat die Nennung von Funktionsträgern an wunderanfälligen Orten. Diese werden in ihrer Funktion als Autoritäten über das Wunderbare oder über den Ort genannt, wo das Wunderbare sich ereignet hat. Guibert gibt im Text keine weiteren Hinweise auf seine Beziehungen zu dieser Gruppe von Zeugen.

\subsubsection{Hinweise auf schriftliche Quellen der Wundererzählungen}

Explizite Hinweise auf schriftliche Quellen der Wundererzählungen finden sich weit weniger häufig als solche, die auf Zeugen hinweisen, ohne das Kommunikationsmedium der Erzählung genauer zu spezifizieren. Die aus schriftlichen Quellen geschöpften Wundererzählungen weisen auf bestehen-

155 Ibid. III, 18, S. 436, 438. Zum Zusammenhang dieser mündlichen Version mit der schriftlichen siehe unten, S. 128-130.

156 Guibert de Nogent, Quo ordine, P, I, Z. 225-227.

157 Zur Berichterstattung des Klerus siehe WARD, Miracles, S. 35. 
des hagiographisches Schrifttum, auf Predigtliteratur, aber auch auf historiographische Literatur der klassischen Antike hin.

Die meisten dieser Hinweise finden sich im Reliquientraktat, worin sich der Autor im Laufe seiner grundsätzlichen Überlegungen zu Wundern auch mit der schriftlichen hagiographischen Tradition auseinandersetzt. Hier rekurriert er sowohl auf biblische Wunder, die keines Quellenverweises bedürfen, als auch auf die profane Literatur. Sueton wird als einzige Referenz der profanen Geschichte explizit als Quelle einer Wundererzählung herangezogen ${ }^{158}$. Oft zitiert Guibert ohne Quellenverweis. Die Alexander-Episode, deren Quelle Guibert nicht ausweist, ist bei Flavius Josephus überliefert, dessen Werk im Mittelalter in der lateinischen Version des Rufinus greifbar war ${ }^{159}$.

Die aufgezählten Vorzeichen für Schicksale weltlicher Herrscher werden nur kurz angesprochen und als Exempla in der Argumentation verwendet ${ }^{160}$. Die Verwendung historischer Beispiele wurde ab Ende des 11. Jahrhunderts vor allem in den Streitschriften des Investiturstreits, einer argumentativen Gattung, gebräuchlich ${ }^{161}$. Vorzeichen für Herrscher wie das Erscheinen von Kometen oder ein Sturz vom Pferd waren durch diese Schriften, wie auch durch die ursprünglichen Texte, beispielsweise Herrscherviten, bekannt.

Bei der Betrachtung von Erzählungen aus schriftlichen Quellen sind die Herkunft und der Überlieferungszusammenhang der Geschichte sehr wichtig. So unterscheidet sich eine Wundererzählung eines Heiligen, die Teil eines hagiographischen Dossiers ist, von einer einzeln aufgeführten Legende oder Dämonenerzählung außerhalb des Kontextes eines Kults. Verschriftlicht werden neben den Wundern aus biblischer, klassisch-lateinischer und historiographischer Tradition vor allem Wunder, die in klerikalem Umfeld geschehen und die für diejenigen, welche sie festhalten, von Interesse sind ${ }^{162}$. Heilungswunder zeigen die Kraft eines Heiligen, Auffindungswunder in Gründungsgeschichten legitimieren Klostergründungen. Guiberts Auswahl von Wundern hingegen geht nicht entlang dieser Interessen. Sein Interesse in der Reliquienkritik ist das Aufzeigen von Mißständen, also wählt er aus der schriftlichen Tradition problematische Beispiele aus. So im Falle von unwürdigen Heiligen. Vom Fall des Piro, der seinen Tod fand, nachdem er betrunken in einen Brunnen gefallen war, hat Guibert Kenntnis, weil er davon in der Vita des heiligen Samson gelesen hat ${ }^{163}$. Explizit auf die hagiographische Produktion von Mira-

158 Guibert de Nogent, Quo ordine, P, I, Z. 150f.: [...] lege Suetonium, quomodo Vespasianus impactum pedis pollice sustulerit claudum.

$159 \mathrm{Da}$ die Chroniken des Rufinus in der Kathedrale von Reims greifbar waren, schließt Lesne, Scriptoria, S. 601 aus Zitaten des Hinkmar von Reims. CARY, The Medieval Alexander, S. $126 \mathrm{f}$.

160 Siehe oben, S. 62.

161 GoEtz, Geschichte als Argument.

162 Siche dazu Signori, Maria, S. 33-36.

163 GuiberT DE Nogent, Quo ordine, P, I, Z. 107-110. Guibert berichtet, er hätte diese Passage den Umstehenden vorgelesen: Legi, testor deum, et iis qui michi presto fuerant cum 
kelbüchern bezieht sich Guibert im Fall des Wunderbuches von Saint-Médard de Soissons. Dieses hat ihm in schriftlicher Form vorgelegen. Er zitiert aus dem Wunderbuch des Klosters, um seine Kritik daran zu üben. Durch ironisierende Darstellung werden die Episoden ins Lächerliche gezogen. Die Quellenverweise, die Guibert selbst gibt, weisen auf eine schriftliche Vorlage: [...] immo scripti illius vilis admodum probatur indignitas. Nam in eorum libello [...] ut pagina illa refert ${ }^{164}$. Diese Quellenverweise lassen sich mit der handschriftlichen Überlieferung der Wunderbücher aus Saint-Médard in $\mathrm{Zu}$ sammenhang bringen, ist doch die älteste bekannte Handschrift, welche die angesprochenen Episoden berichtet, auf das Ende des 11. Jahrhunderts zu datieren ${ }^{165}$.

In bezug auf Wunder, die in hagiographischen Texten festgehalten sind, stehen diese Erzählungen in Guiberts Werken sozusagen auf dritter Stufe im Verschriftungsprozeß. Das folgende Modell soll diesen Prozeß idealtypisch beschreiben ${ }^{166}$. Ereignisse, die als Wunder gedeutet werden, werden zumeist in einer monastischen oder kanonischen Gemeinschaft verschriftet, in deren Mitte Wunder durch einen Mittler (beispielsweise Reliquien oder auch ein Marienaltar) erwartet werden. Als erste Stufe der Verschriftung gelten Notizen, welche die Funktionsträger am wunderwirksamen Ort festhalten ${ }^{167}$. Als zweite Stufe gilt ein literarisch überarbeitetes Wunderbuch, wie beispielsweise dasjenige der Mönche aus Saint-Médard de Soissons ${ }^{168}$. Als dritte Stufe des Verschriftungsprozesses soll hier das Einfügen von Wunderepisoden aus einem Wunderbuch in einen neuen Kontext, beispielsweise in Guiberts Reliquientraktat, angesehen werden. Die intertextuellen Bezüge zwischen den verschiedenen Stufen können enger (wörtliches Zitat) oder lockerer (literarische Umarbeitungen) sein.

In den Monodiae wird zweimal explizit auf die schriftliche Tradition zurückgegriffen. Die Quilius-Legende als Gründungsgeschichte des Klosters Nogent wird mit einer metrischen Schrift authentifiziert ${ }^{169}$ :

Quaedam autem sunt in eadem ecclesia literae metro compositae, quibus ego nulla adniterer auctoritate, nisi quaedam, quae plurimum earum roborant fidem, viderem hodieque constare. Quae historia sic se habere secundum scripturae huius seriem traditur ${ }^{170}$.

nimia detestatione relegi, scilicet in Vita Sansonis celeberrimi apud Francos et Britones sanc$t i[\ldots]$.

164 Ibid. P, I, Z. 589-596.

165 BLOCH, Die wundertätigen Könige, S. 67 scheint die handschriftliche Überlieferung der Wunderbücher aus St. Médard nicht gekannt zu haben. Die genauere Darlegung des Zusammenhangs der Wunderbücher aus St. Médard und Guiberts Traktat folgt unten, Kap. 5.1.

166 Zum Modell siehe ausführlicher Fuchs, Wundererzähler, S. 327-331.

167 SIGNORI, Maria, S. 33. Zum Klerus an den Stätten des Wunders siehe oben, S. 124f.

168 SIGNORI, Maria, S. 36.

169 Es geht aus Guiberts Quellenangabe nicht hervor, ob er eine Inschrift vor Augen hatte oder ob er von einer Schrift in Pergamentform spricht.

170 Guibert de Nogent, Autobiographie, II, 1, S.210-212. 
Ob der Rückgriff auf eine schriftliche Tradition diesen bretonischen König Quilius, der in den hagiographischen Repertorien nicht figuriert, als Heiligen institutionalisieren soll, ist nicht klar ${ }^{171}$. Als sanctus wird Quilius von Guibert nicht bezeichnet. Trotzdem ist die Geschichte so angelegt, daß Quilius mit einem Reliquienkästchen in Nogent begraben wird und auch eine elevatio dieses Reliquienkästchens stattfindet. Diese elevatio geschieht nicht irgendwo, sondern am Ort, wo schon in vorchristlicher Zeit ein Tempel gestanden haben soll, welcher der virgo paritura geweiht war, der Jungfrau, die in $\mathrm{Zu}$ kunft den Gottessohn gebären sollte. An dieser Stelle habe seit alten Zeiten eine kleine Kirche gestanden, in der auch Wunder geschehen sein sollen ${ }^{172}$. Auf dem Siegel der Abtei Nogent aus dem 13. Jahrhundert wird dann der sanctus Quilius rex vermerkt ${ }^{173}$. Für diese Gründungslegende kann nur auf eine schriftlich fixierte Tradition zurückgegriffen werden. Sie wird von Guibert der relativ jungen Geschichte der Gründung von Nogent durch die Herren von Coucy mit Hilfe von Mönchen aus Saint-Rémi von Reims entgegengesetzt $^{174}$.

Auf die Predigtliteratur bezieht sich Guibert im sogenannten Wunderanhang im dritten Buch der Monodiae. Dies in Zusammenhang mit einem Strafwunder, das die Nichtbeachtung des Festtages des heiligen Nicasius durch ein Mädchen sanktionierte. Vom Ablauf dieses Wunders und der anschließenden Erlösung durch die Jungfrau Maria hatte Guibert mündlich durch den Priester dieser Kirche erfahren ${ }^{175}$. Danach weist er in knapper Form auf die Ergänzung der mündlichen Tradition durch die schriftliche hin: Simile quid etiam in die Annunciationis beatae Mariae nostra aetate est actum, quod a Ratbodo, urbis episcopo, constat scriptum ${ }^{176}$.

Guibert gibt also an, eine schriftliche Version der Erzählung zu kennen und unterscheidet sie von der Erzählung, von der er angibt, sie mündlich am Ort des Geschehens erfahren zu haben. Für die Bezugnahme auf die schriftliche Version genügt ihm ein knappes Zitat.

Eine ähnliche Geschichte findet sich denn auch in der handschriftlichen Überlieferung einer Predigt des Radbod von Noyon († 1097/98), dem Sermo

171 Der Name Quilius wird im Namenbuch für den westfränkischen Bereich nicht aufgeführt. Siehe Morlet, Noms de personne, Bd. 1 für die germanischen Namen, Bd. 2, S. 95 für die lateinischen Namen.

172 Guibert de Nogent, Autobiographie, II, 2, S. 224.

173 Ibid. S. 222, Anm. 2.

174 Das Kloster Nogent stand in enger Beziehung zu Coucy: Bis 1132 lagen alle Güter von Nogent auf Gütern von Coucy, siehe BarThéLemy, Les deux âges, S. 58. Auch die Beziehung zu Reims hat Tradition, denn Coucy war im 10. Jahrhundert ein wichtiger Verteidigungspunkt der Reimser Kirche, siehe Sor, Miracles et le temps de l'histoire, S. 206. Guibert führt neben der Schrift auch die Anordnung der Gräber und ein Reliquienkästchen als Beweise für das hohe Alter der Kultstätte an, siehe dazu oben, S. 115.

175 Siehe oben, S. $124 \mathrm{f}$.

176 Guibert de Nogent, Autobiographie, III, 18, S. 438. 
Radbodi de Annuntiatione beatae Mariae Virginis ${ }^{177}$. Der ausdrückliche Verweis Guiberts auf eine schriftliche Quelle zeigt, daß solche Angaben nicht unbegründet als fiktiv behandelt werden können. Wie die schriftliche Version mit der mündlichen zusammenhängt, ist nicht klar. Vorstellbar ist, daß beide mit Abweichung das gleiche Wunder berichten. Narratives Material kann zwischen der mündlichen und schriftlichen Form hin und her wechseln, ohne daß dies bemerkbar wäre ${ }^{178}$.

Vom Sermo Radbodi ist eine schriftliche Version in der Patrologia Latina ediert. In der Tat ist er im 11./12. Jahrhundert in verschiedenen Handschriften bezeugt ${ }^{179}$. In einer Handschrift aus dem 11. Jahrhundert (Troyes BM 1171) ist der sermo zusammen mit einer Zusammenstellung vor allem von Passiones und Vitae verschiedener Heiliger, aber auch mit einigen Hymnen, Predigten und anderen liturgischen Texten überliefert ${ }^{180}$. Des weiteren ist der Sermo Radbodi in Marienmirakelsammlungen aus Nordfrankreich enthalten, die in Handschriften aus dem 12. und 13. Jahrhundert auf uns gekommen sind. Er ist in zwei Handschriften in der gleichen Form wie in der Handschrift aus dem 11. Jahrhundert kopiert ${ }^{181}$. Weitere Handschriften von Marienmirakelsammlungen überliefern den Sermo in gekürzter Form ${ }^{182}$. Die einleitenden, eher Allgemeines über Maria, ihre Jungfräulichkeit, über die Verkündigung und die Geburt Christi enthaltenden Abschnitte werden dort weggelassen. In die-

\section{Radbodi sermo.}

178 Sтоск, Implications, S.80. Wie Mündlichkeit und Schriftlichkeit von Predigten zusammenhängen, ist ein nach wie vor ungelöstes Problem. Siehe dazu MaIER, Sermons as Evidence, S. 230-238.

179 Radbodi sermo, Sp. 1498. Der Sermo Radbodi ist gemäß der Histoire Littéraire de France, Bd. VIII, S. 457 in drei Handschriften überliefert: In einer Handschrift aus SaintMartin de Tournai, in einem Lektionar der Abtei Saint-Eloi de Noyon und in einer Handschrift der Kathedrale von Noyon. Von den drei genannten Handschriften konnte nur eine aus St. Martin de Tournai, die nun in der British Library liegt (BM Addit. 35112), identifiziert werden. Ediert ist der Sermo in der Patrologia latina 150, welche die Edition von Actes Reims, S. 100-105 kopiert. Diese Edition wiederum bezieht sich auf GC X, Instr. col. 368, die aber einzig mit dem Hinweis ex authentico zitiert.

180 Die mittelalterliche Herkunft des Codex ist mir unbekannt. Siehe dazu Catalogue Troyes, I-II, S. 482. Er stammt aus dem Collège de l'oratoire de Troyes, das es von den Brüdern Pithou erhalten hat (Pierre 1539-1596, François 1543-1621). Zu den Brüdern siehe Grosley, Vie de Pierre Pithou. Die Predigt des Radbod ist in einem Ternion aufgeführt (fol. 140-144), nach einem Hymnus der Jungfrau Theodosia und vor einer Predigt des Ambrosius Autpertus, De assumptione Mariae, ed. in: Ambrosil AUtPERTI opera, S. 1027-1036. Diese Predigt ist auch als sermo des Pseudo-Augustinus 208 bekannt.

${ }^{181}$ Es sind dies die Handschriften Cambrai BM 804 aus Saint-Sépulchre, fol. 26v-29v (Die Herkunft des Codex ist nicht ganz klar, bekannt ist aber, daß er im 13. Jahrhundert in der Abtei St. Sépulcre in Cambrai lag.) und Bibliotheca Vaticana, Ottoboni lat. 3025, fol. 62r$64 \mathrm{v}$ (12. Jahrhundert).

182 Die Handschriften BN lat. 3177, fol. 58v, aus Beaupré (12. Jahrhundert), BN lat. 13336, fol. 124r, ev. aus Saint-Maur (13. Jh.), BN lat. 12593, fol. 155r, aus Corbie (13. Jahrhundert) und BN lat. 17491, fol. 40r (13. Jh.), ev. Jacobins de Paris. 
sen Handschriften werden nur noch diejenigen Teile überliefert, die von der Festsetzung des Festtages und vom Wunder in Noyon handeln.

Die Datierung der ersten Handschrift vor die Niederschrift der Monodiae und die Beziehungen des Radbod von Noyon zur Abtei Nogent und zu Gottfried von Amiens, Guiberts Vorgänger als Abt, machen es wahrscheinlich, daß Guibert eine Abschrift dieses Sermo Radbodi gesehen hat ${ }^{183}$. Die handschriftliche Überlieferung zeigt, daß diese Predigt in der Diözese Noyon zum Fest von Mariä Verkündigung in verschiedenen Kirchen und Klöstern gelesen wurde ${ }^{184}$. Die Handschrift aus Saint-Martin de Tournai weist darauf hin, daß der sermo nicht nur innerhalb der Diözesangrenzen, sondern auch in einem regionalen Umfeld bekannt war. Sowohl im sermo als auch bei Guibert wird das Marienwunder im gleichen Kontext berichtet: Zentral sind dabei die Probleme der Festtagssetzung und der Festtagsheiligung. Guibert erzählt das schriftlich festgehaltene Wunder nicht noch einmal, sondern weist nur darauf hin.

Ein ähnlicher Umgang mit Erzählen, Andeuten und Verschweigen ist bei der letzten Episode des 18. Kapitels des dritten Buches der Monodiae ersichtlich: Gegenstand der Erzählung ist die versuchte Vergiftung eines Priesters durch einen Bauern mit Hilfe einer Kröte, die dieser zerstückelte und dem Meßwein beimischte. Die wunderbare Heilung geschah, nachdem der sterbende Priester einen Trank mit Staub vom Altar des heiligen Marcellus von Paris zu sich genommen hatte. Danach folgt der Hinweis Guiberts auf eine Begebenheit, die sich zu Lebzeiten des Heiligen abgespielt hatte: Nec mirum si Deo praesens Marcellus haec peragat, qui ab eo corporis interstitio absens olim non minora in simili re partrarat ${ }^{185}$. Dies ist eine Anspielung auf die Begegnung des Heiligen mit einer Schlange, die er auf wunderbare Weise vertreiben konnte. Diese Begegnung wird in der Vita des Fortunat erzählt ${ }^{186}$. Während Guibert aktuelle Ereignisse ausführlich berichtet, weist er auf die schriftliche Tradition nur kurz hin.

Guibert de Nogent macht in seinen Schriften mehrmals von der schriftlichen Tradition Gebrauch. Außer im Fall des Zitats der legendenhaften Quilius-Geschichte können diese Verweise in der handschriftlichen Überlieferung außerhalb der Texte Guiberts nachgewiesen werden. Dies spricht für sorgfältigen Umgang Guiberts mit der schriftlichen Tradition. Ein Beispiel für das parallele Bestehen von schriftlicher und mündlicher Tradition ist die Geschichte des Mädchens mit dem Faden in der Zunge, die sowohl in schriftlicher Ver-

183 Gottfried von Amiens wurde von Radbod von Noyon zum Priester geweiht. Siehe Vita S. Godefridi, I, 17, AASS Nov. III, S. 911.

184 So auch die Bemerkung von Migne in PL 150.

185 Guibert de Nogent, Autobiographie, III, 18, S. 442.

186 Siehe Venantius Fortunatus, Vita Sancti Marcelli. Der Kampf mit der Schlange wird in ikonographischen Quellen dargestellt, bspw. in Form einer Statue über dem St. AnnaPortal der Kathedrale Notre Dame de Paris, siehe dazu Bibliotheca Sanctorum, Bd.8, Sp. 671, Rom 1967. 
sion festgehalten wurde wie auch mündlich, in der Predigt oder in anderen Zusammenhängen, kommuniziert wurde.

\subsubsection{Die Edmund-Geschichte: Schriftlichkeit oder Mündlichkeit?}

Der heilige Edmund, König von Ostanglien, wurde 869/870 bei der Däneninvasion ermordet, indem er geköpft wurde ${ }^{187}$. Der Anlaß seines Todes, die Verteidigung seines christlichen Volkes gegen die heidnischen Dänen, begünstigte den Kult des Märtyrers Edmund, des heiligen Königs ${ }^{188}$. Rund hundert Jahre nach dessen Tod, 985-987, schrieb Abbo von Fleury während seines Aufenthalts in Ramsey die Passio des heiligen Edmund nieder ${ }^{189}$. In dieser Passio wird das Wunder des corpus incorruptum berichtet: Der abgeschlagene Kopf soll wiedergefunden und gemeinsam mit dem Körper bestattet, dann auf wunderbare Weise mit dem Körper wieder vereint worden sein. Dieses Wunder wurde zweimal bei Überprüfungen des heiligen Körpers bestätigt.

Guibert berichtet in seinen Werken zwei Wundererzählungen des heiligen Edmund. Beim ersten handelt es sich um ein Strafwunder in Zusammenhang mit dem Wunder des corpus incorruptum: Ein Abt des Klosters Bury St. Edmund, wo der Leib des Heiligen lag, prüfte mit einem Helfer durch Ziehen, ob der Kopf wirklich mit dem Körper verbunden sei. Beide wurden darauf durch Lähmung ihrer Hände bestraft. In der zweiten Episode wurde ein lahmendes Reh am Grab des heiligen Edmund geheilt.

Die erste Erzählung, die hier genauer analysiert werden soll, referiert Guibert sowohl in den Monodiae als auch im Reliquientraktat. Parallel dazu ist sie in verschiedenen hagiographischen und historiographischen Texten überliefert. Gerade beim Versuch, Quellen für Episoden nachzuweisen, die Guibert möglicherweise aus schriftlichen Vorlagen entnommen hat, ergeben sich Probleme, die anhand dieser Erzählung aufgezeigt werden sollen. Es erweist sich als schwierig, direkte Beziehungen zwischen diesen Texten herzustellen, gerade wenn die einzelnen Texte in mehreren Versionen überliefert sind. $\mathrm{Zu}$ dem sind wir konfrontiert mit Guiberts literarischem und stilistischem Anspruch $^{190}$. Episoden werden nicht einfach übernommen, sondern in eigenen

187 869: Cownie, Cult of St Edmunds, S. 177; Mostert, Art. »Edmund «; 870: Cronica Jocelini de Brakelonda, S. XV.

188 Schon zwanzig Jahre nach seinem Tod ließ König Alfred Münzen des heiligen Edmund prägen. Siehe Gransden, Bury St. Edmunds, S. 2.

189 Folz, Saint Edmond, S. 228. Laut Gransden ist Ramsey für die Reform der Klerikergemeinschaft zu einer benediktinischen Kongregation in Beodrisworth verantwortlich, was auch die Abfassung der Passio durch Abbo und die Beziehung zu Fleury, einem wichtigen benediktinischen monastischen Zentrum des 10. Jahrhunderts, erklären würde. GransDEN, Bury St. Edmunds, S. 18f. Zu Abbos Aufenthalt in Ramsey siehe auch MosterT, Abbon de Fleury.

190 So äußert sich Guibert in den Dei Gesta per Francos zum Bericht Fulchers von Chartres, den er für mehrere Episoden als Quelle nimmt, zu deren stilistischer Überarbeitung unter Bezug auf die ars poetica des Horaz folgendermaßen: Cum enim vir isdem am- 
Worten erzählt. Dabei nimmt er bei der Überarbeitung der Erzählungen nicht nur stilistische Änderungen, sondern auch solche vor, die sich auf deren Aussage auswirken, oder er deutet Ereignisse neu ${ }^{191}$. Somit führt ein Textvergleich, wie er sich bei Chronisten zum Teil als wertvoll erweist, zumeist nicht zum Ziel. Sicherlich aber hängt die schriftliche Überlieferung auch mit der mündlichen zusammen und verläuft teilweise parallel ${ }^{192}$. Im einzelnen Fall ist jedoch schwierig zu beurteilen, ob eine mündliche Version oder das stilistische Bemühen des Verfassers eine Geschichte verändert. Im Fall der Wunder des heiligen Edmund, Märtyrer und König von Ostanglien ( $† 870)$, ist Guibert zeitlich und geographisch relativ weit vom wunderbaren Geschehen und auch von der hagiographischen Produktionsstätte, dem Kloster Bury St. Edmunds, entfernt. Das hagiographische Dossier des heiligen Edmund, das gut überliefert ist und im 11./12. Jahrhundert mit neuen Wunderbüchern wiederholt ergänzt wurde, soll auf seine Überarbeitungen und auf seine Beziehungen zu Guiberts Versionen des Edmund-Wunders hin untersucht werden. Neben den Texten müssen hierfür auch konkrete Beziehungen Guiberts oder der Region Laon zu England beachtet werden.

Guibert erwähnt die Geschichte der Überprüfung des Körpers des heiligen Edmund sowohl in den Monodiae als auch im Reliquientraktat. Guibert weist in beiden Fällen darauf hin, daß er das Wunder des corpus incorruptum verschweigt. In der Version der Monodiae gibt Guibert keine Hinweise auf die Quellen der Episode ${ }^{193}$, erst in der Version des Reliquientraktats erwähnt er die Passio als schriftliche Quelle, worin dieses Wunder gelesen werden kann ${ }^{194}$. Auch der Begriff Passio als Terminus technicus für die schriftliche Aufzeichnung des Martyriums eines Heiligen weist darauf hin, daß Guibert die schriftliche Quelle vorgelegen haben muß oder er zumindest von der Passio und deren Inhalt gewußt hat. Sein Hauptinteresse gilt dann jedoch dem Strafwunder, das die frevlerische Überprüfung des heiligen Körpers sanktioniert. Durch den Hinweis, was verschwiegen und was gesagt werden will, wie auch durch die Zeitangabe nostra aetas, tempus nostrum wird ein Gegensatz zwischen dem wunderbaren Körper und der frevlerischen Tat konstruiert, die sich in jüngster Zeit abgespielt hat. Ob die Quellenangabe uti vulgabatur in der Version

pullas et sesquipedalia verba proiciat et luridos inanium scematum colores exporrigat, nuda michi rerum gestarum exinde libuit membra corripere meique qualiscumque eloquii sacco potius quam pretexta contegere. GUIBERT DE NoGENT, Dei Gesta, VII, 32, S.329; Üb. Guibert De Nogent, Geste, S. 285.

191 Siehe dazu Kap. 4.4.2.

192 Siehe oben, S. 129.

193 Taceo de ejus corpore pigmentis non hominum, sed coelestibus hactenus incorrupto, in quo acsi viventis unguium ac crinium excrementa miramur. Sed illud dicere est, quod in tanto miraculo positus a nemine patitur se videri. GUIBERT DE NOGENT, Autobiographie, III, 20, S. 460.

194 GUIBERT DE NOGENT, Quo ordine, P, I, Z. 690-692: Nostra enim aetate, ut ea quae in eius Passione leguntur taceam, abba quidam eius loci, plus equo curiosus utrum, uti vulgabatur, caput eius post abscisionem corpori esset unitum, [...]. 
des Reliquientraktats einen Hinweis gibt auf eine konkrete mündliche Kommunikationssituation, die für die zeitgenössische Episode naheliegend wäre, ist hingegen nicht eindeutig, da mit vulgare sowohl schriftliche wie auch mündliche Verbreitung gemeint sein kann ${ }^{195}$. Guibert interessiert sich aber offensichtlich nicht für den unverwesten Leib, ein häufiges Attribut mittelalterlicher Heiliger ${ }^{196}$. Er interessiert sich im Zusammenhang mit den übergeordneten Themen der beiden Schriften für andere Aspekte des Geschehens: Im Falle der Monodiae steht das Verhalten des Abtes gegenüber dem Heiligen im Zentrum, im Falle des Reliquientraktats die Bewahrung von dessen Grabesruhe.

In der Passio des Abbo von Fleury werden zwei Überprüfungen des corpus incorruptum erwähnt. Das erste Mal anläßlich der translatio des Körpers nach Beodricsworth (Bury St. Edmunds) zwischen 903 und 925197, das zweite Mal durch Bischof Theodredus ${ }^{198}$. Anläßlich dieser zweiten Überprüfung kam es laut der Passio zur frevelhaften Tat des Adeligen Leofstan, der erzwang, daß ihm der heilige Körper gezeigt werde. Zur Strafe verlor er auf der Stelle den Verstand, kurz darauf starb er und wurde von Würmern zerfressen ${ }^{199}$. Der Gegensatz des Heiligen zum frevlerischen Adeligen wird parallelisiert im Schicksal ihrer Körper: Der eine bleibt unverwest, der andere wird von Würmern zerfressen. Diese erste Überprüfungsgeschichte wird im 12. Jahrhundert von William von Malmesbury in den Gesta regum Anglorum wieder aufgenommen ${ }^{200}$.

Das von Guibert erzählte Strafwunder ist im Wunderbuch des Archidiakons Hermann oder Bertram von ca. 1097 erstmals erzählt ${ }^{201}$. Dieser verfaßte das Wunderbuch unter dem Abt Baldwin, einem ehemaligen Mönch von Saint-Denis und Vertrauten von Edward dem Confessor. Das Wunderbuch ist in einer Handschrift aus Bury St. Edmunds überliefert, die Rodney Thomson um 1100 datiert $^{202}$. Der Anlaß des Strafwunders ist fast derselbe wie in der

195 Siehe dazu unten, S. 136.

196 ANGENENDT, Corpus incorruptum, hier 321-326.

197 Аввo Floriacensis, Passio S. Eadmundi, Kap. 15 und 16, S. 19f. Zur translatio auch Cronica Jocelini de Brakelonda, S. XVI.

198 Ibid. Kap. 16, S. 22. Es ist nicht klar, ob es sich um Bischof Theodred von London (926-

51) oder Bischof Theodred von Elmham (975-995) handelt. Siehe ibid. S. 20, Anm. a.

199 Ibid. Kap. 17, S. 23.

200 William of Malmesbury, Gesta Regum II, 213, Bd. 1, S. 396.

201 Die Frage des Autors ist nicht restlos geklärt. Siehe zur Verfasserschaft GransdeN, Composition, S. 39-44. (Unter dieser Einschränkung wird in der Folge vom Wunderbuch des Hermann gesprochen). Gransden, Composition, S. 39f. äußert die Vermutung, daß Hermann erst Mönch wurde, nachdem er die Abfassung des Mirakelbuchs begonnen hatte. Dazu auch Cownie, Cult of St Edmunds, S. 192, Anm. 15.

202 London, B.M. Cott. Tib. B. II. Datierung aus Thomson, Saint's Life, S. 385. Schon Felix LieBERMANN in: Ungedruckte Anglo-Normannische Geschichtsquellen, S. 230 hat die Schrift um 1100 datiert, während Thomas Arnold in: Hermannus ArChidiaconus, De miraculis S. Eadmundi, S. XXVIII der Datierung von HARDY, Descriptive Catalogue, S. 533 ins 11. Jahrhundert folgt und aus der Handschrift ein Autograph macht. Von dieser Hand- 
Passio: Der Körper des heiligen Edmund wurde unter dem Abt Leofstan (1044-65), nachdem sein Kult etwas vernachlässigt worden war, feierlich mit den üblichen liturgischen Vorkehrungen erhoben ${ }^{203}$. Im Anschluß daran schritt der Abt zur frevlerischen Tat, die außerhalb der üblichen Liturgie stand: Durch Ziehen überprüfte er, ob der Kopf wieder mit dem Körper verbunden sei. Diese Tat wurde wie diejenige des ersten Leofstan ebenfalls bestraft, diesmal durch eine Lähmung der Hände ${ }^{204}$. Der größte narrative Unterschied von Hermanns Wunderbuch zu Guiberts Version ist, daß bei Hermann der Abt den Frevel alleine begeht. In Guiberts Versionen vollbringt der Abt in den Monodiae die Tat gemeinsam mit einem capellanus, im Reliquientraktat gemeinsam mit einem monachus. Nur in der Version der Monodiae wird präzisiert, daß der eine den Heiligen am Kopf und der andere an den Füßen zieht.

Teile des Wunderbuchs des Hermann sind auch in der illuminierten Handschrift New York, Pierpont Morgan Library 736, gemeinsam mit zwei Viten des Edmund, wieder aufgenommen. Nach Thomson wurde diese Handschrift ebenfalls in Bury St. Edmunds geschrieben. Er datiert sie auf 1124 bis 1125205. Zwischen 1097 und ungefähr 1124 überarbeitete ein Mönch aus Bury St. Edmunds das Wunderbuch, gemäß Thomson aus stilistischen Gründen, und fügte einige Ergänzungen an ${ }^{206}$. Die Überprüfungsgeschichte ist in dieser Version

schrift sind zwei Abschriften abhängig: 1. Bodleian Digby 39, gemäß Hardy, S. 534 und Bodleian Library Catalogues, Bd. 1, S. 35; Bd. 2, S. 22 aus dem ausgehenden 11. Jahrhundert aus Abingdon, Irland. Wenn diese Handschrift eine Abschrift ist, müßte sie wohl auch ins 12. Jahrhundert datiert werden. 2. Paris, BN lat. 2621, Herkunft unbekannt, aus dem 12. oder 13. Jahrhundert, in: Veterum scriptorum, Bd. 4, S. 821 ediert, bringt nur Auszüge aus dem Wunderbuch, die Überprüfungsgeschichte ist nicht dabei. Ein Vergleich der zwei Versionen findet sich bei Gransden, Composition.

203 Zum Fasten als Bestandteil der Liturgie der Erhebungen Angenendt, Corpus incorruptum, S. 330.

204 Ungedruckte Anglo-Normannische Geschichtsquellen, § 29, S. 241 f.: His visis, sanctoque revestito novis quibus competebat induviis, rememoratur abbas sancti sancte decapitationis, ac remorans, suis innuit monachis, utrum, ut alias legitur, caput hujus martyris decollatum cum corpore jam sit solidatum, et memorans temptat, temptando probat. Caput accipit inter ambas manus, trahit, totumque sequitur corpus. Quam mirabilis Deus! Operatur mirabilia solus; resolidavit ac redintegravit, quod solidum dudum integrumque creavit. Expavefactus abbas ad hoc miraculum, in locello reponit priori pignus sanctissimum; ejus manibus torpore perpetuo captis in reliquum, fortasis quod fuerat actum Deo nec sancto beneplacitum. Ein weiteres Beispiel für die Bestrafung von Überprüfungen von Reliquien, die nicht innerhalb der üblichen Liturgie durchgeführt wurden, ist dasjenige der Überprüfung der Reliquien des heiligen Audoen durch Osbern und Eadmer von Canterbury. Siehe dazu Rubenstein, Osbert of Clare, S. 32f. Auch in der Chronik des Ademar von Chabannes wird nach der inventio und elevatio der Gebeine Karls des Großen ein Mißbrauch der Reliquien bestraft (Ein Kanoniker versuchte, sich die kaiserliche Krone aufzusetzen und verglich die Länge seiner Beine mit denjenigen Karls), siehe dazu Srock, Implications, S. $511 \mathrm{f}$.

205 Thomson, Early Romanesque Book-Illustration, S. 212.

206 Ders., Saint's Life, S. 393. 
ebenfalls enthalten, mit beträchtlichen Änderungen. Der Vorgang wird zu einer völlig anderen Szene umgestaltet ${ }^{207}$. Die Geschichte wird nun viel farbiger geschildert: Wie bei Guibert hat der Abt einen Komplizen. Dieser hat jetzt einen Namen, Turstan, und ist ein ihm besonders vertrauter Mönch. Weiter sind Dialog-Passagen in direkter Rede eingefügt. In beiden Versionen aus Bury St. Edmunds findet sich in gleicher Weise wie bei Guibert ein Hinweis auf die Passio als schriftlichen Bericht des Martyriums.

In der Zusammenstellung weiterer Wunder durch Osbert von Clare kurz nach 1139 ist das Überprüfungswunder nicht enthalten, es wird jedoch in der erneuten Überarbeitung des Wunderbuchs während der Amtszeit von Abt Samson (1182-1211) wieder eingefügt, jetzt nur noch geringfügig stilistisch umgearbeitet ${ }^{208}$. Diese Überprüfungsgeschichte ist in den beiden Wunderbüchern aus Bury St. Edmunds, bei Guibert de Nogent, wie auch bei William von Malmesbury überliefert. Bei William findet sich der Bericht in den Gesta Pontificum, die den Schwerpunkt auf die Bistümer und das kirchliche Leben in diesen Bistümern legt, im Abschnitt über Bury St. Edmunds. Angefügt ist eine Rede des Abtes an den heiligen Edmund ${ }^{209}$.

207 Transkription der Passage aus der Handschrift Pierpont Morgan Library 736, S. 88f.: Legerat siquidem in ipsius passione, caput corpori conpaginatum cohesisse. Proponit ergo sententia, indicit obedientiam, ut se manibus utrisque caput martyris complectente, unus illorum arripiat plantas, quatinus dum ad se quisque nititur, nil ulterius ambigui veritas examinata in cuiuslibet pectore residere patiatur. Ad hoc expavescunt singuli, nullus illicita praesumit. Non rebellionis quidem protervia, sed timoris nimirum reverentia. Tum ille singulis circumspectis, unum eorum nomine Turstanum, quem a puero intra sacras monasterii disciplinas educaverat, taliter affatur: $" T u$ prę ç̨teris", inquiens, "mihi peculiarem debes obędientiam. Tibi vel ad momentum meis reniti mandatis facultas nulla suppeditat. Accede ergo nil dubitans, animum vacillantem gradu firmiore consolida." Tum illo beati pedes martyris annisu, quo valebat adstringente, sepefatus abbas alteram cervici, alteram mento supponens manum: tanto traxit impetu, ut e diverso reluctantem post sacratissimum corpus inclinaret et monachum. Post hęc percutiens cor suum, exhorruit ausum extremum factum. Non enim ad distrahenda vel divaricanda reverenda testis Christi membra, sed ad curanda honorifice atque condienda fuerat invitatus. Ideoque statim punitur praesumptio, debilitatis nota torquente. Stupentibus etenim nervis manus utraque contrahitur, acies luminosa obducitur, lingua torpescit.

208 Samsonus, De miraculis $S$. Eadmundi, S.133f. Dazu Cownte, Cult of St Edmunds, S. 183; Thomson, Saint's Life, S. 393.

209 William von Malmesbury, Gesta Pontificum II, 74, S. 155f.: Per successiones abbatum fuit ibi abbas Lefstanus tempore regis Eduardi. Hic quibusdam de incorruptione sancti male credulis consulens, suo discrimen aliorum fidei prospexit. Prolatumque in publicum corpus, inspitiendum exhibuit, ipso a capite monacho suo a pedibus, trahente. Palam itaque imprecatus est dicens: 'Domine sancte Edmunde, tu nosti quod non infideli mente sed pro aliorum salute hoc fecerim, ne divinum in te mundo celaretur miraculum. Quia tamen multorum peccatorum sum reus, nec a me debuisset contrectari sancti Spiritus organum, si tibi factum displicet in me temporaliter ulciscere; prestat enim et malo ut aliqua insigniar corporis clade quam aeterna involvar ultione. Vix orationem finierat, cum ecce! ambarum manuum digiti, vel retro miserabiliter retorti vel volis pertinaciter infixi, pena quam rogaverat virum multavere. 
Der Kult des heiligen Edmund ist ein Paradebeispiel von regelmäßig wiederkehrender Überprüfung und Zurschaustellung des Wunders des unversehrten Körpers ${ }^{210}$. So werden im Wunderbuch des Samson weitere öffentliche Erhebungen des Körpers beschrieben, anläßlich derer beispielsweise die Priester von Pilgern gezwungen werden, den Körper noch einmal zu zeigen ${ }^{211}$. Auch in der Chronik des Jocelin von Brakelonde wird berichtet, daß der Abt Samson den Körper erneut umbetten ließ212. Die Tat des Abtes Leofstan ging aber über die üblichen Riten hinaus und wurde als Frevel durch den Heiligen bestraft.

Auf welche Weise Guiberts Texte mit dem hagiographischen Dossier in Beziehung stehen, ist schwierig festzustellen. In Guiberts Text finden sich nur indirekte Hinweise auf die Quelle seiner Geschichte. Guibert verweist in seinem Reliquientraktat auf die Passio des heiligen Edmund als schriftliche Quelle. In Bezug auf diese Passio und die darin erzählten Begebenheiten wählt Guibert die Ausdrücke legere und vulgare ${ }^{213}$. Diese Wortwahl deutet auf ein schriftliches Umfeld hin. Auch in beiden Versionen der Wundererzählung aus Bury St. Edmunds findet sich zu Anfang der Erzählung ein Hinweis auf die schriftliche Passio. Die Frage ist nun, ob Guibert das erzählte Wunder im Gegensatz zu den Ereignissen, die schriftlich in der Passio festgehalten waren, als aktuelles Wunder, von dem er mündlich erfahren hat, verschriftete oder ob er das Wunder im Wunderbuch des Hermann oder in der zwischen 1100 und 1124 überarbeiteten Version in schriftlicher Form zur Kenntnis genommen hatte. Das Wunderbuch des Hermann ist in der Handschrift aus dem Kloster Bury St. Edmunds ${ }^{214}$ an die Passio des Abbo von Fleury angefügt. So fügt auch Guibert die Geschichte des heiligen Edmund an Begebenheiten aus Fleury an. Labande vermutet ein assoziatives Prinzip der Zusammenstellung der Erzählungen. Abbo von Fleury könnte so als gedankliches Bindeglied zwischen den Erzählungen aus Fleury und derjenigen des heiligen Edmund angesehen werden ${ }^{215}$. Die handschriftliche Überlieferung der beiden Versionen des Wunderbuchs ist für diese Fragestellung nicht sehr aussagekräftig: neben den zeitgenössischen Abschriften aus dem Kloster Bury St. Edmunds selber ist nur eine Abschrift aus dem Kloster Abingdon in Irland überliefert, welche die Überprüfungsgeschichte wiedergibt.

Guiberts Version der Erzählung stellt in Bezug auf die Darstellung der Akteure eine Art Zwischenstufe zwischen den beiden Versionen aus Bury St. Edmunds dar, abgesehen davon, daß die Erzählung bei ihm gerafft wird. Guibert verschweigt zudem, daß der Frevel anläßlich einer Umbettung des Leibes des

210 Cownie, Cult of St Edmunds, S. 179, Anm. 32.

211 Hermannus Archidiaconus, De miraculis $S$. Eadmundi, S. 173f.; Dazu Cownie, Cult of St Edmunds, S. 180.

212 Cronica Jocelini de Brakelonda, S. 111-115.

213 vulgare: verbreiten, publizieren, klass. (eine Schrift) veröffentlichen.

214 London B.M. Cott. Tib. B II (A).

215 Guibert De Nogent, Autobiographie, S. 460, Anm. 1. 
heiligen Edmund geschah. Im Text sind alle Elemente des Frevels vorhanden, vom Fasten bis zur Überprüfung und der Lähmung der Hände der Protagonisten. Bei Hermann führt der Abt jedoch die Überprüfung alleine durch, bei Guibert gemeinsam mit einem Assistenten aus dem Konvent. In der zweiten Version aus Bury St. Edmunds wird die Geschichte erweitert, der Abt hat jetzt ebenfalls einen Assistenten.

Eher gegen eine schriftliche Vorlage spricht die Episode, die in den Monodiae auf das Überprüfungswunder folgt, eine Geschichte, welche die Heilung eines lahmenden Rehs am Grab des heiligen Edmund beschreibt ${ }^{216}$. Diese wird in den Wunderbüchern aus Bury St. Edmunds nicht wiedergegeben.

Enge Beziehungen der Diözese Laon, aber auch von Guiberts Familie im Umkreis des Bischofs von Beauvais in den anglo-normannischen Raum machen wahrscheinlich, daß Guibert über Beziehungen zu Bec und dem Kreis um Anselm auf mündlichem oder schriftlichem Weg zu seinen Kenntnissen über die Wundertaten des heiligen Edmund gekommen ist. Die Normandie und England bildeten seit der normannischen Eroberung Englands 1066 einen engen monastischen Kulturraum. Zwischen den Klöstern auf dem Kontinent und in England herrschte ein reger Austausch von Mönchen und Handschriften $^{217}$. So wurde in den 1080er Jahren ein Kontingent von Mönchen von Bec nach Bury St. Edmunds geschickt ${ }^{218}$. Kult-Beziehungen sind ebenfalls festzustellen: So ist im Kalender von Bec der heilige Edmund neben anderen englischen Heiligen angeführt. Das Kloster besaß auch Reliquien des Heiligen $^{219}$. Im nahegelegenen Kloster Saint-Evroult befand sich im 12. Jahrhundert eine Handschrift der Passio des Abbo von Fleury 220 .

Zudem bestanden auch vielfache Beziehungen des weiteren nordfranzösischen Raumes zu den englischen Klöstern. Die Beziehungen der Klöster Bury St. Edmunds und Saint-Denis werden dadurch manifest, daß von 1065 bis 1097 Baldwin, ein Mönch aus Saint-Denis und physicus des Königs Edward des Bekenners die Abtwürde in Bury St. Edmunds innehatte. Auf seine Initiative wurde das Wunderbuch des Hermann verfaßt ${ }^{221}$. Guibert spricht zudem in den Monodiae von einem Altar des heiligen Edmund in der Basilika von

216 Ibid. III, 20, S. 460.

217 Nortier, Bibliothèques, S. 37f.: St. Etienne de Caen, Canterbury, La Chaise-Dieu, St. Cyprien de Poitiers.

218 (Anselmi Opera) Anselm von Canterbury, Opera Omnia, III, Nr. 92; dazu Thomson, Library of Bury St Edmunds, S. 624, der die Beziehungen von Bury St. Edmunds zum Kontinent aufzeigt.

219 Siehe dazu Gazeau, Effect of the Conquest, S. 134 und Porée, Histoire du Bec II, S. 579-591 (Edition des Kalenders), I, S. 651-656 (Edition des Reliquienverzeichnis).

220 NorTier, Bibliothèques, S. 231.

221 Hermannus A rchidiaconus, De miraculis S. Eadmundi, S. XXVIIf. Hermann schreibt seine Miracula als "pièces justificatives« für eine Exemption, gegen den Bischof von East Anglia, Losinga, der seinen Sitz nach Beodricsworth verlegen will. Siehe dazu GranSDEN, Bury St. Edmunds, S. 8-12. 
Saint-Denis ${ }^{222}$. Die Beziehungen der Diözese Laon zur anglo-normannischen Welt, auf dem Kontinent und auf der Insel, waren ebenfalls eng. Einerseits müssen die Beziehungen des Kathedralkapitels von Laon zu den britischen Inseln genannt werden. Die Kleriker der Kathedrale organisierten eine Reliquientournee nach England. Obwohl Bury St. Edmunds als Station nicht vermerkt wird, kamen die Kleriker nach Canterbury, Winchester und Exeter, wo sie von Schülern Anselms von Laon aufgenommen wurden. Andererseits war der heilige Edmund in Laon kein Unbekannter. Dort war im 12. Jahrhundert ein Missale aus Winchester in Gebrauch, das auch eine Messe des heiligen Edmund enthielt ${ }^{223}$. Dies könnte auch damit erklärt werden, daß wiederholt Bischöfe aus dem anglonormannischen Gebiet wie Helinand und Gaudry das Bischofsamt in Laon bekleideten. Zuletzt ist der oben genannte Kreis um Anselm von Bec/Canterbury zu erwähnen ${ }^{224}$. Anselm war mit Bury St. Edmunds in Kontakt, wo er 1102 den unkanonischen Abt Robert absetzte und 1107 ein Kreuz weihte 225 . Der Neffe Anselms, Anselm von St. Saba, der auch zum Kreis um Anselm gehörte, hatte von 1121 bis 1148 die Abtwürde in Bury St. Edmunds inne ${ }^{226}$. Dieser Anselm spielte auch für die Verbreitung der Marienwunder eine wichtige Rolle ${ }^{227}$.

Das Beispiel des Wunders des heiligen Edmund zeigt, daß die intertextuellen oder kommunikativen Beziehungen zwischen Texten oft nicht genau nachvollzogen werden können, da die mündliche und die schriftliche Überlieferung von Wundergeschichten eng zusammenhängen. Hingegen konnte aufgezeigt werden, $\mathrm{da} \beta$ die Wundererzählungen innerhalb eines monastischen und domklerikalen sozialen Kreises weitergegeben wurden und von Angehörigen dieser Kreise in unterschiedliche Texte eingefügt wurden, wie dies neben Guibert de Nogent auch William von Malmesbury mit der Geschichte des heiligen Edmund praktizierte.

222 Guibert de Nogent, Autobiographie, III, 20, S. 466.

223 Sacramentaires, S. 219-221.

224 Siehe oben, S. 113, Anm. 89.

225 Absetzung: S. Eadmer, Vita, 139f. mit Anm. 3, 168f.; Thomson, Library of Bury St Edmunds, 629; Weihung eines Kreuzes: AbBo Floriacensis, Passio S. Eadmundi, XIX.

226 Cownie, Cult of St Edmunds, S. 183.

227 Siehe unten, Kap. 5.2.1. 


\subsection{Referentielle Bezüge der Erzählungen}

Auf Kommunikationsorte und -netze von Wundererzählungen wurde in einem ersten Schritt aus den expliziten Quellenverweisen in Guiberts Texten geschlossen. In einem zweiten Schritt soll die narrative Struktur der Wundererzählungen im Zentrum stehen. So können auch Erzählungen, die ohne Quellenangabe in einem Textumfeld stehen, in bezug zu Guibert situiert werden. Aufgrund der referentiellen Bezüge der Erzählungen auf eine Realität außerhalb des Textes soll versucht werden, diese in einem schriftlichen oder mündlichen kommunikativen Umfeld zu verorten.

Neben den Zeugen- oder Quellenangaben können auch innerhalb der Erzählung Bezüge auf eine Realität außerhalb des Textes hergestellt werden. Das von Monika Otter genannte Ort-Zeit-Akteur-Schema, das für die Verortung eines Textes in einem literarischen Genre wichtig ist, bietet oft vielfache Bezüge zur außertextlichen Realität. Dieses Schema, von Michail Bachtin als Chronotope bezeichnet 228 , wurde auch schon von mittelaIterlichen Autoren wie Hugo von Saint-Victor im 12. Jahrhundert und anderen genannt. Hugo sah diese drei Momente - Ort, Zeit, Akteure - als konstituierend für das Genre Geschichtsschreibung an ${ }^{229}$. Diese Kriterien werden auch für die Einordnung von Wundern als wahres Geschehen für wichtig erachtet ${ }^{230}$.

Diese Momente, Ort, Zeit und Akteure, sind auf die Beziehungen zu Guibert zu untersuchen. Nach Otter verwendet ein Autor diese Schemata bewußt, um die Referenzsituation eines Textes zu klären. Hierzu ein Beispiel aus Guiberts Marienlob: Ein Wunder über einen Verwandtenmord, die Geschichte über die sogenannte »femme de Laon«, führt Guibert damit ein, daß der Ort des Geschehens so bekannt sei und die Zeugen so zahlreich, daß Zweifel völlig unnötig seien ${ }^{231}$. Guibert, der sonst gerne Zeugen beim Namen nennt, schweigt sich hier über diese aus. In der Geschichte selber wird jedoch ein zeitlich und örtlich - relativ genauer Raum aufgespannt, der sie in zeitliche und geographische Nähe zu Guibert situiert und der Erzählung somit eine relativ große Aktualität gibt. Guibert agiert bewußt mit diesem Schema, handelt aber auch getreu nach seinem einleitenden Satz, im Folgenden zeitgenössische

\footnotetext{
228 BaCHTIN, Formen der Zeit, S. 7-9.
}

229 Otter, Inventiones, S. 4. Siehe auch oben, S.96, Anm. 7. Weitere Beispiele auch bei GoETz, res gesta, S. 699.

230 Dazu auch Boesch Gajano, Expériences, S. 61.

231 GuiberT DE NogENT, De laude, Sp. 564C-D: Rei autem gestae locus, ac testes tanta sunt contiguitate probabiles, nec sua numerositate putabiles, ut scrupulo vel insanus haerere non debeat. Zur Geschichte siehe KaISER, Verbrechen und Strafe. Eine parallele Überlieferung bei Hermann von Tournai, De miraculis sanclae Mariae Laudunensis, eine Zusammenfassung und Nennung weiterer Quellenstellen bei Mussafia, Marienlegenden I. Eine ähnliche Zeugenangabe findet sich in den Dialogi Gregors des Großen: Nec res est dubia, quam narro, quia paene tanti in ea testes sunt, quanti et eius loci habitatores existunt. GrÉGolre le Grand, Dialogues, III, 7, S. 278. 
Wunder zu berichten ${ }^{232}$. Otter hat an den von ihr benutzten Texten auch gezeigt, daß das Referenzsystem in diesen Texten nicht durchgängig ist. Sie interpretiert gerade die Wundererzählungen in ihren Texten oft als Orte, wo die Verweise auf eine außertextliche Realität aufgehoben werden. Diese stellen somit nach Otter selbstreferentielle, fiktionale Einschübe dar. Gerade für Guiberts Texte würde dies sowohl den Prinzipien des Wahrheitsbezugs von Mirakelsammlungen als auch der Forderung nach Authentizität von Exempla widersprechen. Guiberts Umgang mit Orts-, Zeit- und Akteursangaben seiner Wunder muß daher geprüft werden. Ebenso wird die Frage zu stellen sein, inwieweit die Verweise innerhalb der Erzählungen mit den Verankerungen auBerhalb der Erzählungen in Zusammenhang stehen.

Die Unterscheidung zwischen mündlicher und schriftlicher Überlieferung ist, wie oben dargestellt, für einzelne Geschichten schwerlich vorzunehmen. Am wahrscheinlichsten ist schriftliche Überlieferung für Episoden, die aus einem hagiographischen Dossier stammen. Wie aber der Exkurs über das Edmund-Wunder gezeigt hat, ist es auch in diesem Fall schwierig, direkte Beziehungen zwischen Texten zu etablieren, es sei denn, der Überlieferungsbefund weist deutlich darauf hin.

Für sehr viele Episoden, auch Wunder von Heiligen, kann jedoch nicht mehr nachvollzogen werden, ob sie je in einer Mirakelsammlung festgehalten und somit vom Klerus kontrolliert waren oder nicht. Diese Unterscheidung ist dann nicht mehr so wichtig, wenn das Augenmerk auf die narrative Struktur gerichtet wird, sagt doch der Inhalt einer Erzählung einiges über Beziehungen des Erzählers zum Erzählten aus.

\subsubsection{Zeit}

\section{Verankerungen im Laufe der Zeit}

Nicht alle Episoden in Guiberts Werken enthalten Angaben über den Zeitpunkt ihres Geschehens. Für eine ganze Reihe von Erzählungen macht Guibert keine Zeitangaben. Dies sind einerseits solche, denen auch keine Angaben über Zeugen vorangestellt sind. Viele davon sind in den Exkursen der Monodiae zu finden, wie beispielsweise eine Serie von drei Wundern aus dem 18. Kapitel des dritten Buches, einer Strafe für übermäßige Bedrückung der Kirche durch den Vogt, einer bestraften Reliquienschändung in Saint-Just und der Heilung einer versuchten Vergiftung eines Priesters durch Staub vom Altar des heiligen Marcel von Paris in der Region von Beauvais ${ }^{233}$.

Andere Erzählungen zeigen, daß Guibert die zeitliche Einordnung des Ereignisses bewußt verschweigt. Dies ist oft der Fall, wenn sich Guibert auf eine

232 Guibert de Nogent, De laude, Sp. 564: [...] dignum est etiam ut quae nostra aetate peregerit intexamus.

233 Guibert de Nogent, Autobiographie, III, 18, S. 440-442. 
schriftliche Tradition bezieht. So beispielsweise in den Dei Gesta per Francos, als er das Wunder der schiffbrüchigen Kreuzfahrer erwähnt, die, als sie an Land geschwemmt wurden, ein Kreuz auf die Schulter tätowiert hatten ${ }^{234}$.

In der Quelle Guiberts, der ersten Redaktion der Historia Hierosolymitana des Fulcher von Chartres, wird das Ereignis auf den Ostersonntag, 5. April 1097, datiert ${ }^{235}$. Robert B. C. Huygens hat aufgrund der Zitierweise wahrscheinlich gemacht, daß Guibert die Chronik gelesen hat ${ }^{236}$. Daß Guibert die zeitliche Präzisierung wegläßt, geht einher mit den Bemerkungen, die seine Zweifel an der Quelle und an der Glaubwürdigkeit des Erzählten signalisieren ${ }^{237}$. Grund, das Wunder zu kommentieren und festzuhalten, waren die Mißbräuche, die in Folge dieses Wunders in Guiberts Umgebung getrieben wurden. Viele hätten sich mit Fruchtsaft oder Blut ähnliche Kreuze auf ihre Körper gemalt und behauptet, diese Auszeichnungen auf wunderbare Weise erhalten zu haben ${ }^{238}$.

Eine in der Historiographie und Hagiographie häufige Möglichkeit, eine Erzählung im zeitlichen Ablauf zu situieren, ist der vage Bezug auf die JetztZeit. Wunder mit oder ohne Zeugennennungen werden als non ante multos annos, ante aliquot annos oder nostrorum temporum oder modernae aetatis geschehen bezeichnet. Diese Hinweise sind relativ grob, es haftet ihnen daher der Verdacht auf Topik an. Gleichzeitig signalisieren diese Angaben jedoch Aktualität, die mit mündlicher Tradition in Verbindung zu bringen ist. Im Falle des Edmund-Wunders kann der Hinweis auf die aktuelle Zeit durchaus ernst gemeint sein: Im Gegensatz zu den Ereignissen, die in der Passio festgehalten sind (Edmund starb 870), ist die Überprüfung des Leibes nostra aetate, während des Abbatiats des Leofstan (1044-1065, Guiberts Geburt wird um 1054 angenommen) geschehen ${ }^{239}$.

234 Guibert de Nogent, Dei Gesta, VII, 32, S. $329 \mathrm{f}$.: Dicitur in sui [Fulchers von Chartres], nisi fallor, opusculi referre principio quosdam, qui Iherosolimitanum adorsi videbantur iter, illud quod Appulos Epirotasque dirimit, locatis puppibus, equor ingressos et utrum inexplorato sese commiserint mari seu carinas nimia sui numerositate depresserint nescio, constat tamen sexcentos pene illic navem fregisse viros. Qui intercipientibus omnes sali turbidi procellis enecti, nec mora impatientis estu pelagi ad continentem eiecti eo ipso, quo in birris, palliis ac tunicis uti consueverant, universi in superficie scapularum sunt insignes crucis signo reperti. Quod sacrum stigma divinitus cuti eorum potuisse imprimi ob ipsorum fidei evidentiam faciendam nemo licet fidelis ambigat, tamen ei qui hoc scripsit, si advivit, sollicite pensandum est an res se habeat.

235 Fulcher von Chartres, Historia, Ed. Recueil des Historiens de la Croisade 3, S. $329 \mathrm{f}$., Ed. HAGENMEYER, S. 169.

236 GuiberT DE Nogent, Dei Gesta, Introduction, S. 15. Garand meint aufgrund von ungenauen Referenzen, daß Guibert das Werk zwar gelesen, nicht aber bei der Niederschrift seines Berichtes zur Verfügung gehabt habe. GuiBert de Nogent, Geste, S. 19f.

237 Zum Verhältnis Guiberts zu Fulcher und ssinem Kreuzzugsbericht siehe GuIBERT DE NoGent, Dei Gesta, Introduction S. $15 \mathrm{f}$.

238 Guibert de Nogent, Dei Gesta, VII, 32, S. 330.

239 Gulbert de Nogent, Quo ordine, S. 107. 
Guibert situiert seine Erzählungen zeitlich, indem er Personen erwähnt, zu deren Lebzeiten ein Ereignis geschehen ist. In einigen Fällen ist dies er selbst, der etwas gesehen oder erlebt hat, beispielsweise seine in den Monodiae erwähnte Fieberheilung, als er ein kleiner Junge war, oder Exorzismen ${ }^{240}$ im Kloster SaintGermer-de-Fly, die er beobachtet hatte. Zeitliche Ankerpunkte sind aber auch andere Personen aus seinem Umfeld, beispielsweise »zur Zeit, als Anselm Abt von Bec war « oder die Erwähnung der Amtszeit eines Bischofs oder Abtes ${ }^{241}$. Auch breit bekannte Ereignisse oder Kirchenfeste werden als Ankerpunkte erwähnt, zu deren Zeit sich die wunderbaren Ereignisse abspielen. Ereignisse wie die Reliquienreise oder eine Graböffnung sind dafür gute Beispiele ${ }^{242}$. Während dieser Ereignisse, wie auch um die Hochfeste oder die Festtage der Heiligen konnten Wunder in großer Zahl erwartet werden ${ }^{243}$. Die Wunder werden aber auch mit Ereignissen aus der Geschichte der Region verbunden, wie beispielsweise "nach dem Massaker an den Juden in Rouen " oder "nach der Zerstörung des Klosters durch die Normannen und dessen Wiederaufbau «244. Andere Episoden lassen sich in der Zeit gut verankern, weil sie sich im Abstand einiger Jahre zur Niederschrift des jeweiligen Werkes ereignet haben sollen, dies allerdings nur für Leser, die mit dem regionalen Umfeld Guiberts vertraut waren. Häufig sind Angaben wie nuperrime, scilicet Pascha preterito oder die illa qua Gualdricus episcopus, disposita nece Gerardi, Romae proficisci coeperat ${ }^{245}$.

Genaue Zeitangaben nach Inkarnationsjahren sind für Wundererzählungen wie auch für andere Ereignisse in Guiberts Werken selten. Das einzige Mal, daß er wunderbare Ereignisse mit Datumsangaben fixiert, ist in der Kreuzzugschronik, als Guibert zwei Mondfinsternisse erwähnt. Diese genaue Datumsangabe wird begründet:

Ubi dicendum quod, licet luna in pleniluniis naturaliter patiatur defectiones, sunt tamen aliquae in ipsis colorum eius mutationibus portensiones, unde et in pontificalibus et regum Gestis exinde solerent fieri annotationes. Visa sunt et alia pleraque, quae narrare supersedimus $^{246}$.

Die Phänomene werden von Guibert als natürlich eingeordnet. Dies hindert ihn nicht, sie trotzdem als Zeichen (portenta) zu deuten. Sie werden traditionellerweise auch in den Lebensbeschreibungen von Königen und Bischöfen

$240 \mathrm{Zu}$ den Exorzismen in der Bewertung der päpstlichen Kurie, die problematisch waren, weil Heilungen kraft priesterlicher Worte und nicht kraft Verdiensten geschahen, vgl. Wirtmer-Butsch, Rendtel, Miracula, S. 61, Anm. 157.

241 Zum Beispiel Guibert de Nogent, De laude, Sp. 564-568, »Zur Zeit des Bischofs Helinand « oder GuiberT DE Nogent, Autobiographie, I, 11, S. 64-66: im Gefolge des Manasses von Reims geschieht ein Frevel.

242 Siehe zur Massierung von Wundern zu Hochfesten für die karolingische Zeit RöcKELEIN, Hagio-Geo-Graphien.

243 GoETz, Wunderberichte, S. 213.

244 GuiberT DE Nogent, Autobiographie, II, 5, S. 246-252, bzw. ibid. I, 20, S. 170.

245 Guibert de Nogent, Quo ordine, P, I, Z. 178f., bzw. Guibert de Nogent, Autobiographie, III, 13, S. 392.

246 Guibert de Nogent, Dei Gesta, II, 17, S. 134. 
erwähnt. So werden auch von Guibert genaue Datumsangaben in den Zusammenhang der Geschichtsschreibung gestellt. In den Monodiae wird ein einziges Ereignis, die Ermordung des Bischofs von Laon, präzise auf den Freitag in der Osterwoche, den 26. April 1112, datiert ${ }^{247}$. Somit kann auch die Diskussion über das Wunder der Helligkeit der Nacht, nachdem die Brände in der Stadt gelöscht waren, genau datiert werden ${ }^{248}$. Daß Datumsangaben für wunderbare Ereignisse zumeist nicht geliefert werden, hängt in großem Maße mit Konventionen der Textgattung zusammen. Guibert scheint solche Datierungen nach Inkarnationsjahren nicht als sehr wichtig erachtet zu haben.

\section{Der zeitliche Ablauf der Geschichte}

Wichtig für die Einordnung einer Geschichte ist neben ihrer Fixierung in einen größeren chronologischen Bezugsrahmen die Art, wie der zeitliche Ablauf des Geschehens innerhalb der Erzählung dargestellt wird. Oftmals wird nur ein zeitlicher Fixpunkt genannt, wie beispielsweise "an einem Samstag, gegen Abend« oder "als das Grab geöffnet wurde «249. Längere Geschichten hingegen werden detailliert in ihrem zeitlichen Ablauf beschrieben, beispielsweise die Erzählung der drei Blitze, die im Kloster Saint-Germer-de-Fly einschlugen. Der erste Blitz schlug nur einige Wochen nach dem vorhergehend beschriebenen Ereignis, einem ungewöhnlichen Tod in Saint-Germer-de-Fly, an einer Vigil des Festes der Märtyrer Gervasius und Prothasius (18. Juni) in die Klosterkirche ein. Einige Jahre später, als das Jakobsfest (25. Juli) auf einen Sonntag fiel, schlug ein zweiter Blitz ein. Ein dritter suchte das Kloster wieder einige Jahre später heim, als Guibert dieses schon verlassen hatte ${ }^{250}$.

Wie wichtig das zeitliche Schema für die Erkennung einer Episode als »historisch «, »wahr « oder »Zweifelhaft « ist, zeigt sich, wenn Guibert dieses bewußt aufhebt. Eine solche Geschichte, für die das zeitliche Schema der Quelle bewußt nicht übernommen wird, findet sich im Reliquientraktat. Diese Episode übernimmt Guibert kritisch aus dem Mirakelbuch von Saint-Médard de Soissons $^{251}$. Die Aufhebung des zeitlichen Schemas ist Teil des ironischen Stils, der die Skepsis Guiberts am Berichteten aus schriftlicher Quelle deutlich macht:

Nam in eorum libello, qui super dente hoc et sanctorum loci miraculis actitat, de monacho aliquo refertur quod scorto soleret mulieris abuti, quo tamen noctu tum pergeret aquas tranare propinquas necessario oporteret, in quo transitu inter undas eum peccati sui pondus enecuit. Qui abbatis iudicio a cimiterio fratrum extorris est habitus. Sed abbati, ut pagina illa refert, nescio quis sanctorum inibi, ut dicitur, apparuit eique, ut dicitur, dixit: „Confer «, ait, "eum ceteris, quia in obedientia tua mortuus est ${ }^{252}$.

247 Guibert de Nogent, Autobiographie, III, 11, S. 372; dazu KaISER, Guibert de Nogent, S. 128 ,

248 Guibert de Nogent, Autobiographie, III, 9, S. 356.

249 Ibid. III, 19, S. 454; ibid. I, 24, S. 194.

250 Ibid. I, 23, S. 178, 182, 186. Zum Weiterleben der Geschichte siehe oben, S. 27.

251 Siehe unten, Kap. 5.1.

252 Guibert de Nogent, Quo ordine, P, II, Z. 590-597. 
Das genaue zeitliche Schema der Geschichte in der Version des Wunderbuchs von Saint-Médard fällt bei Guibert ganz weg. Dort wird der zeitliche Ablauf der Geschichte folgendermaßen geschildert: Normalerweise geht der Mönch noctu seinem Tun nach, kehrt ad horas matutinas wieder zu den Mönchen zurück, um an den Laudes teilzunehmen. Quadam nocte läutet aber die Glocke, bevor er zurückkehren kann; er ertrinkt auf dem hastigen Rückweg. Mane, am Morgen, suchen ihn der Abt und die Mitbrüder überall, sie finden ihn und beerdigen ihn in der Kloake. Post paululum vero temporis kommt der Engel des Herrn mit den Heiligen und ermahnen den Abt dermaßen, daß er confestim, sofort, befiehlt, den Sünder aus der Kloake zu ziehen und ihn in Ehren bei den anderen zu beerdigen ${ }^{253}$.

Diese Aufhebung des zeitlichen Schemas kann als reine Stilfrage gedeutet werden, ist aber meines Erachtens aussagekräftig für die Situierung dieser Episode. In Kombination mit der Repetition der vagen Quellenangabe ut dicitur entfaltet das Spiel mit den Hinweisen auf eine außertextliche Wirklichkeit seine Wirkung. Indem Guibert das zeitliche Schema, das chronikalisch wirkt und somit Fixpunkte im Lauf der vergangenen Zeit bietet, konsequent wegläßt, entzieht er der Geschichte jegliche Glaubwürdigkeit und gibt sie der Lächerlichkeit preis.

Guibert greift also zumeist auf Wunder zurück, die sich in einem Zeitraum von bis zu 100 Jahren vor der Niederschrift abgespielt haben. Ausnahmen davon sind die Gründungsgeschichte von Nogent, die um Christi Geburt angesiedelt ist, die Kritik an einer Episode aus dem Wunderbuch der Mönche von Saint-Médard aus karolingischer Zeit und die wenigen Hinweise auf die schriftliche Tradition. Dies kann natürlich nur für Wunder festgestellt werden, für die im Text eine zeitliche Fixierung geliefert wird. Sigal zeigt, daß Wunder, die aus mündlichen Quellen geschöpft wurden, selten weiter als 100 Jahre zurückgehen, während Historiographen auch auf eine weiter zurückliegende Vergangenheit zurückgreifen ${ }^{254}$. Guibert beruft sich für die Wunderberichte auf schriftliche wie mündliche Quellen, die zumeist in seiner unmittelbaren Vergangenheit zu situieren sind.

\subsubsection{Raum}

Der geographische Raum

Im Gegensatz zu der zeitlichen Fixierung, die längst nicht für alle Episoden hergestellt wird, sind die meisten Geschichten im Raum verankert, das heißt, der geographische Ort des Geschehens wird in den meisten Fällen angegeben. Guibert scheint die räumliche Verortung von Erzählungen wichtiger eingeschätzt zu haben als eine zeitliche. Dabei stellt sich die Frage, ob die Erinne-

253 Cat. CoD. Bruxellensis I, S. 240.

254 SIGAL, Travail, S. 154. 
rung des Ortes eines wunderbaren Geschehens stabiler ist als diejenige der Zeit ${ }^{255}$. Dies handhaben nicht alle Verfasser von Wunderbüchern auf gleiche Weise: So zeigt Michel Sot, daß für Flodoard von Reims in der Historia ecclesiastica Remensis die wichtigste Fixierung von Wundern diejenige in der Zeit ist. Auch Flodoard fügt, wie Guibert, Wunder unterschiedlicher Herkunft in ein nicht-hagiographisches Werk ein. Allerdings geschehen diese Wunder alle in Zusammenhang mit den Reimser Heiligen, in der Stadt selber, auf Reimser Gebiet oder an Orten, wohin Reliquien von Reimser Heiligen übergeführt wurden. Für diesen Autor scheint aber die zeitliche Dimension sehr wichtig zu sein. Er stellt die zeitliche Kontinuität von vergangenem Geschehen zur Gegenwart, bei Wundern vor allem im Zusammenhang mit dem Schutz des Kirchenguts, her, indem er ein ganz altes, ein zwischenzeitliches und ein zeitgenössisches Wunder erzählt. Sot spricht denn auch in diesem Zusammenhang von Wunderketten, die Ereignisse aus der Vergangenheit mit gegenwärtigen in Zusammenhang setzen ${ }^{256}$. Für den Historiker Flodoard sind Wunder historische Ereignisse, die für die Geschichte des Bistums konstitutiv sind ${ }^{257}$. Im Gegensatz dazu handhabt Guibert die örtliche Situierung genauer als die zeitliche, die oft nur ungenau beschrieben wird.

Die große Mehrheit der von Guibert berichteten wunderbaren Ereignisse ist in der Region zwischen Beauvais, Reims, Soissons, Laon und Cambrai/Arras situiert, das heißt in der Picardie und dem südlich und nördlich angrenzenden Gebiet oder - kirchenorganisatorisch gesprochen - in der Kirchenprovinz Reims. Schauplätze sind die Abtei Saint-Germer-de-Fly, Beauvais und das Beauvaisis, die Region, in der Guibert den ersten Teil seines Lebens verbracht hat. Weitere Episoden sind in Laon und Soissons angesiedelt, einige auch in Noyon und Reims. Aus Nogent selbst stammen nur zwei Wundererzählungen. Außerhalb dieses Gebietes weisen einige Geschichten in das Gebiet des Vexin, nach Saint-Denis und Paris, eine in die Normandie nach Caen und eine Gruppe von Erzählungen nach Fleury. Mit den Reliquienreisen werden die Regionen an der Loire und in Südengland berührt. Da Guibert nicht einen Bericht der Reisen der Kleriker abfaßt, sondern nur einige beispielhafte Wunder auswählt, sind nicht alle Stationen der Reliquienreise erwähnt. Diese können durch den Vergleich von Guiberts Bericht mit dem Wunderbuch des Hermann von Tournai genauer eruiert werden ${ }^{258}$. Die Ortschaften des von

255 Die Funktionsweise der ars memorativa, die stark mit Verortung als Erinnerungsprinzip arbeitet, weist in diese Richtung. Siehe dazu MüLlER-OberhäuSER, Art. »Mnemotechnik «.

256 Sor, Miracles et le temps de l'histoire, S. 210.

257 Ibid. S. 215.

258 Siehe Signori, Maria, S. 103-105; allgemein zu Reliquienreisen KaISER, Quètes itinérantes und Sigal, Voyages de reliques. Karten der Reliquienreisen der Kleriker aus Laon bei Sigal auf S. 101 und 102. Guibert nennt von den besuchten Ortschaften auf der einen Reise die Touraine als Überbegriff, Buzançais, Angers und einen Ort in der Diözese Angers. Auf einer weiteren Reise werden Nesle, Lihons, Winchester und Exeter genannt. 
Guibert berichteten Wundergeschehens sind jedoch genau genannt, nur in einem Fall kann Guibert nur die Diözese als örtliche Situierung nennen ${ }^{259}$.

Nur wenige Erzählungen weisen über dieses nordfranzösisch-anglonormannische Gebiet hinaus: Einige Wundererzählungen spielen in Italien, eine in der Region Grenoble und eine auf dem Pilgerweg nach Santiago de Compostela. Die Wunder aus der Kreuzzugschronik geschehen auf dem Weg des ersten Kreuzzuges und hängen eng mit dem Bericht der Expedition zusammen. Die Erzählungen kommen zu großen Teilen aus einem geographisch begrenzten Raum, aus dem auch ein Großteil der identifizierbaren Zeugen stammt.

\section{Orte des Wundergeschehens}

Neben der Verortung von Ereignissen im geographischen Raum ist auch der Frage nach der Situierung von Wundern in Räumen oder an Örtlichkeiten Beachtung zu schenken.

Das Heilungswunder, das Guibert selbst erlebte, fand in geordneten klerikalen Bahnen statt: Der junge Guibert verbrachte eine Nacht am Altar des heiligen Leodegar, um geheilt zu werden. Ein weiteres Wunder, wovon Guibert unmittelbarer Ohren-Zeuge war, ist eine Marienvision, ein Strafwunder, das sich unabhängig von einem Schrein abspielte. Ein Adeliger berichtete Guibert unmittelbar nach seinem Erlebnis in einem persönlichen Gespräch von seiner Traumvision, einem nicht-öffentlichen Ereignis ${ }^{260}$. Dieses Gespräch scheint im Kloster Nogent stattgefunden zu haben; der Aufenthaltsort des Adeligen während der Vision wird nicht genannt. Guibert als Abt seines Klosters stellt selbst die Autorität dar, der das Wunder zugute kommt.

Der Ort der wunderbaren Heilungen von Skrofulösen durch den französischen König wird von Guibert hingegen nicht erwähnt ${ }^{261}$. Aus seiner Darstellung geht nicht hervor, ob die königliche Berührung, deren Zeuge er war, innerhalb eines Sakralraumes oder unter freiem Himmel stattgefunden hatte. Hingegen erwähnt Guibert, daß sich eine große Menschenmenge um den König drängte. Diese wunderbaren Berührungen, die nicht unumstritten waren, scheinen liturgisch nicht eingebunden gewesen zu sein und konnten somit bei jedem Kontakt des Königs mit Armen aus dem Volk geschehen. So soll Robert II. (987/996-1031) gemäß seinem Biographen Helgaud von Fleury in sei-

Guibert spricht im Gegensatz zu Hermann von drei anstatt zwei Reliquienreisen. Eine Station des Klerus, das castrum Nigellus (Nesle), ist auch aus dem Wunderbuch des Hugo Farsit bekannt (Wunder: de inflato mulieris utero sanato festis paschalibus, PL 179, 1794, Charleville BM 168, fol. 47v: Apud castrum quod Nigella dicitur in Veromandensi pago situm).

259 Guibert DE Nogent, Autobiographie, III, 12, S. 382: Alias, sed quo id actum sit oppido plane exprimere non possum, in eadem tamen diocesi [...].

260 Ibid. III, 18, S. 438-440.

261 Der Ort der Heilung wird von PoLy, Gloire des rois, S. 181 und BLOCH, Die wundertätigen Könige, S. 69 in Laon oder Umgebung vermutet. 
ner Pariser Pfalz bei Tisch einen Blinden durch Besprengen mit seinem Waschwasser geheilt haben ${ }^{262}$.

Guibert referiert wenige Schreinswunder. Auch Gräber als Orte des Heiligenkults spielen eine eher untergeordnete Rolle. Daß Gräber aber als wichtige Orte erachtet wurden, zeigt sich anhand des Reliquientraktats, wo Guibert für die Respektierung der Grabesruhe plädiert ${ }^{263}$. Guibert referiert mehrmals Wunder rund um Gräber, meist aber problematische Fälle von unerklärbar leeren Gräbern oder Bestattungen von sündhaften Mönchen. So auch das wundersame Fehlen des Körpers eines schlechten Bischofs bei der Graböffnung in der Reimser Kathedrale264. Die göttliche Macht wirkte gemäß Guibert direkt, indem sie einen unwürdigen Körper von einem heiligen Ort entfernte. Hier zeigt sich die Wichtigkeit der Gräber als Kultorte auch in allgemeinerem Sinne.

Reliquien als wunderwirksame $>$ Orte , werden hingegen wiederholt angesprochen. Dies vor allem bei der Beschreibung der Wunder, die auf den Reliquienreisen der Kleriker von Laon geschahen. Die Reliquien wurden auf dieser Reise in verschiedenen Dörfern und Städten in Kirchen aufgestellt. Guibert beschreibt aber auch Wunder, die sich ereigneten, als die Kleriker mit den Reliquien unterwegs waren, beispielsweise ein Heilungswunder im Haus einer adeligen Dame ${ }^{265}$. Straf- aber auch Erlösungswunder säumten den Weg der Kleriker. Reliquien wurden als Schutzschilde eingesetzt und Überprüfungen von Reliquien fanden in Dörfern statt ${ }^{266}$. Oft werden in diesen Erzählungen Konfrontationen des Klerus mit Gläubigen oder Ungläubigen anläßlich von Prozessionen, Translationen oder Elevationen oder der bewußte Einsatz von Reliquien durch die Kleriker thematisiert. Daß aber die Kirche als sakraler Raum ein wichtiger Ort des Wundergeschehens war, zeigen die Wunder, die in der Klosterkirche von Saint-Germer-de-Fly geschahen, beispielsweise anläßlich von Exorzismen, welche die Mönche von Saint-Germer-de-Fly veranstalteten, oder von Weissagungen, die vor den Reliquien gemacht wurden $^{267}$.

Eucharistiewunder sind wiederum als eigene Art von Wundererzählungen anzusehen, die an jedem Ort, wo Eucharistie zelebriert wurde, ortsunabhängig in jeder Kirche geschehen konnten. Dabei handelt es sich um Visionen, die im Handlungsbereich der Kleriker geschahen. Sie sind als Wunder zu betrach-

262 Ehlers, Der wundertätige König, S. 8. Dazu auch Poly, Gloire des rois, 181 f.; zu den Örtlichkeiten aufgrund der ikonographischen Quellen siehe LE GofF, Vorwort zu BLOCH, Die wundertätigen Könige, S. 27.

263 Siehe dazu Kap. 4.2.2.

264 GuiberT DE Nogent, Autobiographie, I, 24, S. 194. Siehe dazu oben, S. 54.

265 Ibid. III, 12, S. 382.

266 Ibid. III, 18, S. 440, Kleriker prozessieren während eines Aufstandes mit den Reliquien; ibid. III, 20, S. 462, Reliquien des heiligen Arnulf werden einer Feuerprobe unterzogen.

267 Ibid. I, 25, S. 200. 
ten, die in einen zeremoniellen Handlungskontext eingebettet sind. Diese spielten in theologischen Kontroversen um die Realpräsenz eine Rolle und verdeutlichten bildhaft die Präsenz Christi in der Hostie ${ }^{268}$. Wichtig scheint aber zu sein, daß der Kirchenraum ein öffentlicher Raum ist. Gerade die Eucharistiewunder spielten sich während der Messe ab. Auch Wunder, die sich in der Klosterkirche ereigneten, beispielsweise während des gemeinsamen monastischen Gebets, spielten sich im öffentlichen Raum ab. Das Eucharistiewunder von Saint-Quentin zeigt, daß auch die genaue Lokalisierung im Kirchenraum detailreich beschrieben wird ${ }^{269}$.

Ähnlich ortsungebunden wie die Eucharistiewunder sind die Marienwunder, die an Orten des Marienkults, aber auch außerhalb von sakralen Räumen geschehen konnten ${ }^{270}$. Die wundersame Strafe und Heilung im Falle des Petrus von Grenoble, die im Marienlob berichtet wird, ist nicht an einen Kultort gebunden. Der "miraculé«, der bestraft wurde, weil er an einem Magdalenentag gepflügt hatte, betete in einer Magdalenenkirche und in einer Marienkirche um die Erlösung von seiner Strafe. Maria erschien ihm gemeinsam mit Hippolyt, aber nicht an einen bestimmten Kultort gebunden. Dasselbe Schema von Strafe und anschließender Erlösung ist auch im Wunder aus Noyon vorhanden, durch das der heilige Nicasius eine Mißachtung seines Festtages damit bestrafte, daß einem Mädchen, das an diesem Tag eine Näharbeit ausführen wollte, der Faden in der Zunge stecken blieb. Das anschließende Erlösungswunder durch die heilige Maria fand dann aber in der Kathedrale, nach langem Beten, statt ${ }^{271}$. Hier wird zudem durch die Erwähnung einer großen Menschenmenge, die das Mädchen und seine Mutter begleitete, die Öffentlichkeit des Geschehens betont.

Es zeigt sich also, daß ebenso viele ortsabhängige wie ortsunabhängige Wunder von Heiligen, vor allem aber auch von der ortsunabhängigen Gottesmutter Maria erzählt werden. Da Guiberts Wunderbegriff breiter ist als derjenige des post-mortem-Wunders und der Verfasser nicht die Wunder eines spezifischen Heiligen aufzeichnet, ist die Palette der Orte, an denen Wunder geschehen, breiter und unabhängiger von einzelnen Kultorten ${ }^{272}$. Oft ist aber wichtig, daß sich das Ereignis in der Öffentlichkeit abspielt ${ }^{273}$. Der Öffentlichkeit kommt eine wichtige Autorisierungsfunktion für Wunder zu.

268 Dazu Snoek, Medieval Piety, der Parallelen zwischen Hostien- und Reliquienkult aufzeigt.

269 Guibert de Nogent, Quo ordine, S. 92.

270 Daß die Gottesmutter ortsungebunden Wunder wirkt, zeigt SIGNORI, Maria.

271 GuiberT DE Nogent, Autobiographie, III, 18, S. 436.

272 Dies beispielsweise im Gegensatz zu Flodoard, der Wunder in seine Reimser Kirchengeschichte einfügt. Siehe zu Guiberts Wunderbegriff oben, Kap. 2.1.

273 Zur Rolle der Öffentlichkeit siehe WenZ-HAubFLEISCH, Miracula post mortem, S. 128131. Dies in Zusammenhang der Funktion der Öffentlichkeit bei Rechtsakten. Siehe dazu OGRIS, Art. »Publizität«; CoRDEs, Art. »Publizität«. 
Anders stellt sich die Situation bei Dämonenerzählungen dar. Dämonen können jede Person - seien es Geistliche, Adelige oder Bauern - immer und überall heimsuchen. Die Einzelpersonen werden von Dämonen oft im Schlaf oder Halbschlaf oder während Visionen überfallen ${ }^{274}$. Dies ist vor allem der Fall in der klösterlichen Gemeinschaft, wird aber auch in Geschichten aus dem unmittelbaren familiären Umfeld Guiberts berichtet ${ }^{275}$. Diese Erzählungen sind zumeist in den Monodiae eingefügt. Wichtig ist dabei aber auch, da 3 die Person, welche die Erfahrung in den meisten Fällen alleine macht, dann von der Gemeinschaft getragen wird. Entweder wird die Gemeinschaft durch den Betroffenen über die Vision unterrichtet oder durch dessen auffälliges Verhalten darauf aufmerksam gemacht ${ }^{276}$.

Die Rolle der Öffentlichkeit zeigt sich auch beim Wunder des Mädchens, das von seinem Liebhaber in einen Brunnen gestoßen wurde und dort trotz seiner Steinwürfe, ohne Wasser und Nahrung, vierzig Tage überlebte ${ }^{277}$. Erst die Öffentlichkeit, die eine Begebenheit als Wunder auszeichnet, die fama, welche die Neuigkeit verbreitete, machte das Ereignis zum miraculum:

»Und sogleich eilte eine Menge von Bauern dorthin, auch viele Frauen strömten zusammen, es hielt nicht die Zartheit die Jungen, nicht die Trägheit der Jahre die alten Weiber davon ab, raschestens dorthin zu eilen. Einer wurde hinuntergelassen, der die Hinuntergestürzte emporzog und den wartenden Scharen zeigte; nachdem diese herumgezeigt war und den Hergang dieser großartigen Rettung erzählt war, blieb die Kunde von diesem Wunder nicht auf den Landstrich beschränkt, sondern die Kunde von diesem Wunder, das zu dieser Zeit gänzlich ungewöhnlich war, machte auch in fernen Gegenden die Runde «278.

\subsubsection{Akteure}

Das dritte Element des Bezugs eines Textes zur außertextlichen Wirklichkeit ist dasjenige der Situierung der Akteure des Geschehens. Wenn in einem Text der Leserschaft vertraute Personen aus deren sozialem Umfeld genannt werden, ist dadurch eine Kontrollmöglichkeit des Geschehens gegeben. Zwei Gruppen von Personen, die innerhalb der Erzählungen verschiedene Funktio-

274 Paul, Le démoniaque et l'imaginaire, S. 375-378.

275 Siehe zu Guiberts Visionen Schmit, Les rêves de Guibert de Nogent.

276 Guibert de Nogent, De laude, Sp.571: So beispielsweise der geheilte Petrus von Grenoble, der als Eremit in seiner Zelle vom Teufel versucht wird, so daß er vor Müdigkeit kaum mehr mit seinen Besuchern sprechen kann. Dies auffällige Verhalten wird vom Bischof bemerkt, der dann die Zelle überwachen läßt. Siehe dazu Anhang 2.

277 Siehe dazu oben, S. $60 f$.

278 Nec mora illo ruit rusticana frequentia, muliebre convolat vulgus, non teneritudo puerulos, non annos pigricia pressit aniles quin otior quisque concurreret. Demittitur quoque qui demersam funibus efferat et expectantibus turmis exhibeat; qua exhibita et relato tantae salvationis eventu, non intra rus idem miraculi sese fama cohibuit, sed in remotas se regiones virtus isti tempori prorsus inusitata circuntulit. GUIBERT DE NoGENT, Quo ordine, P, I, Z. 284 291. Die fama wird von RöCKELEIN, Reliquientranslationen, S. 48 als mittelalterliche Öffentlichkeit bezeichnet. Zur Öffentlichkeit auch HaverKaMp, Öffentlichkeit. 
nen haben, sind zu nennen. Einerseits sind dies die durch die Wunder Betroffenen, andererseits die /Verwalter des Wundergeschehens, zumeist Kleriker oder Mönche. Schließlich ist die Frage zu stellen, wie diese Akteure mit den außerhalb der Erzählung genannten Zeugen in Beziehung stehen.

Die Betroffenen stammen im überwiegenden Teil der Geschichten aus der einfachen Bevölkerung. Diese werden oft nicht bei ihrem Namen genannt, sondern als quaedam puella paupercula, mulier quaedam, quidam parvulus, muliercula quaedam, homo quidam foenoribus undecunque deditus, rusticus quidam nur sehr unbestimmt bezeichnet ${ }^{279}$. Diese unbestimmte Nennung der Akteure wird in allen vier betrachteten Werken gepflegt; im Marienlob stehen jedoch einer Erzählung mit unbestimmter Nennung der betroffenen Frau zwei gegenüber, worin die Betroffenen mit Namen genannt werden. Die Protagonistin in der Erzählung "femme de Laon « wird Theodeberta genannt, der junge Mann aus Grenoble Petrus ${ }^{280}$. Die unbestimmte Namensnennung läßt sich durch die intendierte Funktion der Erzählungen als Exempla plausibel machen. Wenn das Verhalten von quidam durch ein Wunder sanktioniert wird, kann dies auch einer beliebigen anderen Person in der gleichen Situation passieren. Diese Erklärung greift für die Funktion der Wunder in den Monodiae. Diese geben dort Beispiele für Verhaltensweisen in ähnlichen Situationen wie sich die Hauptfigur des Berichts, Guibert selber, befindet ${ }^{281}$. Die Wunder haben moralisch-adhortative Funktion.

Im Falle der Wunder im Marienlob ist die Lage komplizierter. Hinweise sprechen dafür, daß diese als aktuelle Beispiele im Kontext der Predigt gedacht sind ${ }^{282}$. Die namentliche Nennung der Protagonisten könnte mit Guiberts Forderung nach möglichst lebensnahen, aktuellen Beispielen für die Predigt in Zusammenhang stehen ${ }^{283}$. Durch die Namensnennung kann diese Aktualität geschaffen werden, aber auch die Wirkung der in der Geschichte enthaltenen moralischen Botschaft durch eine Art Prangerwirkung verstärkt werden. Gerade im Fall dieser zwei Geschichten erweist sich die Namensnennung jedoch als nicht sehr stabil. So nennt Hermann von Tournai die Protagonistin der Erzählung »femme de Laon« in seinem Mirakelbuch, in den 1140 er Jahren verfaßt, Soiburga ${ }^{284}$. In der zweiten Version der Geschichte des Petrus von Grenoble wird dieser nicht beim Namen genannt, sondern als mercennarius bezeichnet, und in den Abschriften von Guiberts Version wird die

279 Guibert de Nogent, Autobiographie, III, 18, S. 434; Guibert DE Nogent, De laude, Sp. 573; Guibert de Nogent, Quo ordine, P, I, Z. 212; Guibert de Nogent, Dei Gesta, VII, 32, Z. 1685; Guibert DE Nogent, Autobiographie, III, 19, S. 450; ibid., III, 19, S. 454.

280 GulBERT DE Nogent, De laude, Sp. 564-574.

281 Siehe dazu unten, Kap. 4.1.2.

282 Siehe dazu unten, Kap. 4.3.2.

283 Siehe dazu Guibert DE Nogent, Quo ordine, S, Z. 388-397.

284 Hermann von TournaI, De miraculis sanctae Mariae Laudunensis, Sp. 1008. Zur Abfassungszeit siehe KaISER, Verbrechen und Strafe, S. 90, der sie um 1146/47 situiert; SigNORI, Maria, S. 114, die für 1145 plädiert, mit Angabe weiterer Literatur. 
einführende Namensnennung zu Beginn der Erzählung teilweise weggelas$\operatorname{sen}^{285}$.

Im Reliquientraktat sind die Wundererzählungen eher als argumentative Exempla eingesetzt. Die Namen der Akteure scheinen aber für die Glaubwürdigkeit des Erzählten keine große Rolle zu spielen. Guibert scheint in den meisten Fällen nicht so nahe bei den Ereignissen gewesen zu sein, daß er die Betroffenen hätte namentlich nennen können oder aber die Nennung der Namen für sein Publikum als wichtig erachtet hätte. Nur im Falle der Geschichte des Büßers Erlebaldus, von dem Guibert angibt, ihn persönlich gekannt $z u$ haben, wird ein Name genannt.

Namensnennungen für Protagonisten von Wundererzählungen scheinen bei Guibert keine wichtige Funktion für die Verankerung dieser Erzählungen in einer außertextlichen Wirklichkeit zu spielen. Sie können einerseits mit der literarischen Gestaltung der Episoden erklärt werden, andererseits mit der Funktion von Wundererzählungen als Predigtexempla. Der Fokus von Guiberts Wundererzählungen liegt zudem eher auf dem Verhalten von Personengruppen und dann vor allem auf der Wunder wirkenden göttlichen Intervention, die gewisse Verhaltensweisen sanktioniert.

Die ungenannten Akteure stehen aber während des wunderbaren Geschehens oft mit Klerikern oder Mönchen in Kontakt, die wie auf der Reliquienreise der Kleriker von Laon Verwalter der wunderwirkenden Reliquien sind. In der Klosterkirche von Saint-Germer-de-Fly wurde eine Frau durch Exorzismen von einem Dämon befreit und eine Besessene durch die Reliquien des heiligen Geremarus geheilt. Im Falle eines Strafwunders in Compiègne waren die Kleriker Begünstigte der Bestrafung von Laien, die sich ihnen gegenüber ungebührlich verhalten hatten ${ }^{286}$. Die agierenden Geistlichen in den Wunderepisoden weisen, analog zu den Zeugen der Erzählungen, ins Umfeld Guiberts. Der Klerus und die Mönche sind als Verwalter des Religiösen und somit auch der Zeichen des Herrn zugleich ins Geschehen involviert, wie sie auch Akteure der Kommunikation dieser Zeichen und Wunder sind.

Die weiteren Gruppen von Akteuren in Guiberts Wundern stammen wie die Zeugen der Erzählungen aus Adel, Mönchtum und Weltklerus. Wenn Adelige, Ritter und ihr Gefolge im Mittelpunkt von Erzählungen stehen, wird oft ihr Verhalten gegenüber Vertretern der Kirche bestraft. Diese Akteure werden analog zur obigen Gruppe oft nicht namentlich genannt, beispielsweise wenn im ersten Buch der Monodiae ein Strafwunder an einem scelestus quidam eques $^{287}$, der sich an Kirchengut vergreift, erwähnt wird. Guibert schildert den

285 Nennung als mercennarius z. B. in BN lat. 12593, fol. 160v; Unterlassung des Namens zu Beginn der Erzählung in BN lat. 673, fol. 205r. Siehe den Vergleich der Versionen unten, Kap. 5.2.3.

286 GuIBert DE Nogent, Autobiographie, III, 12-13 (Reliquienreise); I, 25, S. 200 (in der Klosterkirche von Saint-Germer-de-Fly); III, 18 (Compiègne).

287 Ibid. I, 11, S. 66. 
schlechten Tod des Johannes von Soissons - seine Seele wurde mit dem Einverständnis Mariens von Dämonen geholt - in einer Folge von Untaten dieses Grafen, Bruder des Manasses, Bischof von Soissons (†1109)288. Die Erzählung steht also nicht isoliert, der Protagonist ist aus den vorhergehenden Schilderungen bekannt, wo er auch namentlich genannt wird ${ }^{289}$. Eine andere Gruppe von Akteuren stammt aus Guiberts erweitertem familiärem Umfeld. Darunter sind eine Heilung an einem Cousin durch den heiligen Arnulf, die Dämonenvisionen seiner Mutter oder ein wunderbares Vorzeichen im Umfeld der Gräfin von Eu/Chester zu zählen ${ }^{290}$. Diese Personen werden namentlich oder in Beziehung zu Guibert genannt. Wilhelm, der von der Gräfin von Chester/Eu gerettete Knabe, wird in den Monodiae nochmals erwähnt: Guibert übergibt ihm eine seiner Schriften zur Lektüre ${ }^{291}$.

Vom adeligen Milieu darf das Mönchtum nicht völlig getrennt betrachtet werden. In einem großen Anteil der wunderbaren Episoden sind Mönche betroffen - ihr Lebenskreis steht im Zentrum. Abgesehen von drei Episoden im Zusammenhang mit der Kritik am Wunderbuch von Saint-Médard werden alle Mönchsgeschichten in den Monodiae im Zusammenhang mit Guiberts eigenen Erfahrungen erzählt. Mönche aus Saint-Germer-de-Fly werden teilweise namentlich genannt, so Suger, Prior des Konvents, oder der Mönch Otmund ${ }^{292}$. In anderen Erzählungen spielen Mönche eine Rolle, von denen nur Herkunft oder Funktion, jedoch nicht deren Namen genannt ist ${ }^{293}$. Ein Beispiel dafür, daß Guibert Namen auch verschweigt, ist die Erzählung eines Priestermönchs, der Kapellan bei seiner Mutter gewesen war und dessen Name Guibert wohl gekannt hat. Ob das bewußte Verschweigen des Namens mit dem unrühmlichen Lebenswandel des Priestermönchs zusammenhing, muß Vermutung bleiben ${ }^{294}$. Auch im Falle der Überprüfung des Leibes des heiligen Edmund durch einen Abt von Bury St. Edmunds verschweigt Guibert den Namen des Akteurs. Wie im obigen Fall kann vermutet werden, daß er dies mit Absicht tut. Im Mirakelbuch des Hermann und auch in dessen Überarbeitung wird der Abt bei seinem Namen, Leofstan, genannt. Guibert legt sein Augenmerk auch hier auf die frevelhafte Tat und deren Bestrafung 295 .

288 Ibid. III, 16, S. 422-428.

${ }^{289} \mathrm{Zu}$ Johann von Soissons siehe KAISER, Bischofsherrschaft, S. 596-597. Das Todesdatum muß aufgrund der seither erschienenen Forschung zur Abfassungszeit der Monodiae vor $1114 / 15$ gesetzt werden.

290 GuiberT DE NoGEnt, Autobiographie, III, 20, S. 46; I, 13, S. 90-92; bzw. II, 5, S. 246-252.

291 Ibid. II, V, S. 252.

292 Ibid. I, 20, S. 170, bzw. I, 25, S. 196-200.

293 Bspw. Guibert DE Nogent, Autobiographie, III, 19, S. 458: quidam Floriacensi monachus; II, 6, S. 262 in einer Folge von zwei Erzählungen, worin Personen mit Wachfunktionen Hauptrollen spielen: Apud Sanctum Medardum itidem homo erat, idem (d. h. custodia, Anm. K.F.) in abbatia ipsa habens officium.

294 Ibid. I, 24, S. 190-192.

295 Zur Edmund-Geschichte siehe oben, S. 131-138. 
In zwei Fällen werden Äbte durch ihre Funktion sowie durch ihre namentliche Nennung situiert. Beide hatten ihr Amt zwanzig bis dreißig Jahre vor der Niederschrift der Monodiae während Guiberts Zeit in Saint-Germer-de-Fly inne. So wird die Vision des Abtes Ivo von St. Denis ( $\dagger$ 1094) nach dem Einsturz des Turmes, den Wilhelm der Eroberer in Saint-Denis hatte erbauen lassen, erwähnt. Der Abt Johann von Saint-Nicaise in Reims spielt in der Erzählung über den schlechten Tod eines neu aufgenommenen Mönches eine wichtige Rolle ${ }^{296}$. Diese Äbte sind einmal als Empfänger einer Vision zentrale Akteure, ein andermal Kontrollinstanz eines Wunders. Erzählungen über Ereignisse während deren Abbatiat scheinen im Mönchsmilieu kursiert zu haben.

Als letzte Gruppe sei der Weltklerus genannt. Kleriker sind in Guiberts Werken weit weniger von Wundern betroffen als Mönche; die Grenze zwischen den Gruppen ist jedoch nicht leicht zu ziehen. Das obenstehende Beispiel der Geschichte aus Saint-Nicaise zeigt einen Maler, der erst Regularkanoniker war, dann wieder in die Welt zurückging und heiratete und schließlich ins Kloster eintrat. Auch die Geschichte einer Versuchung eines jungen Mannes aus der Gefolgschaft des Bischofs von Beauvais durch Dämonen zeigt, daß die Welt der Mönche nicht von der des Weltklerus zu trennen ist. Zum Zeitpunkt der Versuchung, nachdem er sich entschlossen hatte, zum Mönchtum zu konvertieren, war der zukünftige Mönch nicht allein. Der Dämon suchte den jungen Mann heim, als er gemeinsam mit Yvo von Saint-Quentin, Mönch und Prior aus Cluny und verschiedenen anderen Adeligen und Klerikern, im Zimmer des Bischofs von Beauvais schlief ${ }^{297}$. Der Mönch verbrachte die Nacht also gemeinsam mit Adeligen und Weltklerikern. Die Erscheinung wurde von den Angehörigen des Adels beobachtet, am folgenden Morgen berieten alle Anwesenden über die Einordnung des Geschehens.

Wie eng der Weltklerus mit dem monastischen Milieu verbunden war, zeigt auch die folgende Erzählung, eine versuchte Hexerei, die durch das Anrufen Marias verhindert werden konnte. Sie wird von Guibert am Schluß des ersten Buches der Monodiae wiedergegeben und betrifft einen Kleriker, den Guibert nicht explizit einer religiösen Gemeinschaft zuordnet. Die Erzählung steht in derjenigen Gruppe von wunderbaren Ereignissen, die Guibert in der Umgebung seines Klosters Saint-Germer-de-Fly erfahren hat. Diese Gruppe schlieBt das erste Buch der Monodiae ab. Die Zeugen werden nicht explizit genannt. Die handelnden Personen zeigen aber, daß die Erzählung in der nächsten Umgebung Guiberts im Kloster Saint-Germer-de-Fly, allerdings im Milieu der Kle-

296 GuiberT DE Nogent, Autobiographie, III, 20, S. 466: Cumque plurimum ab Ivone, tunc temporis abbate, [...] zu Saint-Denis unter Ivo I. und der Turmgeschichte siehe GrossE, St. Denis, S. 82-83; II, 6, 264: [...] directis ad abbatem Sancti Nichasii, ea tempestate Joannem, [...]. Abt Johannes unterschrieb 1093 eine Bischofsurkunde des Bischofs von Laon, siehe Actes Laon, Nr. 43.

297 GuiberT de Nogent, Autobiographie, I, 15, S. 118-120. 
riker, vielleicht sogar der Domkanoniker zu situieren ist ${ }^{298}$. Der betroffene Kleriker diente als Schreiber in Saint-Germer-de-Fly (Quidam clericus in Belvacensi pago scriptandi arte vivebat, quem et ego noveram, nam Flaviaci in hoc ipso opere conductus laboraverat ${ }^{299}$ ). Diesen beschreibt Guibert als ihm persönlich bekannt (quem et ego noveram). Um mit Hilfe des Teufels ohne Anstrengung Geld verdienen zu können, brachte er diesem ein Opfer dar, bekam es aber mit der Angst zu tun und rief die Jungfrau Maria an, die den Teufel darauf vertrieb. Nach der frevelhaften Tat und seiner Rettung durch die Jungfrau Maria legte der Schreiber bei Lisiard von Beauvais die Beichte ab ${ }^{300}$. Dies läßt vermuten, daß Lisiard Angehöriger des Domkapitels war. Er war Archidiakon in Beauvais und Guiberts Onkel und gehörte somit zu seinem engsten Familienkreis ${ }^{301}$. Guibert macht im Text deutlich, daß ihm die Akteure, sowohl der Sünder wie auch der Vertreter der kirchlichen Autorität, gut bekannt waren. Aufgrund dessen läßt sich vermuten, daß Guibert die Geschichte von einem der beiden oder von jemandem aus seinem engen familiären oder monastischen Umfeld erfahren hatte. Wiederum zeigt sich, daß die monastische Welt keineswegs von derjenigen des Weltklerus abgeschottet war, sondern im Gegenteil in vielfachem gegenseitigem Kontakt stand ${ }^{302}$. Auch für Akteure aus dem Klerus verwendet Guibert sowohl unpersönliche als auch persönliche Nennungen, für Bischöfe wie auch für einfache Kleriker ${ }^{303}$. So auch im Fall des Büßers Erlebaldus. Am Ende der Erzählung präzisiert Guibert, daß er mit Erlebaldus freundschaftlich verbunden war ${ }^{304}$.

Akteure oder Betroffene der Wunder sind in Guiberts Erzählungen am wenigsten deutlich ausgewiesen, obwohl Guibert auch Episoden referiert, die im Umfeld von persönlich Bekannten oder Verwandten situiert sind. Weitaus öfter sind die Akteure jedoch nur grob in ihrer gesellschaftlichen Funktion charakterisiert und werden als quidam bezeichnet. Die Dimension »Akteur « scheint in Guiberts Werken in bezug auf den Verweis auf die außertextliche

298 Ibid. I, 26, S. 206-208.

299 Ibid. I, 26, S. 206.

300 Die private Beichte mit dem Beichtgeheimnis des Priesters wurde erst auf dem 4. Laterankonzil (1215) geregelt. Siehe Dekrete der ökumenischen Konzile, S. 245.

301 Guibert DE Nogent, Autobiographie, I, 26, S. 208.

302 Wünschenswert wären detailliertere Kenntnisse über die Verbindungen von SaintGermer-de-Fly und dem Bischofshof von Beauvais. Karl der Kahle schenkte die Abtei Saint-Germer-de-Fly 863 der Kirche von Beauvais. GuyotJEannin, Episcopus et comes, S. 17. Sie wurde in der Mitte des 11. Jahrhunderts durch den Bischof Drogo restauriert, es wurde ein Abt aus Saint-Maur-des-Fossés eingesetzt. (Narratio qualiter reliquias beati patris nostri Geremari accepimus, AASS Sept. VI, S. 705), ibid. S.29; Saint-Germer-de-Fly versuchte in den $1170 \mathrm{er}$ Jahren unabhängig zu werden, ibid. S. 90, 132. Siehe auch Papsturkunden in Frankreich, S. 50-52.

303 So z. B. Bischof Artaldus von Reims: GutBert DE Nogent, Autobiographie, I, 24, S. 194 oder Ansellus, Matricularius der Kathedrale von Laon: Ibid. III, 15, S. 418-423.

304 Guibert De Nogent, Quo ordine, P, I, Z. 358-360: Fuit autem homo iste cum sacerdotio, quo fulgebat, et in Scripturae scientia copiosus et michi valde amicicia affinis, [...]. 
Realität die flexibelste zu sein. Obwohl sich der Gedanke aufdrängt, darf aus der mangelnden namentlichen Fixierung von Akteuren nicht auf weit entfernte Geschichten geschlossen werden. Dies zeigen auch die relativ genauen Nennungen der involvierten Kleriker als Vertreter der kirchlichen Autorität. Zu bedenken ist auch, daß Nennen oder Verschweigen von Namen stilistisches Element ist. Zudem scheinen sowohl das wunderbare Ereignis als auch das Verhalten der Akteure wichtiger zu sein als deren Situierung durch namentliche Nennung.

Die Betrachtung der referentiellen Bezüge hat gezeigt, daß die Erzählungen am häufigsten im geographischen Raum fixiert werden. Die meisten Erzählungen enthalten Angaben zur Ortschaft, in der das wunderbare Ereignis stattgefunden haben soll. Die Situierung in der zeitlichen Dimension, der wichtigste Faktor des historiographischen Genres, spielt für die Wundererzählungen eine untergeordnete Rolle ${ }^{305}$. Die Texte zeigen nur grobe zeitliche Einordnungen, eine genaue Situierung der wunderbaren Ereignisse auf der chronologischen Achse scheint als Element der Verankerung des Erzählten in einer außertextlichen Wirklichkeit als nicht sehr wichtig angesehen worden $\mathrm{zu}$ sein. Dasselbe gilt für die Betroffenen der Wunder. Diese sind oft nur ungenau beschrieben und können nur genauer gefaßt werden, wenn Guibert angibt, daß sie zu seinem persönlichen Umfeld gehörten oder wenn er eine Beziehung dieser Betroffenen zu sich angibt. Häufiger hingegen sind die Vertreter der kirchlichen Autorität angegeben. Aufgrund der Akteurangaben können Erzählungen oft innerhalb von sozialen Gruppen situiert werden, was wiederum Hinweise gibt auf die Relevanz der sozialen Gruppe als Kategorie der Identifikation.

305 Zur Bedeutung des Faktors Zeit für die Geschichtsschreibung: GoETZ, res gesta, S. 708 . 


\subsection{Zusammenhang von Quellenangaben und referentieller Situierung von Erzählungen}

Guibert de Nogent stellt in seinen Texten für viele Wundererzählungen Bezüge zu einer außertextlichen Realität her, um die Glaubwürdigkeit der Erzählungen sicherzustellen. Die Analyse von Guiberts Umgang mit den Verweisen auf Quellen hat gezeigt, daß der Verfasser an seine Texte hohe Anforderungen in Bezug auf diese Realitätsbezüge stellte. In mehreren Fällen wird deutlich, daß Guibert explizit auf eine schriftliche Überlieferung hinweist. Dies zeigt ein hohes Bewußtsein für die Unterschiede von mündlichem und schriftlichem Zeugnis. Auch wenn Wundererzählungen als Exempla mit moralischer Funktion eingesetzt werden, ist Wahrheitsbezug gefordert.

Seine Anforderungen an die Realitätsbezüge macht er vor allem in Kommentaren zu seiner Kreuzzugschronik deutlich. Diese kann zur Gattung Historiographie gezählt werden, wofür die Konventionen seit der Antike vor allem durch die Rhetorik geprägt sind. In der Reliquienkritik setzt sich Guibert mit den Konventionen des hagiographischen Genres auseinander. Guibert beugt sich den Gattungskonventionen, spielt aber auch mit ihnen, wenn er selbst Zweifel an der Wahrheit des Berichteten äußert oder durch Ironie Kritik am Berichteten ausdrückt.

Die Untersuchung der Quellenangaben der Wundererzählungen hat gezeigt, daß die genannten Zeugen und Texte auf Personengruppen hinweisen, innerhalb derer über Wunder kommuniziert wurde. Dies sowohl in formalisierten Abläufen als auch in informellen Zusammenhängen. Wichtig erwiesen sich neben Guiberts familiärem Umfeld die monastische Gemeinschaft und vor allem eine Gruppe aus dem Weltklerus, die geographisch und institutionell auf die Kirchenprovinz Reims einzugrenzen ist und deren Angehörige zu einer Gruppe von Kirchenreformern zu zählen sind.

Dank dem Umstand, daß Guibert oft Informanten für die Wundererzählungen nennt und zudem die Handlung innerhalb der Erzählungen zumeist im geographischen Raum situiert ist, läßt sich die Herkunft der Erzähler mit dem Handlungsort der Erzählung in Bezug setzen:

In den meisten Fällen, in denen Guibert Zeugen für Wunder nennt, stehen diese mit dem Ort, an dem das Ereignis stattgefunden hat, in Beziehung. Es sind entweder Priester der jeweiligen Kirche, Mönche im Kloster oder Bischöfe der Diözese, in der das Wunder passierte. Dies gilt zumeist auch für Wunder aus entfernten Gegenden, beispielsweise für jenes aus Montecassino, für welches Guibert einen Zeugen aus dem dortigen Kloster anführt. Die Ausnahmen von dieser Regel sind Episoden, die eine große Verbreitung hatten. Dies ist einerseits die Jakobspilgergeschichte, für die Guibert einen Mönch aus Cluny als Zeugen nennt. Alle Versionen dieser Erzählung, deren Geschehen sich an einem nicht genannten Ort auf dem Jakobsweg zutrug, nennen 
Cluny als deren Kommunikationsort ${ }^{306}$. Der Zusammenhang von der örtlichen Situierung und den genannten Zeugen gilt auch für das Marienwunder an einem jungen Mann aus Grenoble. Daß der Bischof von Viviers sich dann des Wunders annahm und auch als Zeuge auftrat, wird von Guibert begründet. Die Angelegenheit wurde laut Guibert an diesen Bischof herangetragen, weil sie sich zwar zu Anfang in der Diözese Grenoble ereignete, dann aber in der Diözese Viviers spielte ${ }^{307}$.

Für die Geschichte des Büßers Erlebaldus, die sich in Cambrai abspielte, nennt Guibert seinen Bischof Barthélémy als Zeugen. Gleichzeitig erwähnt er eine Zeugenbefragung, die unter den Einwohnern der Kirchenprovinz des Erlebaldus durchgeführt wurde. Dies deutet darauf hin, daß die Angelegenheit im Rahmen der kirchlichen Institutionen verhandelt wurde. So ist auch plausibel, daß der Vorsteher des Nachbarbistums davon erfuhr. Wie oben gezeigt, sind die Diskussionen um wunderbare Ereignisse durch die Angehörigen des Weltklerus in ein Bemühen um Kultreform und Kontrolle des Kultes durch den Klerus einzuordnen ${ }^{308}$. Die Diskussionen um Wunder in einer monastischen Gemeinschaft wie Saint-Germer-de-Fly sind in Zusammenhang mit der Organisation eines geordneten, ruhigen Gemeinschaftslebens zu sehen.

Anhand der Orte des Wundergeschehens, aber auch der genannten Zeugen läßt sich ein regionaler Raum erkennen, innerhalb dessen Wunder, wunderbare Ereignisse und Wundererzählungen kommuniziert wurden.

Wenn Heilige oder Kultorte in diesen Erzählungen eine Rolle spielen, läßt sich ein regionaler hagiographischer Raum aufspannen. Außer dem heiligen Edmund in Bury St. Edmunds, dem heiligen Swithun in Winchester und dem heiligen Benedikt in Montecassino werden vornehmlich Wunder regionaler Heiliger oder in der Region verehrter Heiliger geschildert. Als Mittler genannt werden Reliquien des heiligen Arnulf von Tours/Crépy in Guiberts (unbekanntem) Heimatort und in Guise, einer Burg in der Region von Laon ${ }^{309}$, des heiligen Leodegar in einer Kapelle der Mutter Guiberts, des heiligen Justus aus dem Beauvaisis, der heiligen Cornelius und Cyprian in Compiègne und des heiligen Nicasius in Noyon. Aus der Nachbarprovinz sind dies die Reliquien des heiligen Dionysius in Saint-Denis und des heiligen Marcellus in Paris. Nicht

\footnotetext{
306 Siehe oben, S. 114.

307 Guibert DE Nogent, De laude, Sp. 570: Praeterea cum ubique loci rei adeo inusitatae ferretur opinio ad Leodegarium Vivariensem, qui nunc advivit, episcopum pervenit relatio, idipsum plane in Gratianopolitano territorio, unde homo erat oriundus, fieri coeperat, sed in dioecesi Vivariensi finis obvenerat.

308 Siehe oben, Kap. 2.2 .

309 GuiberT DE NOGENT, Autobiographie, III, 20, S. 462-464. Es könnte sich beim martyr Arnulfus um Arnulf von Crépy, einen Märtyrer aus Tours (6. Jh.) handeln, der berühmt dafür ist, Entzündungskrankheiten zu heilen. Siehe BHL 706-711, dazu RACINET, Implantation et expansion, S. 25-36; Racinet, Les maisons de l'ordre de Cluny, S. 9. Guibert erzählt in Guibert DE Nogent, Autobiographie, I, 10, S. 60-62 die Geschichte der Konversion des Simon de Crépy, der den Körper seines Vaters nach Saint-Arnoul de Crépy überführen läßt. Der Zusammenhang zum heiligen Arnulf ist also gegeben.
} 
vergessen werden dürfen die Heiligen und Reliquien aus Saint-Médard de Soissons. Die hagiographische Produktion und der Kult in diesem Kloster spielt in Guiberts Reliquienkritik eine wichtige Rolle ${ }^{310}$. In vielen Erzählungen ist allerdings die Gottesmutter Maria die hauptsächliche Wundertäterin.

Bei den Verweisen auf die schriftliche Tradition muß zwischen Schriften, die Ereignisse aus der Vergangenheit belegen, und denjenigen, welche von aktuellen Ereignissen zeugen, unterschieden werden. Bei Ereignissen aus der Vergangenheit mußten die Quellen nicht eigens belegt werden. Dies gilt sowohl für solche aus der biblischen oder antiken Überlieferung, wie auch für solche aus der karolingischen Chronistik. Der Nachweis dieser Quellen muß eher mit Fragen nach Guiberts Bildung und Bibliotheksbenutzung in Zusammenhang gestellt werden. Der Rückgriff auf Wunder, die in zeitgenössischen Texten festgehalten sind, ist wie die mündlichen Zeugnisse in regionalen kommunikativen Zusammenhängen zu sehen, die sich teilweise mit denen decken, die für den mündlichen Bereich ausgemacht werden konnten. So beispielsweise im Fall der Wunderbücher aus Saint-Médard de Soissons. Guibert stand verschiedentlich mit Soissons in Beziehung. Guibert nennt als Zeugen einer mündlich überlieferten Erzählung einen Mönch aus Saint-Médard de Soissons ${ }^{311}$. Der Bischof Lisiard von Soissons war gemeinsam mit Guibert in einen Häresieprozeß involviert ${ }^{312}$, spielte aber auch eine führende Rolle bei der Heiligsprechung des Arnulf, Abt von Saint-Médard de Soissons ${ }^{313}$. Zudem war er bei der Rekonziliation der Kathedrale von Laon nach dem Bischofsmord anwesend ${ }^{314}$. Schließlich ist die Kreuzzugschronik Bischof Lisiard und die zweite Serie der Tropologiae Abt Gaufried von Saint-Médard de Soissons gewidmet. Ähnliche Kreise zeigen sich auch in der Überlieferung der schriftlichen Versionen der Wundererzählungen. So sind die Wunderbücher aus SaintMédard de Soissons in den eng verbundenen, reformorientierten Abteien Anchin und Marchiennes überliefert ${ }^{315}$. Aus diesen Abteien stammen auch Abschriften einzelner Werke Guiberts ${ }^{316}$. Die Betrachtung der Edmund-Wunder hat gezeigt, daß mündliche mit der schriftlichen Überlieferung so eng verquickt ist, daß nicht mehr unterschieden werden kann, ob die mündliche oder die schriftliche Überlieferung Grundlage einer Wundererzählung war.

310 Siehe zu Saint-Médard unten, Kap. 5.1.

311 GuiberT DE NogENT, Autobiographie, II, 6, S. 262.

312 Ibid. III, XVII, S. 432-434.

313 MGH SS XV, S. 902. Siehe dazu oben, Kap. 2.2.

314 GC 9, Sp. 528-30. Zu den Beziehungen Guiberts zu Lisiard von Soissons siehe PoLY, Gloire des rois, S. 180, Anm. 54; dazu auch BARThÉLEMY, Les deux ages, S. 54f.

315 Siehe Kap. 5.1.3.

316 Abschriften aus Anchin, 12. Jh., Handschrift Douai, BM 285: Quo ordine sermo fieri debeat, Moralia in Genesim, Huygens, Tradition manuscrite, S. 13f.; Abschriften aus Marchiennes, 12. Jh., Handschrift Douai, BM 354: De laude sancte Marie (nicht vollständig), De bucella ludae data et de veritate dominici corporis in einer Handschrift, die auch Schriften Anselms von Bec/Canterbury überliefert. Siehe dazu HuYgeNs, Tradition manuscrite, S. 58. 
Die Quellenangaben außerhalb der Erzählungen, wie auch die Ort-, Zeitund Akteurangaben im Laufe der Erzählungen lassen schließen, daß Guibert Wundererzählungen in seine Schriften einfügt, die aus einem regionalen Kontext stammen. Zudem ist der Kreis seiner Zeugen in einem regionalen Umfeld zu situieren. Auch die Wundererzählungen aus schriftlichen Quellen, sofern es sich nicht um traditionelle Schriften handelt, sind in der Region zu verorten. Guibert steht immer wieder auf der Schwelle zwischen oraler Überlieferung und Verschriftung der Wundererzählungen. Er ist oft auch relativ nahe an der Produktion von hagiographischen Texten, in welchen diese Wundererzählungen eine Rolle spielen. Guibert beschäftigt sich aber nicht nur mit den Berichten über wunderbare Ereignisse, sondern erzählt auch von eigenem Erleben von Wundern. Diese Ereignisse werden in Guiberts Umfeld registriert, sie werden beurteilt und auf ihren Wahrheitsgehalt geprüft und mit Bedeutungen für die Gemeinschaft versehen.

Wenn die Ergebnisse aus dem 3. Kapitel denjenigen aus dem 2. Kapitel gegenübergestellt werden, zeigt sich, da $\beta$ in Guiberts Schriften das System »Glaubwürdigkeit von Wunderzählungen durch Bezeugung« und das System »Anerkennung von Ereignissen als Wunder « ${ }^{317}$ in einen für Guibert schwer aufzulösenden Gegensatz treten können:

In einem Beispiel aus den Monodiae wird für die Erzählung eines mirakulösen Ereignisses während des Brandes der Stadt Laon folgende Quelle genannt: Asserunt certe qui illi negotio interfuerunt [...]. Augenzeugen berichten, daß die Nacht nach dem Brand wunderbarerweise nicht dunkel geworden sei. Die weiteren Ausführungen zeigen, daß Guibert diese Erzählungen nicht ohne weiteres glaubt, auch Augenzeugenschaft alleine nicht als Kriterium genügt. Sein Einwand, daß die Helligkeit durch den Lichtschein der Brände zu erklären sei, wird dadurch entkräftet, daß die Brände zu diesem Zeitpunkt schon gelöscht seien. Dieses Argument erkennt der Erzähler an. Die Wahrheitsfrage wird anschließend jedoch nicht gelöst, sondern in der Schwebe gelassen oder der Meinungsbildung der Leser überlassen ${ }^{318}$. Daß zuweilen nur noch Ironie hilft, um die beiden Systeme der Anerkennung von Wundern zu harmonisieren, zeigt sich in der Kreuzzugschronik gegen Schluß des Berichts. Dort trägt Guibert Legenden aus verschiedenen Quellen zusammen, zumeist von Augenzeugen, aber auch aus einer anderen Kreuzzugschronik, verfaßt von Fulcher von Chartres. Die Argumentation beginnt mit einer wunderbaren Gegebenheit, die darin schriftlich festgehalten ist. Ein Schiff, das zu viele Kreuzfahrer an Bord hatte, sei gesunken, die Kreuzfahrer ertrunken. Diese seien an das Ufer geschwemmt worden und hätten als Zeichen ein Kreuz an der Schulter eingra-

317 Siehe oben, Kap. 2.1.

318 GuIBERT DE NOGENT, Autobiographie, III, 9, S. 356: Asserunt certe qui illi negotio interfuerunt ita diem diei sequenti tunc continuatum, ut nulla noctis occubitum opacitatis signa praetenderint. Quibus cum obicerem claritatem ignium hoc fecisse, sacramentis astruebant, quod et verum erat, ignes interdiu obrutos consumptosque fuisse. 
viert gehabt ${ }^{319}$. Die Glaubwürdigkeit des schriftlichen Zeugnisses wird mit der folgenden Bemerkung angezweifelt: Quod sacrum stigma divinitus cuti eorum potuisse imprimi ob ipsorum fidei evidentiam faciendam nemo licet fidelis ambigat, tamen ei qui hoc scripsit, si advivit, sollicite pensandum est an res ita se habeat $t^{320}$. Die folgende Aufzählung von Mißbräuchen mit eingravierten Kreuzen, aber auch die Erwähnung einer Interpretation von Wolkentürmen als Kreuz durch eine Menschenmenge in Beauvais signalisieren einerseits die Schwierigkeit, Zeichen zu interpretieren, andererseits, die Glaubwürdigkeit von schriftlichen Zeugnissen wunderbarer Ereignisse einzuschätzen. Diese Zweifel unterstreicht auch das angefügte Beispiel, dessen Kommentar lautet: „Was ich jetzt erzählen werde, ist lächerlich, aber die, von denen ich es habe, sind keine lächerlichen Zeugen «21. Guibert scheint hier sein eigenes System der Anerkennung als Wunder zu durchbrechen, indem er der moralischen Autorität der Zeugen den Vorzug gibt. Am Schluß der Serie bezeichnet er diese Geschichte jedoch mit den anderen als fabula, die dem christlichen Glauben auf keine Weise zugute kommt. Er anerkennt die Wunder demnach nicht als authentifiziert, obwohl im Fall der letzten Geschichte die Zeugen akzeptiert worden wären. Im Falle der heiligen Lanze, die von Fulcher angezweifelt wurde, spielt das Abwägen der Vertrauens- und somit auch Glaubwürdigkeit der Zeugen ebenfalls eine große Rolle. So wägt er das Zeugnis des Fulcher gegen Augenzeugen und einen Brief des Balduin von Edessa an seinen Erzbischof Manasses von Reims ab und gibt dem zweiten und dritten Zeugnis den Vorzug ${ }^{322}$. Guibert macht die Kritik an Fulchers Kreuzzugsbericht deutlich, indem er die mirakulösen Berichte und Vorzeichen in dessen Chronik anzweifelt oder aber deren Erwähnung als unnötig darstellt. Im Gegensatz zu Fulcher anerkennt Guibert die heilige Lanze und führt als Beweis auch ein Wunder an ${ }^{323}$.

Wenn die Kriterien eines der beiden Systeme nicht erfüllt werden, können diese je nach Kontext von Guibert unterschlagen oder aber als entscheidend für eine Argumentation eingesetzt werden. Guiberts Umgang mit den Kriterien für wahre und gute Wunder ist also durchaus flexibel, auch läßt die Konkurrenz dieser Systeme nicht immer eindeutige Entscheidungen zu.

319 Guibert de Nogent, Dei Gesta, VII, 32, S. $329 \mathrm{f}$.

320 Ibid. VII, 32, S. 330.

321 Ibid. VII, 32, S. 330: Testor deum me, Belvaci per id temporis constitutum, vidisse ad se versum obliquatas aliquantulum die media nubes, ut vix quippiam maius quam aut gruis aut speciem viderentur pretulisse ciconiae, cum ecce crucem celitus sibi missam urbanae passim voces conclamavere frequentiae. Ridiculum est quod dicam, sed non ridiculis auctoribus rem probatam. Siehe dazu RuBENSTEIN, Guibert of Nogent, S. 123. Ähnlich argumentiert William of Newburgh, siehe OTter, Inventiones, S. 102, PARTNER, Serious Entertainments, S. 115.

322 Guibert de Nogent, Dei Gesta, VII, 24, S. 332: Numquidne Fulcherii presbiteri, qui nostris apud Antiochiam fame periclitantibus, feriatus epulabatur Edessae, tot prudentium, qui interfuere dum repperiretur, ingeniis prevalebit argutia, cum etiam Balduinus, qui post regem Balduinum Edessae prefatae prefuit, in sua ad archiepiscopum Manassem profiteatur epistola cum eam beato revelante Andrea repertam, tum a nostris audaciam contra Turcos ingruentes preliandi fiducia ipsius admissam?

323 Siehe unten, Kap. 4.4.2. 